\title{
5 Die Entstehung einer mobilen und expansionistischen Klassen- und Konsumgesellschaft: Wirtschaft und Politik im Gilded Age, 1877-1900
}

Die Eisenbahn wurde nach 1860 zur Schlüsselindustrie und zum Motor des Industriekapitalismus und hatte tiefgreifende Auswirkungen auf das amerikanische Wirtschaftswesen in der Phase nach dem Bürgerkrieg. Erst die Eisenbahnen erschufen einen nationalen Markt, der es Unternehmen erlaubte, überregional zu wachsen. Da bessere Schienen verlegt werden mussten, die höhere Geschwindigkeiten und größere Lasten aushalten konnten, veränderte der Eisenbahnbau auch die Eisen- und Stahlindustrie. Die Eisenbahnen ermöglichten auch den Versand von Frischfleisch und anderen Lebensmitteln mit begrenzter Haltbarkeit. Die Eisenbahn hatte also in den Begriffen der Wirtschaftswissenschaft einen Multiplikatoreneffekt und heizte in mancher Branche das Wachstum ziemlich dramatisch an. Damit unterschied sie sich nicht von der Funktion des Eisenbahnwesens in anderen sich industrialisierenden Nationalstaaten. Auch hier übernahm die Eisenbahn eine Vorreiterrolle bei der Expansion des Kapitalismus. ${ }^{1}$ In einer Hinsicht unterschied sich das amerikanische Modell des Eisenbahnbaus jedoch von den anderen Nationen: Die Finanzierung des größten Eisenbahnnetzes in der Geschichte des 19. Jahrhundert verlief über die Vergabe riesiger Ländereien an die Eisenbahngesellschaften, Land, das wenige Jahre zuvor von indianischen Clans besiedelt gewesen war (Critical Juncture 5). ${ }^{2}$ Eisenbahnbau und Landnahme waren also systemisch gekoppelt: Je mehr Strecke eine Eisenbahngesellschaft verlegte, desto größer wurde der Anspruch, den sie auf Land erwarb. Die Expansion war also self-sustaining, ein Automatismus, der insofern im Chaos

1 Brophy, James M. Capitalism, Politics, and Railroads in Prussia, 1830-1870. Columbus, OH: Ohio State University Press, 1998. Gallego Palomares, José Ángel. Ferrocarril y Transición al Capitalismo en la Mancha, 1850 - 1936. Ciudad Real: Almud, Ediciones de Castilla-La Mancha, 2009. Hernández, Telesforo-Marcial. Ferrocarriles y Capitalismo en el País Valenciano, 1843-1879. Valencia: Excmo. Ayuntamiento de Valencia, Delegación Municipal de Cultura, 1983. Owen, Thomas C. Dilemmas of Russian Capitalism: Fedor Chizhov and Corporate Enterprise in the Railroad Age. Cambridge, MA: Harvard University Press, 2005. Tenório, Douglas Apratto. Capitalismo e Ferrovias no Brasil as Ferrovias em Alagoas. Maceió: EDUFAL, 1979. Tortella Casares, Gabriel. Los Origenes del Capitalismo en España: Banca, Industria y Ferrocarriles en el Siglo XIX. Madrid: Tecnos, 1995. 2 Wilson, G. Lloyd und Spencer, Ellwood H. Growth of the Railroad Network in the United States. Land Economics. 1950 Nov 1; 26 (4):337-345. Taylor, George Rogers und Neu, Irene D. The American Railroad Network, 1861-1890. Urbana, IL: University of Illinois Press, 2003.

Ә OpenAccess. () 2019 M. Michaela Hampf, publiziert von De Gruyter. (cc))BY-NC-ND Dieses Werk ist lizenziert unter der Creative Commons Attribution-NonCommercial-NoDerivatives 4.0. 
enden musste, als der tatsächliche Bedarf für diese Eisenbahnstrecken vollkommen nebensächlich war. Eisenbahnen wurden nicht nur gebaut, um aus dem Betrieb der Linien Gewinne zu erzielen. Der Bau der Eisenbahnlinie selbst wurde das eigentliche Geschäft. ${ }^{3}$ Hier kann man einen weiteren systematischen Lock-in dingfest machen: Die Landvergabe verstärkte den Siedlerimperialismus, weil die Eisenbahnen das Land an Siedlerfamilien weiterverkauften und die Tendenz zur Vertreibung der letzten noch auf ihrem Gebiet verbliebenen Native Americans anheizten (Lock-in 5). ${ }^{4}$ Mit der Landvergabe an Eisenbahnen als staatlicher Anreiz zum ungebremsten Ausbau des Streckensystems gab es keine Möglichkeit mehr, mit den Native Americans zu einer Form des Nebeneinanders oder gar des Miteinanders zu kommen. Die Vertreibung der amerikanischen Indianer und das rasche Vordringen der Eisenbahnen nach Westen waren ein Ursache-Wirkungskomplex, ein autopoetisches System, das einmal in Gang gesetzt, nur ins Stolpern kam, weil die riesige Spekulationsblase im Eisenbahngeschäft mit der Panic of 1893 platzte. Fragt man nach Alternativen, so fällt auf, dass es in der Geschichte der USA vor 1860 auch schon staatlich gelenkte Strukturförderungsprogramme gegeben hat. Dazu zählen die Bonus Bill von 1817, die mit dem Veto Präsident Madisons scheiterte, die vorgesehen hatte, die Erlöse der zweiten Bank of the United States zum Ausbau von Straßen und Kanälen zu verwenden. ${ }^{5}$ Diese Vorschläge kamen übrigens aus dem Lager der agrarisch orientierten Kräfte des Südens und des Westens. Die Erfolgsgeschichte des Erie Canal bewies zudem, dass staatliche Planung und Lenkung bei infrastrukturellen Großprojekten funktionierten und Korruption und Misswirtschaft auf diese Weise vermieden werden konnten. ${ }^{6}$ Was hätte dagegen gesprochen, auch im Falle des Eisenbahnbaus auf bundesstaatlicher wie auf föderaler Ebene Anleihen zu zeichnen, die Bevölkerung auf diese Weise auch an Gewinnen zu beteiligen, die Kosten aber und die Planung staatlich zu überwachen? Die Trassenführung hätte auf das Nötigste beschränkt werden können, Verluste durch spekulative Konkurrenzunternehmen und unterschiedliche Spurweiten wären vermieden und Konflikte mit den Native Americans umgangen worden. Der Hinweis, diese Art von staatlich organisierten Projekten

3 Grodinsky, Transcontinental Railway Strategy, S. 20.

4 Kidwell, Clara Sue. The Choctaws in Oklahoma: From Tribe to Nation, 1855-1970. Norman, OK: University of Oklahoma Press, 2007, S. 90 - 92. Wolmar, Christian. The Great Railroad Revolution: The History of Trains in America. New York: PublicAffairs, 2012, S. 129-158. Hämäläinen, The Comanche Empire, S. 322.

5 Larson, John Lauritz. „Bind the Republic Together“: The National Union and the Struggle for a System of Internal Improvements. The Journal of American History. 1987; 74 (2):363-387.

6 Bernstein, Peter L. Wedding of the Waters: The Erie Canal and the Making of a Great Nation. New York: W.W. Norton, 2005, S. 27. 
gehöre in eine andere Epoche der amerikanischen Geschichte, verfangen nicht, da das Netz von Bundesstraßen und Highways, das nach der Erschließung des Landes durch die Eisenbahn entstanden ist, ebenfalls vom Bund und den Einzelstaaten finanziert worden ist. ${ }^{7}$ Der Eisenbahnhistoriker und Nobelpreisträger für Wirtschaftswissenschaften Robert Fogel hat im Zusammenhang mit der Union Pacific deshalb von einem verfrühten Unternehmen gesprochen und hat nachweisen können, dass die Eisenbahnen nicht notwendig waren, um zu einem selbsterhaltendem ökonomischen Wachstum zu kommen. ${ }^{8}$

Die Tatsache der bloßen ökonomischen Konzentration alleine liefert kein Argument für einen amerikanischen Exzeptionalismus, der im Empire mündete. Auch die britische, französische, deutsche und russische Wirtschaft des 19. Jahrhunderts kannten den Zusammenschluss zu Konzernen, Trusts und Holding Companies. ${ }^{9}$ Die USA unterschieden sich lediglich in ihrem Körperschaftsrecht von europäischen Nationen. Durch die Gleichsetzung einiger Aspekte der Rechte von Körperschaften wie Aktiengesellschaften mit den Rechten natürlicher Personen wurde es sehr erschwert, Körperschaften juristisch zu belangen oder regulativ in sie einzugreifen. Das 14th Amendment, das in der Reconstruction verabschiedet worden war, um die Bürgerrechte von African Americans zu schützen, wurde so „missbraucht“, um die Profitinteressen der Aktiengesellschaften abzusichern (Critical Juncture 6). ${ }^{10}$ Hätte es die Möglichkeit gegeben, katastrophale Preiskriege zwischen den Eisenbahngesellschaften oder in der Stahlindustrie zu verhindern, wäre der Druck der Konkurrenz nicht so hoch gewesen und die Tendenz der Konsolidierung von ganzen Industrien hätte nachgelassen. Durch das Versäumnis der Bundesregierung, regelnd in die Entwicklung der amerikanischen Wirtschaft einzugreifen, wurde der unkontrollierte Konzentrationsprozess des Kapitals beschleunigt. ${ }^{11}$ Dem historischen Klassenkompromiss von 1876 folgte eine Gängelung der Arbeiterbewegung, die eine breite Gewerkschaftsbewegung unterband und so spontaneistischen und anarchistischen Strömungen

7 Due, John F. Government versus Private Financing of the Railroad Industry. Transportation Journal. 1982; 21 (3):16-21.

8 Fogel, Robert William. The Union Pacific Railroad: A Case in Premature Enterprise. Baltimore, MD: Johns Hopkins Press, 1960. Ders. Railroads and American Economic Growth: Essays in Econometric History. Baltimore, MD: Johns Hopkins Press, 1964.

9 Weaver, Frederick Stirton. An Economic History of the United States: Conquest, Conflict, and Struggles for Equality. Lanham, MD, London: Rowman \& Littlefield, 2016, S. 89-92.

10 Bose, Purnima. General Electric, Corporate Personhood, and the Emergence of the Professional Manager. In: Bose, Purnima and Lyons, Laura E. (Hg.). Cultural Critique and the Global Corporation. Bloomington, IN: Indiana University Press, 2010, S. 28-63, S. 59.

11 Weaver, An Economic History, S. 96. 
Auftrieb verlieh. ${ }^{12}$ Fragt man nach anderen Pfaden, so ist $\mathrm{zu}$ betonen, dass grundsätzlich die Möglichkeit der Regulation ungehinderter Kapitalkonzentration und der Unterdrückung der Gewerkschaften bestanden hätte. Die zahlreichen Anti-Trust-Gesetze der Bundesstaaten und das Sherman-Anti-Trust-Gesetz des Bundes von 1890 beweisen dies. Ironischerweise konnten eben diese Gesetze auch gegen Gewerkschaften eingesetzt werden, deren Streikaktivitäten als „Verschwörung“ bezeichnet wurden. ${ }^{13}$ Die Wirksamkeit derartiger Statuten zur Kontrolle des Konzentrationsprozesses wurde durch die geltende Rechtsprechung und den fehlenden Willen der Bundes- und Staatenregierungen stark eingegrenzt. ${ }^{14}$ Mit der virtuellen Gleichsetzung von natürlicher Person und Korporationen, die auf eine lange juristische Vorgeschichte zurückblicken konnte, wurden die Weichen gestellt für die Unterdrückung von Arbeitskämpfen mittels des Vorwurfs der „Verschwörung“ (conspiracy), der einstweiligen Verfügung (injunction) und des auf beide Mittel folgende Militäreinsatz gegen Streikende. ${ }^{15} 4.000$ einstweilige Verfügungen wurden auf diese Weise bis 1905 von Gerichten erlassen, um Streiks zu beenden. ${ }^{16}$ Auch die Möglichkeit, gegen kriminelle Körperschaften vorzugehen, wurde damit stark eingeschränkt. ${ }^{17}$ Es handelt sich also hier um eine von einer längeren Vorgeschichte geprägte langsame Entwicklung, die mit dem Heranreifen des Aktienkapitalismus plötzlich einen qualitativen Sprung vollzog,

12 Laurie, Bruce. Artisans into Workers: Labor in Nineteenth-Century America. Urbana, IL: University of Illinois Press, 1997, S. 186.

13 United States v. Workingmen's Amalgamated Council of New Orleans (1893).

14 Tiedeman, Christopher Gustavus. A Treatise on State and Federal Control of Persons and Property in the United States Considered from Both a Civil and Criminal Standpoint. St. Louis, MO: The F. H. Thomas Law Book Co, 1900. 2 Bände, Band 1, S. 432-456, S. 1052-1060.

15 Forbath, William E. Law and the Shaping of the American Labor Movement. Cambridge, MA: Harvard University Press, 1991, S. 59-62. Der Fall Trustees of Dartmouth College v. Woodward, 17 U.S. 518 (1819) hatte die Rechte von Körperschaften bei Abschluss von Verträgen bestätigt. Santa Clara County v. Southern Pacific R. Co., 118 U.S. 394 (1886) hatte dies in ausdrücklichem Bezug auf den 14. Verfassungszusatz bestätigt. Die Pervertierung des amerikanischen Verfassungsrechts ging in der Folge so weit, dass Korporationen das Recht auf freie Meinungsäußerung dazu benutzen konnten, die Regulierung von Aufwendungen für den Wahlkampf durch den Supreme Court als verfassungswidrig untersagen zu lassen. Siehe Citizens United v. Federal Election Commission, 558 U.S. 310 (2010). Stites, Francis N. Private Interest \& Public Gain: The Dartmouth College Case, 1819. Amherst, MA: University of Massachusetts Press, 1972.

16 Edwards, Rebecca. New Spirits: Americans in the Gilded Age, 1865-1905. New York: Oxford University Press, 2006, S. 271. Estlund, Cynthia und Wachter, Michael L. Research Handbook on the Economics of Labor and Employment Law, Cheltenham, Northampton, MA: Edward Elgar, 2012, S. $433 \mathrm{f}$.

17 Laufer, William S. Corporate Bodies and Guilty Minds: The Failure of Corporate Criminal Liability. Chicago, IL: University of Chicago Press, 2006, S. 19 f., 48. 
indem das Körperschaftsrecht eine Interpretation erfuhr, die von den Intentionen des Gesetzgebers unbeeinflusst waren, ein typischer Lock-in-Effekt (Lock-in 6) im Sinne des Wirtschaftswissenschaftlers William Brian Arthur, da hier ein Wettbewerbsvorteil (juristische Definitionen von Gewerkschaften als „Verschwörung“ oder von Streiks als Eingriff in die Vertragshoheit der Unternehmen) beginnt, sich automatisch zu reproduzieren, bis zu dem Zeitpunkt, an dem dieser Vorteil unüberwindlich wird. ${ }^{18}$ Die Vorteile, die das Recht auf Organisationsfreiheit und Tarifautonomie mit sich gebracht hätten und die hätten helfen können, zumindest die zerstörerischen Massenstreiks der 1890er Jahre zu verhindern, wurden von den Unternehmern und den Aktionären nicht gesehen. Der Blick nach England, der kapitalistischen Vormacht des 19. Jahrhunderts, hätte genügt, um zu zeigen, dass das Koalitionsrecht der Gewerkschaften keineswegs das Ende unternehmerischer Freiheit bedeutet hätte. Seit 1824 waren Streiks in England legal, 1871 wurden auch Gewerkschaften legalisiert. ${ }^{19} \mathrm{Zu}$ groß war die Versuchung, immer neue Konglomerate von Unternehmen zusammenzuführen und zu groß war auch die Angst vor dem „Gespenst des Kommunismus“, das auch in Amerika umging. ${ }^{20}$ Dabei hätte in einer richtig verstandenen Partnerschaft von Kapital und Arbeit die beste Versicherung gegen den höchst unwahrscheinlichen Fall einer einflussreichen sozialistischen oder kommunistischen Partei liegen können. ${ }^{21}$

\subsection{Transport-, Kommunikations- und Marktrevolution, 1863-1893}

Während des Krisenwinters 1894/95 und auf dem Höhepunkt der schwersten Wirtschaftskrise, die die Nation bis dato durchgemacht hatte, trieb den demokratischen Präsidenten der Vereinigten Staaten, Grover Cleveland, die Sorge um, der Staat könne bankrottgehen. Die Goldreserven des Finanzministeriums wa-

18 Roithmayr, Daria. Reproducing Racism: How Everyday Choices Lock in White Advantage. New York: New York University Press, 2014, S. 5. Arthur, Increasing Returns, S. 115.

19 Rimlinger, Gaston V. Labor and the Government: A Comparative Historical Perspective. The Journal of Economic History. 1977; 37 (1):210 - 225, S. 213-215.

20 Heale, M. J. American Anticommunism: Combating the Enemy within, 1830 - 1970. Baltimore, MD: Johns Hopkins University Press, 1990, S. 21-41.

21 Vergl. Sombart, Werner. Warum gibt es in den Vereinigten Staaten keinen Sozialismus? Tübingen: J.C.B. Mohr (P. Siebeck), 1906. Lehmann, Silke. Lorenz von Stein über den amerikanischen Sozialismus und Kommunismus. In: Finzsch, Norbert und Wellenreuther, Hermann (Hg.). Liberalitas: Festschrift für Erich Angermann zum 65. Geburtstag. Stuttgart: Franz Steiner Verlag, 1992, S. 207-222. 
ren so zusammengeschmolzen, dass zu befürchten stand, die USA könnten ihren Zahlungsverpflichtungen nicht mehr nachkommen, es sei denn, zusätzliches Gold könne auf dem freien Markt gekauft werden.

Cleveland war, wie viele seiner Zeitgenossen, der festen Meinung, gutes Geld müsse auf dem Gold als Währungsstandard beruhen. Zwar zirkulierten auch andere Formen des Geldes wie Silbermünzen, Geldscheine und Greenbacks, doch galt es als unumstößliche Doktrin, dass alle diese Formen von Geld jederzeit in Gold ausgezahlt werden mussten. Eine Panik an der Wall Street im Jahre 1893 hatte die Goldreserven bedrohlich zusammenschmelzen lassen, da Banken und Einleger den Umtausch ihrer Einlagen in Gold verlangten. ${ }^{22}$

Ende Januar 1895 waren die Goldbestände des Schatzamts nahezu verschwunden. Die New Yorker Bankiers August Belmont, Jr. (1853-1824) und John Pierpont Morgan (1837-1913) schlugen dem Präsidenten einen Plan vor, nach dem eine Gruppe privater Financiers Gold auf dem Weltmarkt kaufen würden und es dem Schatzamt zur Verfügung stellen würden - im Austausch für Regierungsobligationen (bonds), die das Bankensyndikat dann auf dem freien Markt mit Gewinn zu verkaufen hoffte. Cleveland verstand, dass diese Maßnahme dem Finanzsektor das verlorene Vertrauen zurückgeben würde, er befürchtete aber die öffentliche Meinung, die das Zusammengehen von Politik und Hochfinanz mit sehr kritischen Kommentaren begleiten würden. Cleveland zögerte deswegen, auf das Angebot der Bankiers einzugehen. Im Februar 1895 reiste J. P. Morgan mit seinem Privatwaggon nach Washington, wo er sich mit dem Präsidenten traf. Cleveland weigerte sich, ihn zu empfangen, weil er sich noch nicht entschließen konnte, Morgans Angebot anzunehmen. Der Bankier schien dem Präsidenten die Zurückweisung nicht besonders übel zu nehmen. Vor einer Gruppe von Reportern äußerte er: „I have come down to see the president, and I am going to stay here until I see him.“'23

Am nächsten Tag lud Cleveland Morgan doch noch ins Weiße Haus ein. Als ein Telefonanruf den Präsidenten davon unterrichtete, dass nur noch Gold im Gegenwert von neun Millionen Dollar in der New Yorker Dependance des Schatzamtes verbliebe, informierte Morgan den Präsidenten darüber, dass er von einer offenen Schuld von zehn Millionen Dollar wisse und deutete damit den unmittelbar bevorstehenden Staatsbankrott an. „What suggestion have you to make, Mr. Morgan?“, fragte Cleveland. ${ }^{24}$ Um den Goldstandard zu retten, blieb

22 Timberlake, Richard H. Panic of 1893. In: Glasner, David and Cooley, Thomas F. (Hg.). Business Cycles and Depressions: An Encyclopedia. New York: Garland Pub, 1997, S. 516-518.

23 Brands, H. W. The Money Men: Capitalism, Democracy, and the Hundred Years' War over the American Dollar. New York: W.W. Norton \& Co, 2006, S. 177.

24 Brands, H. W. The Money Men, S. 177. 
dem Präsidenten nichts anderes übrig, als auf das Angebot Morgans einzugehen. Ein Sturm der Entrüstung erhob sich ob des Geschäfts zwischen der Regierung und dem Bankier. Die Presse behauptete, der Präsident habe sich dabei persönlich bereichert, und es kursierten Gerüchte, Morgan habe an dem Deal 8,9 Millionen Dollar verdient. ${ }^{25}$

Der Antisemitismus, eine relativ neue Erscheinung in den Vereinigten Staaten, erhob sein hassverzerrtes Haupt. ${ }^{26} 1877$ schon war dem amerikanischen Bankier Joseph Seligman die Benutzung des Grand Union Hotels in Saratoga, NY, durch den Hotelbesitzer Judge Henry Hilton mit dem Hinweis auf seine jüdische Abstammung verweigert worden. ${ }^{27}$ Der Fall erregte nationales Aufsehen. Hilton war unverschämt genug, sein Verhalten in einem unflätigen Artikel zu rechtfertigen, der in der New York Times erschien. Im Zuge dieser Affäre verweigerten immer mehr Hotels Juden und Jüdinnen den Zutritt. ${ }^{28}$

Cleveland, so wurde jetzt behauptet, hätte die amerikanische Wirtschaft an die Rothschilds ausgeliefert, die zusammen mit JP Morgan angeblich das amerikanische Bankenwesen kontrollierten. ${ }^{29}$ Tatsache war, dass die Rothschild-Bank Teil des Syndikats gewesen war, das Gold im Ausland aufgekauft hatte. ${ }^{30}$ Die New

25 Nevins, Allan. Grover Cleveland: A Study in Courage. Norwalk, CT: Easton Press, 1989, S. 665 f. Der ganze Vorgang und seine Hintergründe sind in der ausgezeichneten Studie der Carossos zusammengefasst. Carosso, Vincent P. und Carosso, Rose C. The Morgans: Private International Bankers, 1854-1913. Cambridge, MA: Harvard University Press, 1987, S. 311-351.

26 Einschlägig hierzu die Dissertation von Kristoff Kerl. Kerl, Kristoff. „To Restore Home Rule“: Angloamerikanische Männlichkeit und Antisemitismus im US-Süden zwischen den 1860er und 1920er Jahren. Disertation, Universität zu Köln, 2015. Löwy, Bella. The Russian Jews. Extermination or Emancipation? The Jewish Quarterly Review. 1894 Apr 1; 6 (3):533-546. Ross, Edward A. The Causes of Race Superiority. Annals of the American Academy of Political and Social Science. 1901, No. 18, S. 67-89. Zur Geschichte des Anti-Semitismus in den USA siehe Dobkowski, Michael N. The Tarnished Dream: The Basis of American Anti-Semitism. Westport, CT: Greenwood Press, 1979. Freedman, Jonathan. The Temple of Culture: Assimilation and Anti-Semitism in Literary Anglo-America. New York: Oxford University Press, 2000. Gerber, David A. Anti-Semitism in American History. Urbana, IL: University of Illinois Press, 1986. Gurock, Jeffrey S. Anti-Semitism in America. New York: Routledge, 1998. Jaher, Frederic Cople. A Scapegoat in the New Wilderness: The Origins and Rise of Anti-Semitism in America. Cambridge, MA: Harvard University Press, 1994.

27 Poliakov, Léon. The History of Anti-Semitism. Oxford, New York, Oxford University Press, 1985, 4 Bände, Band 4: Suicidal Europe, $1870-1933$, S. $224 \mathrm{f}$.

28 Young, Bette Roth. Emma Lazarus in Her World: Life and Letters. Philadelphia, PA: Jewish Publication Society, 1995, S. 46f. Aron, Cindy Sondik. Working at Play: A History of Vacations in the United States. New York: Oxford University Press, 1999, S. 216-218.

29 Nevins, Grover Cleveland, S. $665 \mathrm{f}$.

30 Garbade, Kenneth D. Birth of a Market: The U.S. Treasury Securities Market from the Great War to the Great Depression. Cambridge, MA: MIT Press, 2012, S. 37-40. 
York World, die Joseph Pulitzer (1847-1911) gehörte, verdammte das Syndikat, das die Rettungsmission Clevelands ermöglicht hatte, als „jüdische Blutsauger“. ${ }^{31}$ Karikaturen erschienen in verschiedenen amerikanischen Zeitungen, die in einer Manier, die an den „Stürmer“ der NS-Zeit erinnert, antijüdische und antisemitische Klischees verbreiteten. ${ }^{32}$ Die Populistin, Temperenzlerin und Suffragette Mary Elizabeth Lease (1850 - 1933) sagte anlässlich einer Rede am 11. August 1896: „Redemption money and interest-bearing bonds are the curse of civilization. We are paying tribute to the Rothchilds [sic] of England, who are but the agent of the Jews.“33

Selbst ein Intellektueller wie der Historiker Henry Adams bezog öffentlich hasserfüllte antisemitische Positionen. „I detest the [Jews], and everything connected with them, and I live only and solely with the hope of seeing their demise with all their accursed Judaism. I want to see all the lenders at interest taken out and executed.“34 1894, auf dem Höhepunkt der Wirtschaftskrise, war im Vorgriff auf die Ereignisse um die Bewahrung des Goldstandards ein Aufsehen erregender Roman des Autors William Hope Harvey (1851-1936) erschienen. In „A Tale of Two Nations“ legte der aus dem Süden stammende Autor die Grundlagen für die Verbindung von Antisemitismus und Verschwörungstheorien. Der fiktive Baron Rothe, ein intelligenter und skrupelloser jüdischer Bankier, mit dem offensichtlich Baron Rothschild gemeint war, zettelt in dem Plot des Romans eine Verschwörung an, die darauf abzielt, das Silber zu demonetarisieren und so den Goldpreis nach oben zu treiben und die Wirtschaft der Vereinigten Staaten schwer zu schädigen. ${ }^{35}$

In der Rückschau sind solcher Hass und derartige Anklagen schwer verständlich. Cleveland bereicherte sich nicht bei diesem Geschäft, sondern tat das, was er für politisch notwendig hielt. Morgan verdiente keineswegs 8,9 Millionen beim Verkauf seiner Regierungsanleihen, sondern ganze 295.652 Dollar. ${ }^{36}$ Die Idee, dass man jederzeit zur Bank gehen könne, um seine Spareinlagen als

31 Geisst, Charles R. Wall Street: A History from Its Beginnings to the Fall of Enron. Oxford, New York: Oxford University Press, 2004, S. 112.

32 St. Louis Post-Dispatch, 13. Oktober 1896.

33 The New York Times, 11. August 1896.

34 Zitiert in Michael, Robert. A Concise History of American Antisemitism. Lanham, MD: Rowman and Littlefield, 2005, S. 116. Michaels Buch enthält weitere geradezu abstoßende Beispiele für Adams’ Antisemitismus. Siehe S. 116f. Die Standardbiographie zu Adams erwähnt derartige Ausfälle nur am Rande. Samuels, Ernest. Henry Adams. Cambridge, MA: Belknap Press of Harvard University Press, 1989, S. 291-296.

35 Harvey, William Hope. A Tale of Two Nations. Chicago, IL: Coin Publishing Company, 1894. 36 Bernstein, Peter L. The Power of Gold: The History of an Obsession. New York: Wiley, 2004, S. 274-276. 
Goldbarren ausgezahlt zu bekommen, kommt uns heute grotesk vor. Dennoch hält sich auch heute noch hartnäckig die Vorstellung, das amerikanische Bankenwesen sei von ,jüdischen Geldgebern“ und dem Federal Reserve System, das auch unter jüdischer Herrschaft stehe, kontrolliert. ${ }^{37}$

Auch wenn Morgan und Cleveland gemeinsam den Goldstandard retteten, so half das den von der Krise Betroffenen zunächst wenig. Der Winter 1894/95 war einer der härtesten in der Geschichte der Vereinigten Staaten. Arbeitslosigkeit, Kälte und Hunger setzten der Bevölkerung hart zu. Die anhaltende Depression und die Erkenntnis, dass nicht der Präsident, sondern die Banken die Macht hatten, die nationale Währung und den Staatshaushalt zu retten, stießen den Kommentatoren hart auf. Wie war es möglich, dass Geschäftsleute über so viel Macht verfügten? Was bedeutete dies für die amerikanische Demokratie?

Der Jurist und Diplomat Charles Francis Henry Adams (1807-1886), Enkel des Präsidenten John Adams (1735-1826) and Sohn des Präsidenten John Quincy Adams (1767-1848), drückt die Besorgnis vieler amerikanischer Bürger über die wachsende Macht der großen Unternehmen aus: Die Demokratie werde vom „Cäsarismus“ bedroht, der Diktatur der Aktiengesellschaften. ${ }^{38}$ Die zunehmende Bedeutung des Geldes und des Profitstrebens besorgte auch den Schriftsteller Mark Twain, der den Begriff Gilded Age zur Bezeichnung seiner Epoche prägte.

Die profunden Veränderungen, die die Vereinigten Staaten nach dem Ende des Bürgerkriegs durchlaufen hatten, waren einigen Zeitgenossen verborgen geblieben. Präsident Rutherford B. Hayes konnte noch recht blauäugig behaupten „[w]e are in a period when the old questions are settled, and the new ones are not yet brought forward. “" ${ }^{39}$ Doch die neuen Probleme lagen längst auf dem Tisch. Gegen Ende des 19. Jahrhunderts hatten die USA Großbritannien als führende Industriemacht abgelöst. Die grundlegenden Impulse der Industrialisierung in den USA sorgten aber auch für Spannungen und Widersprüche, die sich mitunter gewaltsam Luft machten. Das wirtschaftliche Wachstum verlief nicht stetig, sondern wurde durch Beschleunigung und Krisen gekennzeichnet. Wirtschaftskrisen wurden in der Regel durch das Platzen von Spekulationsblasen ausgelöst, die wiederum Banken in die Zahlungsunfähigkeit trieben. Arbeitslosigkeit und

37 Zur politisch motivierten Kritik an der Federal Reserve siehe Paul, Ron. End the Fed. New York: Grand Central Publishing; 2009. Zumj Antisemitismus unter den Gegnern der Federal Reserve siehe [Anonymous]. The Federal Reserve - Zionist Jewish Private Bankers.“ [Web Page]: http:// www.rense.com/general85/feddrec.htm. Gesehen am 26.9.2014.

38 Adams, Charles Francis. Chapters of Erie and Other Essays. Bedford, MA: Applewood Books, 1871, S. 383.

39 Williams, Charles Richard (Hg.). Diary and Letters of Rutherford Birchard Hayes. Columbus, OH: The Ohio State Archæological and Historical Society, 1922-1926, 5 Bände, Band 3, S. 467. 
Hunger waren die unmittelbaren Folgen derartiger Kontraktionen des Marktes. 1866 brach die Wirtschaft ein, 1873 kam es dann zur ersten großen Krise nach dem Ende des Bürgerkriegs, 20 Jahr später folgte die Panic of 1893 mit ihren globalen Auswirkungen, die von Buenos Aires bis Wien reichten. ${ }^{40}$

Das industrielle Wachstum war auch regional sehr unterschiedlich. Große Teil der Vereinigten Staaten, vor allem im Süden und Westen, blieben der Landwirtschaft verschrieben. Die Großindustrie entwickelte sich vor allem im Nordosten der Republik und in den Gebieten um die Großen Seen, wo zahlreiche Häfen und das Vorhandensein von Rohstoffen und billigen Arbeitskräfte die Industrialisierung beschleunigten.

Der Aufstieg der Industrie und das Zusammenspiel von Geschäft und Politik waren die beherrschenden Themen des Gilded Age zwischen 1870 und 1890. Eisenbahnen und Telegraphenlinien brachten die Menschen näher zusammen, zumindest als Konsumierende. ${ }^{41}$ Betroffen von der Industrialisierung waren amerikanische Arbeiter und Arbeiterinnen genauso wie die Bewohner der Farmen in Idaho oder Iowa. Das Gefühl, von anonymen Mächten beherrscht zu werden, ohne selbst Kontrolle ausüben zu können, war weit verbreitet. Der Kollaps einer Bank als Folge einer Fehlinvestition im Eisenbahngeschäft betraf Eisenbahnarbeiter gleichermaßen wie Farmer, die einen Kredit bei der kollabierten Bank aufgenommen oder ihre Spargroschen bei ihr deponiert hatten. Die Hoffnungen, Erwartungen, Befürchtungen und Ängste, die Amerikaner und Amerikanerinnen unterschiedlichster Provenienz hatten, äußerten sich oft in der Einstellung zu den großen Industriekapitänen der Zeit, Männern wie Jason „Jay“ Gould (1836-1892), Andrew Carnegie, John D. Rockefeller, and John Pierpont Morgan (1837-1913). Diese berühmten und berüchtigten Männer beherrschten nicht nur weite Teile der amerikanischen Industrie, sondern auch die Vorstellungskraft der Öffentlichkeit. Die einen waren Helden, die anderen Bösewichte oder „Raubritter“. In keiner anderen Periode der U.S.-amerikanischen Geschichte würden die Industriegiganten und die Unternehmen, die sie formten, einen solch wichtigen Platz im allgemeinen Bewusstsein einnehmen.

40 Davies, Hannah Catherine. Transatlantic Speculations: A Transnational and Comparative History of the Panics of 1873. Berlin: Dissertation, Freie Universität Berlin, 2014.

41 Beauchamp, K. G. History of Telegraphy. London: Institution of Electrical Engineers, 2001. Israel, Paul. From Machine Shop to Industrial Laboratory: Telegraphy and the Changing Context of American Invention, 1830-1920. Baltimore, MD: Johns Hopkins University Press, 1992. Zur Bedeutung der Telegraphie im internationalen Datenaustausch siehe Anderson, James. Statistics of Telegraphy. Journal of the Statistical Society of London. 1872 Sep 1; 35 (3):272-326. Müller-Pohl, Simone. The Class of 1866 and the Wiring of the World: Telegraphic Networks in Maritime Space, 1858-1914. Berlin: Freie Universität Berlin, 2012. 


\subsection{Lock-in 5: Der Eisenbahnbau als Schlüsselindustrie für Spekulation, Expansion und Konzentration}

In den Jahren nach dem Bürgerkrieg expandierte die amerikanische Industrie exponentiell. Alte Gewerbe wurden zu neuen Geschäftszweigen umgeformt. Entdeckungen und Erfindungen regten neue Industriezweige, wie die Öl- und die Elektroindustrie an. Eine Reihe von Faktoren ist für das rasche Wachstum verantwortlich. Es gab riesige und leicht abzubauende Rohstofflager im Land. Kohle, Eisen, Bauhölzer, Öl und Wasserkraft kamen zusammen und halfen der Industrialisierung auf die Sprünge. Auch der Vorrat an menschlicher Arbeitskraft schien nahezu unerschöpflich zu sein. Einwandererfamilien strömten in Rekordzahlen ins Land und immer mehr Farmer gaben ihr Land auf und zogen in die Städte. Amerikanische Erfinder, von jeher eher Bastler als Theoretiker, fanden Lösungen für technische Probleme aller Art. Das Telefon, die Schreibmaschine, das elektrische Licht, die Nähmaschine, Kühlaggregate und das Automobil wurden zwischen den Jahren 1870 und 1900 nicht wegzudenkende Neuerungen im amerikanischen Alltagsleben. Parallel zu den technischen Neuerungen wurden revolutionäre Methoden der Betriebsführung entwickelt, die es erlaubten, Firmen von bisher ungeahnter Größe und Komplexität effektiv zu verwalten und zu lenken.

Die Eisenbahnen stimulierten die Entwicklung zahlreicher Industriezweige und verhalfen den USA zu ungeahntem Wachstum. Schon vor dem Bürgerkrieg hatten die Eisenbahnen den Kanälen und den mautpflichtigen Straßen Konkurrenz gemacht, weil sie billiger, direkter und schneller waren als herkömmliche Transportsysteme. 1857 benötigte ein Reisender für die Strecke von New York nach Chicago nur noch drei Tage. Früher hatte er dafür drei Wochen veranschlagen müssen. Noch wichtiger war indessen, dass Eisenbahnen auch im Winter verkehren konnten und die Gleise nicht zufroren wie die Kanäle. Wenn man berücksichtigt, welche immense Bedeutung der Eisenbahn als Transportmittel und als Auslöser des Wirtschaftswachstums auf nationalem Niveau zukam, ist es erstaunlich, dass ihr Bau ohne zentralen Plan oder staatliche Lenkung vonstattenging. Das genau ist auch der Punkt, an dem die US-amerikanische Politik nach Alternativen für diese Form der Kapitalakkumulation hätte suchen können. Hätte der Staat hier direkter eingegriffen, hätte er auf einer ausreichenden Kapitaldeckung bestanden, hätte er die Vergabe des Baulandes stärker überwacht, wären die Spekulationsexzesse ausgeblieben. Dass dies nicht „unamerikanisch“ war, zeigen die verschiedenen Anti-Trust-Gesetze der USA nach 1890, die jedoch zu spät kamen und nur selektiv umgesetzt wurden. Im Falle des Eisenbahnbaus unterblieb eine staatliche Gesamtregelung. Vielmehr entstanden amerikanische Streckennetze aus einer Vielzahl kleiner Linien, die von Spekulanten, Glücksrit- 
tern, Kaufleuten, Investoren, Industriellen und Financiers erbaut wurden. Darunter befanden sich auch ausgemachte Betrüger, die den Eisenbahnbau benutzen, um andere Leute auszunehmen. Trotzdem entstand in weniger als 20 Jahren ein nationales Netz, so dass ab 1880 kaum noch neue Strecken benötigt wurden. Um zu verstehen, welche Bedeutung der Eisenbahnbau für die amerikanische Wirtschaft und das Leben im Allgemeinen hatte, ist es lohnenswert, sich die Karriere Jay Goulds anzusehen, des Mannes, der wie kein zweiter das Gilded Age verkörperte und der in Joseph Schumpeters Terminologie mit Recht „Kapitalist“ genannt werden darf. ${ }^{42}$

Jason „Jay“ Gould (1836-1892) kaufte seine erste Eisenbahnlinie vor seinem 25. Geburtstag. Sie war zwar nur 100 Kilometer lang und in miserablem Zustand, doch konnte er sie nach zwei Jahren mit einem Gewinn von 130.000 Dollar wieder veräußern. So begann die Karriere eines Mannes, der die Entwicklung des amerikanischen Eisenbahnnetzes vorantreiben sollte und dabei zu Amerikas größtem Spekulanten wurde. Gould, der schwächliche und gesundheitlich anfällige Sohn eines Farmers, lief seinen Eltern davon und ging in die Stadt, um ein Vermögen zu machen. Wie viele Zeitgenossen der 1850er Jahre sah er in den Eisenbahnen eine sich nicht wieder bietende Chance zum individuellen Aufstieg. ${ }^{43}$

Gould gab zu, dass er nicht viel von Eisenbahnen verstand. Er war kein Techniker und kein Managertyp. Das alles interessierte ihn auch nicht besonders. Er wollte ein Finanzimperium schmieden, und dazu brachte er Bahnlinie nach Bahnlinie unter seine Kontrolle. Der verschlossene Gould verhielt sich wie ein Haifisch auf dem Meer des Aktienkapitals. Witterte er eine angeschlagene Eisenbahnlinie, kaufte er so viele Aktien, um mindestens eine Sperrminorität zu erreichen, oder er erwarb direkt die Aktienmehrheit. Dann begann er einen Preiskrieg mit seinen Konkurrenten und unterbot sie so lange, bis sie seine Bahnlinie zu überhöhten Preisen aufkauften. Die Linien, die ihm in die Hände fielen, wie die Erie Railroad, und die er lediglich benutzte, um seine Konkurrenten unter Druck zu setzen, waren oft in miserablem Zustand und gingen nach kurzer Zeit bankrott.

42 Schumpeter unterscheidet grundsätzlich zwischen dem Unternehmer und dem Kapitalisten. Unternehmer schaffen Neues, sie wollen Innovationen herbeiführen, während Kapitalisten ihr Kapital vorschießen, um Gewinne zu erzielen. Schumpeter, Joseph A. Theorie der wirtschaftlichen Entwicklung. Leipzig: Duncker \& Humblot, 1911.

43 Gordon, John Steele. The Scarlet Woman of Wall Street: Jay Gould, Jim Fisk, Cornelius Vanderbilt, the Erie Railway Wars, and the Birth of Wall Street. New York: Weidenfeld \& Nicolson, 1988. Grant, H. Roger. „Follow the Flag“: A History of the Wabash Railroad Company. DeKalb, IL: Northern Illinois University Press, 2004. Grodinsky, Julius. Jay Gould: His Business Career, 18671892. New York: Arno Press, 1981. Klein, The Life and Legend of Jay Gould. 
Gould wollte jedoch gar keine profitable Bahnlinie unterhalten; ihm lag lediglich daran, möglichst viel Aktienkapital zu akkumulieren. ${ }^{44}$

Jay Goulds Macht und sein Erfolg gründeten sich auf dem chaotischen Wachstum der Eisenbahnen in den Vereinigten Staaten. Um den Bau neuer Strecken zu beschleunigen, hatten die Regierungen der Bundesstaaten und die Bundesregierung großzügige Landschenkungen und Geldprämien ausgelobt. Bundesstaaten und Gemeinden taten alles, um ihren Staat oder ihre Stadt an das Eisenbahnnetz anzuschließen, weil nur eine funktionierende Eisenbahnverbindung garantieren konnte, dass die betreffende Gemeinde wirtschaftlich florierte. Da der Bund im Besitz riesiger Landmengen im Westen war, die den Native Americans unter Verletzung geltender Verträge abgenommen worden waren, konnte es sich der Kongress erlauben, großzügige Landgeschenke zu machen. Diese Landgeschenke fungierten bei der Zuweisung der Eisenbahnindustrie als Schlüsselindustrie als entscheidende Critical Juncture (Critical Juncture 5).

\subsection{Critical Juncture 5: Landgeschäfte zur Finanzierung der Eisenbahnen}

Die Eisenbahnlinien erhielten also nicht nur das Wegerecht für die eigentliche Trasse, sondern bekamen große Gebiete links und rechts der Eisenbahnschienen geschenkt. Die alternierende Vergabe dieser Ländereien sorgte für das typische Schachbrettmuster der Landvergabe. Die Eisenbahngesellschaften konnten mit dem Land nach Belieben verfahren. Meistens verkauften sie es an landhungrige Siedler, die mit der Eisenbahn nach Westen gelangten. Die Bundesregierung und die Staatenregierungen vergaben auf diese Weise 179 Millionen Acres, ein Gebiet größer als der Staat Texas. ${ }^{45}$ „,The railroads being promoted during those years were land companies before they became railroad companies, and they remained land companies after they had become railroad companies. “46

44 Brands, H. W. The Money Men: Capitalism, Democracy, and the Hundred Years' War over the American Dollar. New York: W.W. Norton \& Co, 2006, S. 134-142. Geisst, Charles R. Monopolies in America: Empire Builders and Their Enemies from Jay Gould to Bill Gates. Oxford, New York: Oxford University Press, 2000, S.1-49. Klein, The Life and Legend of Jay Gould. Morris, Charles R. The Tycoons: How Andrew Carnegie, John D. Rockefeller, Jay Gould, and J.P. Morgan Invented the American Supereconomy. New York: H. Holt and Co, 2005. Renehan, Edward. Dark Genius of Wall Street: The Misunderstood Life of Jay Gould, King of the Robber Barons. New York: Basic Books, 2005.

45 Mercer, Railroads and Land Grant Policy, S. 6.

46 Janeway, The Economics of Crisis, S. 87. 
Der Löwenanteil des Kapitals für den Eisenbahnbau stammte indessen nicht aus dem Landverkauf, sondern von Investoren aus Europa und den USA, die hofften, mit den Dividenden für ihre Aktien viel Geld zu verdienen. Der Bürgerkrieg sorgte für einen vorübergehenden Rückgang des Geschäfts, aber nach 1865 kam es zu einer wahren Bauwut. Die erste transkontinentale Eisenbahnlinie wurde 1869 fertiggestellt, nachdem die Schienen der Union Pacific und Central Pacific in Promontory Point, Utah, zusammentrafen und mit einem symbolischen goldenen Nagel verbunden wurden. Der Bund hatte die Union Pacific dabei mit über 17 Millionen Dollar in Form von Landschenkungen unterstützt.

Zwischen 1870 und 1880 verdoppelte sich das verfügbare Schienennetz. Im folgenden Jahrzehnt kam es wieder zu einer Verdoppelung. 1900 waren 193.000 Schienenmeilen verlegt, mehr als alle Strecken in Europa und Russland zusammengenommen. ${ }^{47}$ Quantität war jedoch nicht gleichbedeutend mit Qualität. Die verschiedenen Eisenbahnlinien waren ohne Rücksicht auf andere Unternehmungen gebaut worden - wildwuchsartig und wenig koordiniert. Die frühen Linien mit Ausnahme der transkontinentalen Eisenbahnen waren noch nicht einmal untereinander verbunden. Spurweiten variierten stark, so dass ein Umsetzen eines Zuges von einer Schiene auf die andere kaum möglich war. Erst 1886 stellten sich die südlichen Eisenbahnen auf die Standardspurweise der Pennsylvania Railroad um. ${ }^{48}$ Es existierten wohl an die Tausend unterschiedliche Unternehmen, die oft nur gegründet worden waren, um an der Börse zu spekulieren. Aktien wurden verwässert, das heißt, es wurden mehr Aktien ausgegeben, als zur Erhebung des Kapitals der Gesellschaft nötig war. Diesen Aktien entsprach aber kein Gegenwert und kein Produkt. Sie dienten lediglich der Bereicherung der Spekulanten. So lange die Investoren annahmen, er werde alles gut, funktionierte dieses Geschäft recht gut. Käufer für überbewertete Aktien fanden sich immer und die Spekulanten erzielten riesige Profite.

Die mangelhafte Planung führte zu einem Überangebot. Schon in den 1870er Jahren war ein erbitterter Kampf der Eisenbahnlinien an der Ostküste entbrannt, die sich gegenseitig die Kunden abspenstig machten. Ein Produzent, der Zugang zum Markt brauchte und das Glück hatte, in einer Region angesiedelt zu sein, in der unter den Eisenbahnlinien ein Verdrängungswettbewerb tobte, konnte seine Produkte mit erheblichen Rabatten an den Mann bringen. Weil klar war, dass die

47 Danaher, Kevin und Mark, Jason. Insurrection: Citizen Challenges to Corporate Power. New York: Routledge, 2003, S. 30. Zum Wirtschaftswachstum allgemein Beatty, Jack. Colossus: How the Corporation Changed America. New York: Broadway Books, 2001.

48 Bianculli, Anthony J. Trains and Technology: The American Railroad in the Nineteenth Century. Newark, DE: University of Delaware Press, 2001-2003, 4 Bände, hier Band 3: Track and Structure, S. 73-84. 
Eisenbahnlinien bei dieser mörderischen Konkurrenz Geld verlieren würden, schlossen sie sich zu „Pools“ zusammen, teilten das Territorium auf und trafen Preisabsprachen. Diese Absprachen waren in der Regel kurzlebig, weil hinter ihnen keine rechtlich verbindliche Organisationsform stand, d. h. die Absprachen nicht justitiabel waren. Männer wie Jay Gould nutzen jede sich bietende Gelegenheit, um aus den Pools auszuscheren, wenn es sich finanziell zu lohnen schien. ${ }^{49}$

In den 1880er Jahren ging Gould z.B. daran, eine zweite transkontinentale Eisenbahn zu bauen, um mit der Union Pacific und der Central Pacific in Wettbewerb zu treten. Seine Entscheidung zwang auch andere Eisenbahnlinien dazu, seine Politik der Expansion und des Aufkaufs konkurrierenden Linien mitzumachen. Die Folge war ein Konzentrationsprozess, so dass in den 1890er Jahren eine Handvoll von Eisenbahnlinien den Ton angaben, darunter die „Riesen“ Southern Pacific, Northern Pacific und die Santa Fe Eisenbahngesellschaft. ${ }^{50}$

Tabelle 5: Staatliche Landsubventionen für die Union Pacific ${ }^{51}$

\begin{tabular}{lr}
\hline Jahr & $\begin{array}{r}\text { Nettolandschenkung } \\
\text { in Tsd. Dollar }\end{array}$ \\
\hline 1869 & 355,9 \\
1870 & 436,1 \\
1871 & 448,7 \\
1872 & 418,4 \\
1873 & 701,2 \\
1874 & 803,1 \\
1875 & 33,6 \\
1876 & 109,8 \\
1877 & 58,0 \\
1878 & 1144,3
\end{tabular}

49 Chandler, Alfred D. The Railroads: Pioneers in Modern Management. New York: Arno Press, 1979. Cleveland, Frederick Albert und Powell, Fred Wilbur. Railroad Promotion and Capitalization in the United States. New York: Arno Press, 1981. Solomon, Brian und Yough, Patrick. Coal Trains: The History of Railroading and Coal in the United States. Minneapolis, MN: MBI Pub. Company, 2009. Immer noch lesenswert ist Fogel, Robert William. Railroads and American Economic Growth: Essays in Econometric History. Baltimore, MD: Johns Hopkins Press, 1964, S. 207-237. 50 Wie skrupellos Gould bei seinen Machinationen vorging, demonstriert Craig Miner in seiner Studie zur St. Louis-San Francisco Transcontinental Railroad. Miner, H. Craig. The St. Louis-San Francisco Transcontinental Railroad: The Thirty-Fifth Parallel Project, 1853-1890. Lawrence, KS: University Press of Kansas, 1972, S. 120-133.

51 Die Zahlen geben die wirklichen Einnahmen aus Landschenkungen nach Abzug der Entwicklungskosten wieder. 
Tabelle 5: Staatliche Landsubventionen für die Union Pacific (Fortsetzung)

\begin{tabular}{lr}
\hline Jahr & $\begin{array}{r}\text { Nettolandschenkung } \\
\text { in Tsd. Dollar }\end{array}$ \\
\hline 1879 & 747,1 \\
1880 & 542,5 \\
1881 & 260,2 \\
1882 & 779,3 \\
1883 & 2291,2 \\
1884 & 6423,0 \\
1885 & 1277,7 \\
1886 & 307,4 \\
1887 & 249,5 \\
1888 & 205,4 \\
1889 & 184,4 \\
\hline Summe & $\mathbf{1 7 7 7 6 , 8}$ \\
\hline
\end{tabular}

Quelle: Mercer, Railroads and Land Grant Policy, Table C-2, S. $196 \mathrm{f}$.

In den Kontoren und Büros sorgten relative unbekannte Personen dafür, dass solche Gesellschaften nicht untergingen. Financiers und Manager wie Daniel Craig McCallum (1815-1878) von der Erie Railroad oder John Edgar Thomson (1808-1874) von der Pennsylvania Railroad sorgten dafür, dass das Geschäft lief. Sie entwickelten neue Buchhaltungstechniken, experimentierten mit neuen Konzernmodellen und machten es so möglich, dass die Gesellschaften trotz der Konkurrenz noch Gewinne erwirtschaften konnten. So entstanden Firmen von ungeahnter Größe, die eine monopolartige Stellung einnehmen konnten und deswegen den Gewinn ihrer Gesellschaft nicht nur über Absatzzahlen, sondern auch über Preissteigerungen des Produkts bestimmen konnten. In den 1850er Jahren waren die größten Betriebe Textilunternehmen gewesen, die bis zu 800 Arbeiterinnen und Arbeiter beschäftigten. 1874 beschäftigte die Pennsylvania Railroad mehr als 55.000 Mitarbeiter und übte die Kontrolle über mehr 6.000 Meilen Schienen aus, die den halben Kontinent umspannten. ${ }^{52}$ Mit einem Kapital von über 400 Millionen Dollar konnten die Manager der Gesellschaft behaupten, sie sei die weltgrößte Firma. Um einen derartigen Behemoth an verschiedenen

52 Chandler, Alfred D. The Visible Hand: The Managerial Revolution in American Business. Cambridge, MA: Belknap Press, 1977, S. 541, FN 24. Dredge, James. The Pennsylvania Railroad: Its Organization, Construction, and Management. London, New York: Offices of „Engineering.“ John Wiley and Sons; 1879. Peden, Henry C. und Shagena, Jack L. The Ma \& Pa Remembered: A History of the Maryland \& Pennsylvania Railroad. Bel Air, MD: Privately printed by the authors, 2011. Weiser, Eugene. The Pennsylvania Railroad. Seaford, DE: Dragonwick Pub, 2013. 
Standorten zu lenken, bedurfte es ausgeklügelter Organisationsformen. Nur mithilfe von Prozessorganisation, komplexen Methoden der Statistik und der Rechnungsführung konnten derartig große Strukturen überwacht und gelenkt werden.

Nicht weniger wichtig war die „Kommunikationsrevolution“ in der Mitte des 19. Jahrhunderts. Schon in den 1840er Jahren hatte Samuel F. B. Morse (1791-1872) einen einfachen Code entwickelt, um Botschaften mittels eines Drahtes elektrisch zu übermitteln. Die Telegraphie revolutionierte den Austausch von Informationen. Der Telegraph setzte sich in enger Verbindung zum Eisenbahnnetz als nationales Kommunikationssystem durch, da die Telegraphendrähte entlang der Eisenbahntrassen verlegt werden konnten. Die Telegraphie war zunächst zu teuer für Privatpersonen, eignete sich aber hervorragend, um Geschäftsinformationen über lange Strecken schnell auszutauschen. Codebücher, die nur den Angehörigen der Firmen zur Verfügung standen, die Geschäfte miteinander machten, sorgten für die Vertraulichkeit der Information und kürzten die Telegramme stark ab, was Kosten sparte. ${ }^{53}$ Die Eisenbahnen bedienten sich der Telegraphie, um Fahrpläne zu koordinieren und Unfälle zu vermeiden. Schließlich operierten die Eisenbahnlinien vor Einführung des Systems der Zeitzonen auf der Basis lokaler Zeitrechnung, was es bei großen Entfernungen schwer machte, Fahrpläne zu berechnen und einzuhalten. Gleichzeitig bildete die Telegraphie ein Dispositiv für die Etablierung transatlantischer und transspatialer Netze und legte damit die Grundlagen für die Entfaltung des amerikanischen Empire. Auch hier hatte Jay Gould seine Finger im Spiel. 1878 gelang es ihm durch Manipulation der Aktienkurse, die Western Union in seine Hand zu bringen und erwarb damit das Monopol der Telegraphenindustrie. ${ }^{54}$

Nicht alle frühen Eisenbahnunternehmer waren Spekulanten ohne Skrupel wie Jay Gould. ${ }^{55}$ James Jerome Hill (1838-1916) ließ die Great Northern bauen, eine sehr solide und gut laufende Eisenbahnlinie. Hill erhielt keine Landschenkungen des Staates, musste also sorgfältig planen und überlegen, wer an seine Trassenführung angeschlossen sein sollte. Im Endergebnis war die Great Northern eine der wenigen Linien, die die wirtschaftliche Krise von 1893 bis 1897 unbeschadet überstanden. ${ }^{56}$ Vergleicht man Hill mit Spekulanten wie Daniel Drew

53 Hampf, M. Michaela und Müller-Pohl, Simone (Hg.). Global Communication Electric: Business, News and Politics in the World of Telegraphy. Frankfurt/Main: Campus, 2013.

54 Wolff, Joshua D. Western Union and the Creation of the American Corporate Order, 1845-1893. Cambridge, New York: Cambridge University Press, 2013.

55 Ambrose, Stephen E. Nothing Like It in the World: The Men Who Built the Transcontinental Railroad, 1863-1869. New York: Simon \& Schuster, 2000, S. 7.

56 Hidy, Ralph Willard. The Great Northern Railway: A History. Boston, MA: Harvard Business School Press, 1988. Luecke, John. The Great Northern in Minnesota: The Foundations of an Em- 
(1797-1879) oder James Fisk (1835-1872), Goulds Partnern bei der Erie Railroad, so kann man von Letzteren eher als Abrissunternehmern sprechen. ${ }^{57}$ Sie ruinierten die Erie Railroad, um sich persönlich zu bereichern. Im Westen hatte Jay Gould Gegenspieler in der Gestalt der „Big Four“ - Amasa Leland Stanford (18241893), Präsident der Central Pacific Railroad (CPR), Collis Potter Huntington (1821-1900), sein Stellvertreter, Charles Crocker (1822-1888), der Chefingenieur der Gesellschaft, und Mark Hopkins (1813-1878), der Schatzmeister des Unternehmens. Sie wurden so mächtig, dass Kritiker behaupteten, die Central Pacific halte Kalifornien in ihren Tentakeln wie ein Oktopus seine wehrlose Beute. ${ }^{58}$

Die Öffentlichkeit zeigte sich alarmiert, wobei ihre Haltung gegenüber den Großunternehmen durchaus differenziert ausfiel. Als Jay Gould 1892 starb, beschrieb ihn die Presse als den reichsten Mann der Welt und schätzte sein Vermögen auf über 100 Millionen Dollar. Sein Konkurrent, „Commodore“ Cornelius Vanderbilt, der die New York Central Railroad hatte bauen lassen, bescheinigte Gould „the smartest man in America“ zu sein. ${ }^{59}$ Für die amerikanische Öffentlichkeit jedoch, die in Gould all das wiederfand, was sie am ungehinderten Gewinnstreben störte, war er mit Sicherheit „the most hated man in America. “60 Die Gründe sind vielfältig. Viele Zeitgenossen erinnerten sich noch an den 24. September 1869, den „Schwarzen Freitag“, an dem Gould mit Jim Fisk versucht hatte, den Goldmarkt zu monopolisieren. ${ }^{61}$ Antisemitismus spielte mit Sicherheit eine wichtige Rolle, da viele Zeitgenossen fälschlich annahmen, Gould sei Jude. ${ }^{62}$

pire. St. Paul, MN: Grenadier Publications, 1997. Young, Biloine W., McCormack, Eileen R. und Atkins, Annette. The Dutiful Son: Louis W. Hill Life in the Shadow of the Empire Builder, James J. Hill. St. Paul, MN: Ramsey County Historical Society, 2010.

57 Fisk wird in der Forschung eine wichtige Rolle in der Partnerschaft mit Jay Gould zugeschrieben. Rugoff, Milton. America's Gilded Age: Intimate Portraits from an Era of Extravagance and Change, 1850 -1890. New York: Holt, 1989, S. 52f. Fuller, Robert H. Jubilee Jim: From Circus Traveler to Wall Street Rogue. The Remarkable Life of Colonel James Fisk, Jr. New York: Texere, 2001. McAlpine, R. W. The Life and Times of Col. James Fisk, Jr. New York: Arno Press, 1981. Stafford, Marshall P. The Life of James Fisk, Jr.: A Full and Accurate Narrative of All the Enterprises in Which He Was Engaged. New York: Arno Press, 1981.

58 Robinson, John R. The Octopus: A History of the Construction, Conspiracies, Extortions, Robberies, and Villainous Acts of the Central Pacific, Southern Pacific of Kentucky, Union Pacific, and Other Subsidized Railroads. San Francisco, CA: Eigenverlag, 1894. Norris, Frank. The Octopus: A Story of California. Mineola, NY: Dover Publications, 2003

59 Renehan, Edward. Commodore: The Life of Cornelius Vanderbilt. New York: Basic Books, 2007, S. 372.

60 Klein, The Life and Legend of Jay Gould, S. 3.

61 Birmingham, Stephen. Our Crowd: The Great Jewish Families of New York. Syracuse University Press ed ed. Syracuse, NY: Syracuse University Press, 1996, S. 109.

62 Henry Adams sprach von Gould als „complex Jew“. Birmingham, Stephen. Our Crowd, S. 108. 
Damit eng in Verbindung stand die Abneigung gegen alle, die ihr Geld mit Spekulationen oder im Bankenwesen machten, anstatt eine Ware zu produzieren, die auf den Markt geworfen werden konnte. 1890 durchquerten mehr als 150.000 Meilen Eisenbahnschienen die Nation und Jay Gould konnte mit Recht für sich in Anspruch nehmen, daran maßgeblich beteiligt gewesen zu sein. ${ }^{63}$

\subsection{Körperschaftsrecht und der amerikanische Kapitalismus (Lock-in 6)}

Der Eisenbahnbau stand direkt mit einer weiteren Schlüsselindustrie in Verbindung - der Stahlindustrie. Frühe Eisenbahnen liefen auf Gusseisenschienen, die bald rissig wurden und brachen, vor allem, nachdem Lokomotiven schneller als 30 Stundenkilometer fuhren. Der härtere und flexiblere Stahl war in der Herstellung jedoch zu teuer, bis ein Engländer namens Henry Bessemer (1813-1898) 1855 ein Verfahren entwickelte, mit dem man aus Gusseisen Stahl machen konnte, das Flussstahl- oder Bessemerverfahren. ${ }^{64}$ Es basierte darauf, dass reiner Sauerstoff durch flüssiges Roheisen in einem schwenkbaren Konverter (Bessemerbirne) geleitet wurde. ${ }^{65}$ Nach dem Bürgerkrieg wurden reiche Eisenerzvorkommen in der Nähe der Großen Seen entdeckt und nun trat der Bessemerstahl seinen Siegeszug an. Andrew Carnegie war unter den Ersten, die die Möglichkeiten des Stahls richtig einschätzten, und er sollte bald zum ungekrönten König des Stahlgeschäfts aufsteigen. ${ }^{66}$ Carnegie verdankte seinen Erfolg seinem Mut und seinem Glück. Noch als Teenager fiel er Thomas Alexander Scott (1823-1883) auf, dem Chef der

63 Husband, Julie und O'Loughlin, Jim. Daily Life in the Industrial United States, 1870-1900. Westport, CT: Greenwood Press, 2004, S. 62.

64 Tracy, Kathleen. Henry Bessemer: Making Steel from Iron. Hockessin, DE: Mitchell Lane Publishers, 2006.

65 Heggen, Alfred. Erfindungsschutz und Industrialisierung in Preussen 1793-1877. Göttingen: Vandenhoeck und Ruprecht, 1975, S. 82. Die Fima Krupp versuchte erfolglos, das Patent zu kopieren.

66 Carnegies schneller Aufstieg zu Reichtum und Ruhm erinnerte an die Helden der populären Romane von Horatio Alger (1832-1899), der den Mythos propagierte, in den USA könne jeder Junge Millionär werden - an weibliche Helden dachte der Autor dabei eher selten. Nackenoff, Carol. The Fictional Republic: Horatio Alger and American Political Discourse. New York: Oxford University Press, 1994. Cook, Charles Orson (Hg.). Horatio Alger: Gender and Success in the Gilded Age. „Ragged Dick“ and „Tattered Tom.“ Hoboken, NJ: Wiley-Blackwell, 2006. Maßgebliche Romane Algers' waren Ragged Dick (Boston, MA: Loring, 1868), Risen from the Ranks; or, Harry Walton's Success (Philadelphia, PA: J.C. Winston Co, 1874) und The Backwoods Boy: Or, The Boyhood and Manhood of Abraham Lincoln (New York: Street and Smith, 1883). 
Pennsylvania Railroad, weil er ein sehr guter Telegraphist war. ${ }^{67}$ Scott stellte den jungen Carnegie ein, beförderte ihn und lieh ihm Geld für seine ersten Geschäfte auf eigene Faust. Carnegie arbeitete zwölf Jahre für die Eisenbahn und das verlieh ihm unschätzbare Einblicke ins Management von großen Betrieben. Diese langjährige Erfahrung konnte er in der Folge in die Restrukturierung der Stahlunternehmen einbringen.

1872 stürzte er sich ins Stahlgeschäft, nachdem er sich mit Aktienspekulationen das nötige Startkapital besorgt hatte. „My preference was always for manufacturing. I wished to make something tangible and sell it [...]“, schrieb er in seiner Autobiographie. ${ }^{68}$ Durch Anwendung seiner Kenntnisse und Fertigkeiten auf dem Gebiet der Buchhaltung und des Managements, die er bei der Pennsylvania Railroad erworben hatte, konnte Carnegie das Stahlgeschäft zu einem Großunternehmen zusammenschließen. In Braddock am Monongahela River heute eine Vorstadt von Pittsburgh, Pennsylvania, - baute er 1872 die modernste Bessemerstahlfabrik seiner Zeit und begann, Stahl im großen Maßstab zu verkaufen. Ein durchschnittlicher Stahlproduzent konnte damals etwa 70 Tonnen Stahl in der Woche erzeugen. Innerhalb von zwei Jahrzehnten schaffte es Carnegie, unglaubliche 10.000 Tonnen pro Woche $\mathrm{zu}$ produzieren. Er konnte dank seiner überlegenen Buchhaltung die Produktionskosten von Stahlschienen von 58 Dollar auf 25 Dollar mehr als halbieren. Carnegies Erfolgskonzept war einfach: „Cut the prices; scoop the market; run the mills full [...] Watch the costs, and profits will take care of themselves."69 Die Profite stiegen ebenso dramatisch, wie die Kosten fielen. 1900 verdiente Carnegie Steel 23 Millionen Dollar in einem einzigen Jahr. ${ }^{70}$

Um die Kosten zu senken und den Ausstoß weiter zu erhöhen, bediente sich Carnegie des Systems der vertikalen Integration. Alle Aspekte des Stahlgeschäfts befanden sich in einer, in Carnegies Hand. Vertikale Integration bedeutete in den Worten eines Zeugen vor einem Untersuchungsausschuss des House of Representatives im Jahre 1912, dass ,from the moment these crude stuffs were dug out of the earth until they flowed in a stream of liquid steel in the ladles, there was never

67 Hessen, Robert. Steel Titan: The Life of Charles M. Schwab. Pittsburgh, PA: University of Pittsburgh Press, 1990, S. 21.

68 Carnegie, Andrew. The Autobiography of Andrew Carnegie. New York: Public Affairs, 2011, S. 176.

69 Buder, Stanley. Capitalizing on Change: A Social History of American Business. Chapel Hill, NC: University of North Carolina Press, 2009, S. 138.

70 Morris, The Tycoons, S. 321. 
a price, profit, or royalty paid to any outsider.“71 Zwischen 1875 und 1900 versuchte Carnegie jeden Handschlag im Zusammenhang mit dem Herstellen von Stahl zu kontrollieren, vom Abbau des Roherzes über die Schmelze von Gusseisen und den Transport desselben über die Großen Seen bis zur Herstellung von Rohstahl und Eisenbahnschienen. ${ }^{72}$

$\mathrm{Zu}$ jeder Zeit hatte Carnegie die Produktionskosten und die Effektivität der Arbeit im Auge. Die hohe Effizienz seiner Betriebe beruhte auf der Konkurrenz seiner Angestellten untereinander, Carnegie war dabei nicht zimperlich. Die Gewinner dieses innerbetrieblichen Wettbewerbs wurden mit Anteilen an der Firma belohnt, die Verlierer wurden entlassen. Für die Arbeiter bedeutete dies lange Arbeitszeiten von zwölf Stunden am Tag, geringe Löhne und gefährliche Arbeitsbedingungen. Bei Schichtwechsel am Ende der Woche wurden auch schon mal 24 Stunden am Stück („kurzer Wechsel“) gearbeitet. Carnegie hielt die absolute Aktienmehrheit und er zahlte den Anteilseignern so gut wie nie Dividenden. Die gemachten Profite wurden sofort wieder reinvestiert, um neue Fabriken zu eröffnen und neue Maschinen zu kaufen. Sogar seine Geschäftspartner empfanden Carnegie als hart. ${ }^{73}$

Andrew Carnegie beherrschte die amerikanische Stahlindustrie während drei langer Jahrzehnte und machte aus Carnegie Steel den größten Stahlkonzern der Welt. Der erste Wolkenkratzer wurde mit Carnegie-Stahl erbaut, Carnegie-Stahl stützt das Washington Monument, aus ihm wurden die Pfeiler der Hochbahnen New Yorks und die Stützelemente der Brooklyn Bridge gebaut. Am Ende des 19. Jahrhunderts war Andrew Carnegie der bekannteste Industrielle der Welt geworden und Stahl hatte Eisen ein für alle Mal verdrängt.

Edwin Laurentine Drake (1819-1880) entdeckte 1859 Erdöl in Pennsylvania und löste damit einen „Ölrausch“ aus, der Tausende bewog, ihren bisherigen Beruf aufzugeben und auf den Ölfeldern nach dem „Schwarzen Gold“ zu suchen. ${ }^{74}$ In den Tagen vor dem Automobil und dem Benzin wurde Rohöl in Schmiermittel für Maschinen und als Kerosin für Lampen raffiniert. Elektrisches Licht war noch unbekannt und der traditionelle Waltran war zu teuer und $\mathrm{zu}$

71 United States, Congress und_House of Representatives. Investigation of United States Steel Corporation: Report No. 1127. Washington, DC: Government Printing Office, 1912 Aug 2, S. 42.

72 Misa, Thomas J. A Nation of Steel: The Making of Modern America, 1865-1925. Baltimore, MD: Johns Hopkins University Press, 1995, S. 155 f.

73 Campbell, Ballard C. Disasters, Accidents, and Crises in American History: A Reference Guide to the Nation's Most Catastrophic Events. New York: Facts on File, 2008, S. 165. Kahan, Paul. The Homestead Strike: Labor, Violence, and American Industry. New York: Routledge, 2014, S. $42-56$. 74 Brice, William R. Myth, Legend, Reality: Edwin Laurentine Drake and the Early Oil Industry. Oil City, PA: Oil Region Alliance of Business, Industry \& Tourism, 2009. 
geruchsintensiv, um weiter als Brennstoff für Lampen zu dienen. ${ }^{75}$ Der Preisunterschied für Rohöl, das bei der Produktion etwa 50 Cents pro Barrel (159 Liter) kostete, im Osten als Kerosin aber für 50 Cents pro Gallone (3,8 Liter) verkauft werden konnte, brachte viele Investoren auf die Idee, Öl in großem Stil zu raffinieren. Eine „Raffinerie“ konnte in den 1860er und 1870er Jahren für wenig Geld erworben werden. Mehr als 25.000 Dollar waren nicht nötig - das war in etwa der Preis einer Meile Eisenbahnschienen. Die Investitionen waren also niedrig und die Rendite war hoch. Rasch entstand eine boomende Erdölindustrie. Allerdings war die Konkurrenz beträchtlich - gerade zwischen den vielen kleinen Raffinerien. Es oblag einem Mann, den chaotischen Wettbewerb an die Kandare zu legen: John D. Rockefeller. Er bediente sich dazu des Trusts, einer neuen Organisationsform, und konnte so nach und nach die Konkurrenz ausschalten. Auf diese Weise gelang es ihm, 90 Prozent des Ölgeschäfts mithilfe seiner Standard Oil Company zu kontrollieren. ${ }^{76}$

John D. Rockefeller wuchs als der Sohn des durchtriebenen Wunderheilers William Avery Rockefeller (1810 - 1906) auf, der angeblich ein Mittel gegen Krebserkrankungen gefunden hatte und damit über Land zog. Unter der unnachgiebigen Anleitung seines Vaters lernte John D. hart $\mathrm{zu}$ verhandeln. ${ }^{77}$ Der Sohn begann als Buchhalter in Cleveland $\mathrm{zu}$ arbeiten und konnte sich mit 21 Jahren als Geschäftsmann selbständig machen. Er hatte Erfolg, weil er immer Kapital in Form von Krediten auftreiben konnte. Rockefeller war ein zurückhaltender junger Mann, für den das Geschäft die einzige Leidenschaft darstellte. Um nicht vom Bürgerkrieg bei seinem Erwerbsstreben behindert zu werden, warb er einen Ersatzmann an, der statt seiner in den Krieg zog und unterschied sich darin nicht von Gould, Carnegie oder J.P. Morgan. Im Jahr 1865 war er bereits ein wohlhabender Mann und kaufte die Geschäftsanteile seines Partners mit geliehenem Geld. Nun kontrollierte er die größte Ölraffinerie von Cleveland, Ohio. Wie andere Geschäftsmänner seiner Zeit wollte er das persönliche Risiko minimieren

75 Tunis, Edwin. Colonial Craftsmen and the Beginnings of American Industry. Baltimore, MD: Johns Hopkins University Press, 1999, S. 67 f.

76 Laughlin, Rosemary. John D. Rockefeller: Oil Baron and Philanthropist. Greensboro, NC: Morgan Reynolds Pub., 2004. Mayhew, Anne. Narrating the Rise of Big Business in the USA: How Economists Explain Standard Oil and Wal-Mart. London, New York: Routledge, 2008. Tarbell, Ida M. und Chalmers, David Mark. The History of the Standard Oil Company. Mineola, NY: Dover Publications, 2003.

77 Chernow, Ron. Titan: The Life of John D. Rockefeller, Sr. New York: Random House, 1998, S. $63 \mathrm{f}$. 
und den Profit maximieren und gab deshalb die Kontrolle seines Geschäfts auf, um eine Aktiengesellschaft zu gründen, die das Geschäftsrisiko auf viele Schultern übertrug. 1870 ging er mit seiner Raffinerie an die Börse und gründete die Standard Oil Company, den Vorläufer der heutigen Exxon. ${ }^{78}$

Als Inhaber der größten Ölraffinerie in Cleveland verlangte Rockefeller „Rabatte“ von den Eisenbahngesellschaften, die seine Produkte transportierten. Diese Rabatte setzte er strategisch ein, um seine Konkurrenten auf dem Markt zu unterbieten. ${ }^{79}$ Die Eisenbahnen waren so erpicht darauf, mit Rockefeller ins Geschäft zu kommen, dass sie ihm nicht nur Rabatte auf die Transportkosten einräumten, sondern ihm sogar Zahlungen zukommen ließen, die aus den Geschäften mit seinen Konkurrenten stammten. Nicht nur konnte Rockefeller sein Öl mit einem Preisnachlass von einem Dollar pro Barrel verschiffen, sondern er erhielt noch einmal einen Dollar für jedes Barrel, das seine Konkurrenten zum Endverbraucher transportierten. Dieser Preisnachlass sorgte bald dafür, dass Rockefeller seine Konkurrenten aufkaufen konnte. 1871 gab es in Cleveland außer Rockefellers Betrieb keine weitere Raffinerie mehr. Nun ging er daran, den nationalen und internationalen Markt zu erobern.

Cleveland, Pittsburgh, Philadelphia und New York City waren die Zentren des Geschäfts mit Rohöl aus Pennsylvania. Standard Oil bediente sich ähnlich fragwürdiger Geschäftspraktiken im Kampf um den amerikanischen Markt wie andere Unternehmen. Effektive Produktion und ein System von „Rabatten“ der Eisenbahngesellschaften ließen die Gesellschaft rasch zum nationalen Player aufsteigen. Konkurrenten gaben auf: Sie waren dem Preiskrieg nicht gewachsen. Als Gegenleistung erhielten sie Aktien der Standard Oil und führten ihre Firmen pro forma unter ihrem alten Namen weiter. So konnte es schon einmal geschehen, dass kleine Raffinerien, die nicht an Rockefeller verkaufen wollten, doch unter dem Dach der Standard Oil landeten, weil sie an einen vermeintlich von Rockefeller unabhängigen Produzenten verkauft hatten, der aber insgeheim längst zum Konzern gehörte. ${ }^{80}$ Dies blieb im Großen und Ganzen geheim, bis das Parlament des Staates New York 1879 einen Untersuchungsausschuss einsetzte, der die Geschäftspraktiken der Eisenbahngesellschaften kritisch beleuchtete. ${ }^{81}$

78 Wall, Bennett H., Carpenter, C. Gerald und Yeager, Gene S. Growth in a Changing Environment: A History of Standard Oil Company (New Jersey), Exxon Corporation, 1950-1975. New York: McGraw-Hill, 1988.

79 Chernow, Ron. Titan: The Life of John D. Rockefeller, S. 114-117.

80 Chernow, Ron. Titan, S. 152-170.

81 Olien, Roger M. und Hinton, Diana Davids. Oil and Ideology: The Cultural Creation of the American Petroleum Industry. Chapel Hill, NC: University of North Carolina Press, 2000, S. $58 \mathrm{f}$. New York, Legislature, Assembly und Special Committee on Railroads. Proceedings of the Special 
John D. Rockefeller hatte mit seinen Geschäftspartnern bis 1881 ein Firmenimperium aufgebaut, das 40 einzelne Unternehmen umfasste. Diese Firmen, die in begrenztem Rahmen schon zusammenarbeiteten, wurden in einem Trust zusammengeschlossen. Die Anteilseigner der verschiedenen Bereiche des Ölgeschäfts übereigneten neun Treuhändern ihre Anteile, die ihnen dafür Anteilsscheine an dem neuen Trust ausstellen sollten. Die Trustees sollten daraufhin als Direktoren aller im Trust zusammengeschlossenen Firmen das gesamte Geschäft vom Ölbohren bis zum Absatz der fertigen Produkte kontrollieren. Die Anteilseigner sollten eine Dividende auf die Gewinne erhalten. Dieses Projekt wurde tatsächlich realisiert und Rockefeller ließ sich in seinem Hauptquartier auf dem Broadway in New York nieder. 1887 war die Standard Oil eine der größten Firmen der Welt und kontrollierte das Ölgeschäft fast vollständig. Standard Oil produzierte nur so viel, dass die Preise stabil und hoch blieben. 1888 untersuchte ein New Yorker Senator die Geschäftspraktiken der Standard Oil, um herauszufinden, wie es zu dieser marktbeherrschenden Stellung kommen konnte. Nachdem es sich verdeutlichte, dass ein Gericht die Aufhebung des Trusts anordnen würde, löste sich der Trust auf und organisierte sich als Standard Oil Company neu. Siebzig Firmen und 23 Raffinerien kontrollierten 84 Prozent des in Nordamerika geförderten Rohöls. Zwar reduzierte sich dieser Anteil durch internationale Konkurrenz und weil sich einige kleinere Unabhängige auf dem Markt behaupten konnten, aber es bedurfte des Eingreifens der Bundesregierung unter Theodore Roosevelt, der 1906 einen Gerichtsprozess gegen die Standard Oil anstrengen ließ, der durch sämtliche Instanzen ging. 1911 entschied der Oberste Gerichtshof, Standard Oil hätte gegen das Sherman-Antitrustgesetz verstoßen und verfügte die Auflösung des Konzerns. Aus diesem Großkonzern entstanden in der Folge Exxon, Mobil, Chevron, American und die deutsche Esso. ${ }^{82}$

Der Trust stellte eine Form horizontaler Integration dar, die sich in bemerkenswerter Weise von Carnegies vertikaler Integration unterschied. Zunächst versuchte Rockefeller nicht, jeden Aspekt des Ölgeschäfts von der Rohölquelle bis zum Verkauf des Kerosins zu überwachen. Er brachte lediglich alle Raffinerien

Committee on Railroads: Appointed under a Resolution of the Assembly to Investigate Alleged Abuses in the Management of Railroads Chartered by the State of New York (1879). New York: Evening Post Steam Presses, 1879, S. 821-827.

82 Tarbell, Ida M. The History of the Standard Oil Company. New York: McClure, Phillips \& Co., 1904, 2 Bände. Tarbell war Muckraker. Zu den Muckrakers siehe Hillstrom, Laurie Collier. The Muckrakers and the Progressive Era. Detroit, MI: Omnigraphics, 2010. Zur Standard Oil: Laughlin, Rosemary. John D. Rockefeller: Oil Baron and Philanthropist. Greensboro, N.C: Morgan Reynolds Pub, 2004. Mayhew, Anne. Narrating the Rise of Big Business in the USA How Economists Explain Standard Oil and Wal-Mart. London, New York: Routledge, 2008. 
unter seine Kuratel. Nachdem er eine beinahe monopolistische Position errungen hatte, konnte er die Profite maximieren, indem er die Produktion beschränkte und so die Preise hochtrieb. ${ }^{83}$ Da Standard Oil den Markt oligopolistisch im Griff hatte, bot sich die Fima als Ziel all derjenigen an, die argumentierten, Trusts stellten eine Verschwörung gegen die Interessen der amerikanischen Bevölkerung dar.

1890 wurde der Sherman Anti-Trust Act verabschiedet. Er legte in $\S 1$ fest: „Every contract, combination in the form of trust or otherwise, or conspiracy, in restraint of trade or commerce among the several States, or with foreign nations, is declared to be illegal.“ In $\S 2$ hieß es: „Every person who shall monopolize, or attempt to monopolize, or combine or conspire with any other person or persons, to monopolize any part of the trade or commerce among the several States, or with foreign nations, shall be deemed guilty of a felony [...]“84

Dieses Gesetz war sehr populär, weil Trusts und Oligopole in populistischer Manier unter Generalverdacht gestellt wurden und das Gesetz versprach, gegen illegale Kombinationen von großen Firmen vorzugehen. Das Problem war, dass dieses Gesetz sehr hastig erlassen worden war und nicht sehr präzise definierte, was als illegal und was als legal angesehen werden sollte. So wurden beispielsweise ungemein wichtige Konzepte wie „Behinderung des Handels“ (,restraint of trade“) oder die Begriffe „combination“ oder „monopolize“ nicht hinreichend genau definiert. Diese Begriffe sind für Laien möglicherweise eindeutig, doch die Gerichtshöfe, die die Einhaltung des Gesetzes garantieren sollten, sahen dies anders. Infolgedessen gab es sehr unterschiedliche Interpretationen des Sherman Anti-Trust Law. Wie widersinnig diese Interpretationen ausfallen konnten, zeigt die Anwendung des Gesetzes gegen Aktionen von Gewerkschaften, die als Verschwörung zum Zwecke der Behinderung des Handels angesehen wurden. Einer der wichtigen Fälle war die Entscheidung Loewe v. Lawler von 1908, auch bekannt als Danburry Hatters' Case. ${ }^{85}$

83 Chandler, Alfred D. und Hikino, Takashi. Scale and Scope: The Dynamics of Industrial Capitalism. Cambridge, MA: Belknap Press, 1994, S. $24 \mathrm{f}$.

841890 USC 647 chapter 26 Stat 209. Miller, Roger LeRoy und Cross, Frank B. The Legal Environment Today: Business in Its Ethical, Regulatory, E-Commerce, and International Setting. Mason, OH: Thomson/West, 2007, Appendix F, S. 750.

85 Loewe v. Lawlor, 208 U.S. 274 (1908). Der Supreme Court der USA entschied in diesem Fall, dass das Sherman-Antitrust-Gesetz gegen Gewerkschaften angewendet werden könne, wenn diese in den zwischenstaatlichen Handel eingriffen, und verfügte, die Gewerkschaftsführer könnten persönlich für Schäden, die ihre Gewerkschaften während eines Streiks verursachten, haftbar gemacht werden. Merritt, Walter Gordon. The Law of the Danbury Hatters' Case. Annals of the American Academy of Political and Social Science. 1910 Sep 1; 36 (2):11-22. 
Immerhin waren Trusts nach der Verabschiedung des Sherman Antitrust Act illegal. ${ }^{86}$ Standard Oil änderte daraufhin seine Taktik und stellte sich als Holding Company neu auf. ${ }^{87}$ Holding Companies operierten ganz ähnlich wie Trusts, waren aber legal. Anstelle miteinander konkurrierender Gesellschaften, die ihre Geschäftsgebiet untereinander aufteilten und Preisabsprachen trafen, fasste die Holding Company miteinander konkurrierende Gesellschaften einfach unter einem Dach mit einer zentralen Verwaltung zusammen. Die Holding Company war damit auch viel leichter zu verwalten als der umständliche Trust mit seinen Treuhändern. Der Staat New Jersey erleicherte die Gründung von Holding Companies enorm, da es 1889 ein Gesetz verabschiedete, das es im Staat zugelassenen Holding Companies erlaubte, Aktien von Gesellschaften zu besitzen, die nicht im Staate New Jersey ansässig waren. ${ }^{88}$ Andere Unternehmen wie Diamond Matches und die American Sugar Refining Company folgten dem Beispiel der Standard Oil, gründeten zunächst Trusts und formten diese später zu Holding Companies um. In den 1890er Jahren war New Jersey der Heimatstaat einer Reihe von Holding Companies geworden, wovon die größte die Standard Oil war. Mit der wachsenden Komplexität des Unternehmens wurde die Kontrolle durch die Zentrale wichtiger.

Rockefeller zog 1884 permanent nach New York um. ${ }^{89}$ Aus seinem Büro auf dem Broadway begann er die Standard Oil nun auch vertikal zu integrieren. Die formale Unabhängigkeit der kleineren Raffinerien wurde beendet und ineffiziente Fabriken wurden geschlossen. Neben der Raffinerie betätigte sich Rockefeller nun auch bei der Ölsuche, dem Transport des Öls und seiner Vermarktung. In den 1890ern kontrollierte er eine riesige vertikal und horizontal integrierte Organisation, die jeden Aspekt des Ölgeschäfts dominierte. John D. Rockefeller wurde sagenhaft reich dabei. Als er 1937 im Alter von 98 Jahren starb, war er der erste Dollarmilliardär. Während seines gesamten Lebens als erwachsener Mann war er immer einer der reichsten Männer Amerikas gewesen. Trotz seiner persönlichen Bescheidenheit, seines baptistischen Glaubens und seiner vielen Spenden für wohltätige Zwecke erreichte er nie die Popularität Andrew Carnegies.

Dies war zum großen Teil das Verdienst der Journalistin Ida M. Tarbell, deren Fortsetzungsreportage „History of the Standard Oil Company“ von 1902 to 1905 die Leserinnen und Leser von McClure's Magazine unterhielt, entsetzte oder be-

86 McNeese, Tim. The Robber Barons and the Sherman Anti-Trust Act: Reshaping American Business. New York: Chelsea House Publishers, 2009.

87 McNeese, The Robber Barons, S. 101.

88 Markham, A Financial History of the United States, Band 1, S. 356.

89 Ernst, Joseph W. (Hg.). Dear Father/Dear Son: Correspondence of John D. Rockefeller and John D. Rockefeller, Jr. New York: Fordham University Press, 1994, S. 2. 
troffen machte. ${ }^{90}$ McClure war eine Qualitätszeitschrift, die das gebildete Bürgertum zu ihrem Zielpublikum rechnete. ${ }^{91}$ Ida Tarbell war in der Ölregion Pennsylvanias aufgewachsen und ihr Vater war der Besitzer einer kleinen Raffinerie gewesen, die von Standard Oil aufgekauft worden war. Sie hatte also durchaus persönliche Motive für ihren Feldzug gegen Rockefeller. Doch waren ihre Methoden und die Präzision ihrer Recherche über jeden Zweifel erhaben, so dass ihre Artikelserie sehr viel Staub aufwirbelte. Als ihre Serie in McClures ausgelaufen war, befürchtete Rockefeller ein Attentat auf ihn und verhielt sich sehr nervös. ${ }^{92}$ Die Standard Oil und der Mann, der sie geschaffen hatte, waren zum Symbol für verbrecherischen Monopolismus geworden. Rockefeller konterte, indem er einen Presseverantwortlichen einstellte, der helfen sollte, sein Image aufzupolieren. ${ }^{93}$

Rockefeller diente als Blitzableiter für die Spannungen, die im Prozess der industriellen Konsolidierung entstanden waren. Man sah in ihm einen Bösewicht, weil man sich zu Recht vor der Macht der Standard Oil fürchtete. Die unsichtbare Hand des Marktes war unwirksam. Die Gesellschaft unterhielt ein betriebseigenes Spionagesystem zu Unterdrückung möglicher Konkurrenten. Sie trug daher zu Recht den Titel „Lithe [geschmeidiger] Sovereign State of Standard Oil“.

Trotz der Ablehnung von Trusts und Großunternehmen, die im Ruf standen, die Gesetze zu missachten, begeisterten sich Amerikaner und Amerikanerinnen für Erfindungen und die Menschen, die sie erdachten. An der Schwelle des 20. Jahrhunderts erreichten die Erfinder Thomas Alva Edison und Alexander Graham Bell Kultstatus. Die Verehrung, die man Männern wie ihnen entgegenbrachte, verschleiert die Tatsache, dass Erfindungen vermarktet werden mussten und die entstehenden neuen Elektrokonzerne bald nicht mehr von den Erfindern, sondern von den Geldgebern kontrolliert wurden. Alexander Graham Bell (18471922), ein Schotte, der versucht hatte, Taubstummen das Sprechen beizubringen, entwickelte eine Methode, Tonaufzeichnungen per Draht $\mathrm{zu}$ übermitteln. Das Telefon war geboren. Bell stellte 1876 seine neue Erfindung auf der Philadelphia Centennial Exposition vor und die Western Union, eine der größten Telegraphiegesellschaften der Zeit, zeigte Interesse. Western Union wurde zeitgleich in eine Auseinandersetzung mit Jay Gould verwickelt, die die vollständige Auf-

90 Tarbell, The History of the Standard Oil Company. Gilbert Holland Montague. The Legend of the Standard Oil Company. The North American Review. 1905 Sep 1; 181 (586):352-368.

91 Für die Qualitätsmagazine maßgeblich ist Saldern, Adelheid von. Amerikanismus: Kulturelle Abgrenzung von Europa und US-Nationalismus im frühen 20. Jahrhundert. Stuttgart: Franz Steiner Verlag, 2013, S. 28-66.

92 Chernow, Titan, S. 452.

93 Weinberg, Steve. Taking on the Trust: The Epic Battle of Ida Tarbell and John D. Rockefeller. New York: W.W. Norton, 2008, S. 239. 
merksamkeit der Direktion erforderte, weshalb die Gesellschaft es versäumte, Bells Patent zu kaufen. Das Resultat war American Bell, die weltgrößte Telefongesellschaft ihrer Zeit unter der Führung des Managers Theodore Newton Vail (1845-1920). ${ }^{94}$ Vail entwickelte das erste Langstreckentelefonnetz der Welt und gründete 1885 die American Telephone \& Telegraph Company (AT\&T) mit Sitz in Bedminster, New Jersey. ${ }^{95}$ Er ließ auch das erste transkontinentale Telefonnetz bauen, das Gespräche zwischen New York und San Francisco ermöglichte und zur Eröffnung der Panama-Pacific Exposition in San Francisco 1915 in Betrieb genommen wurde. ${ }^{96}$

Thomas Alva Edison hingegen verkörperte die altmodischen Werte eines Yankee-Tüftlers und des robusten Individualismus, die die Zeitgenossen sehr bewunderten. Wie einer seiner Dynamos arbeitete er unermüdlich - manchmal bis zu 20 Stunden am Tag. Der Autodidakt unterhielt in Menlo Park im Staate New Jersey sein Laboratorium. ${ }^{97} \mathrm{Zu}$ seinen zahlreichen Erfindungen und Patenten gehörten der Plattenspieler, die Filmkamera und die Glühbirne.

Die Einführung der Elektrizität stellte Ingenieure und Unternehmen vor große Probleme. Mit der Entdeckung eines haltbaren und effektiven Glühfadens für die Glühbirne im Jahre 1879 leitete Edison das Zeitalter der elektrischen Beleuchtung in Privathaushalten ein. Die Frage war nur, wie man diese wunderbare Erfindung vermarkten wollte. Vor der Vermarktung mussten schier unüberwindlich scheinende Probleme gelöst werden. Ein System von Leitungen, Elektrizitätswerken, Generatoren und Sicherungen musste entwickelt und aufgebaut werden. Weil Elektrizität technologisch komplex war und außerdem Gefahr für Leib und Leben in sich barg, musste die Vermarktung alle Aspekte des Einsatzes von elektrischem Strom berücksichtigen. Gefragt waren hier nicht nur Werbefachleute, sondern auch die Ingenieure. Am Anfang der Elektrifizierung der Privathaushalte standen Stromgeneratoren, die im Haus des Endverbrauchers aufgestellt wurden. J. P.

94 Louis Galambos. Theodore N. Vail and the Role of Innovation in the Modern Bell System. The Business History Review, Band 66, No. 1, High-Technology Industries (Spring, 1992), S. 95-126. 95 Hughes, Thomas Parke. American Genesis: A Century of Invention and Technological Enthusiasm, 1870 - 1970. New York: Viking, 1989, S. 150 - 159.

96 Dies wurde ermöglicht, weil in der Zwischenzeit Umsetzer (Repeater) erfunden worden waren, die das Telefonsignal bei großen Entfernungen verstärkten. Murphy, John. The Telephone: Wiring America. New York: Chelsea House Publishers, 2009, S. 87. Froehlich, Fritz E. und Kent, Allen. The Froehlich/Kent Encyclopedia of Telecommunications. New York: M. Dekker, 1991-1999, 18 Bände, Band 2, S. 244.

97 Stross, Randall E. The Wizard of Menlo Park: How Thomas Alva Edison Invented the Modern World. New York: Crown Publishers, 2007. 
Morgan verfügte schon 1882 über elektrisches Licht in seinem New Yorker Anwesen in der Madison Avenue 219. ${ }^{98}$

Jeden Morgen kam ein Ingenieur vorbei, um den Generator anzuwerfen. Als eine Glühbirne in Morgans Bibliothek durchbrannte und sein Schreibtisch Feuer fing, musste ein Ingenieur gerufen werden, der das Problem behob. Derartige Probleme hielten Morgan nicht davon ab, sehr viel Geld in die Edison General Electric Company zu stecken.

Edison arbeitet unermüdlich am Ausbau seines Netzes, indem er Generatorenhäuser errichten ließ, die elektrische Energie in die Haushalte bringen konnten. Er hatte dabei ein unlösbares Problem: Sein System basierte auf Gleichstrom und so war die Reichweite seines Netzes auf ein Gebiet von zwei Meilen im Umkreis des Generators begrenzt. In George Westinghouse (1846-1914), dem Erfinder und Produzenten der Luftdruckbremse für Züge, entstand Edison ein mächtiger Konkurrent. Sein System hatte den Vorteil, Wechselstrom zu verwenden, und daher konnten größere Entfernungen ohne große Spannungsverluste überwunden werden. Westinghouse forderte die Edison General Electric ohne zu zögern heraus. Beide Unternehmen platzierten sich als komplexe, vertikal integrierte Gesellschaften auf dem Markt, um so die Vermarktung ihrer Produkte vom elektrischen Strom über Leitungssysteme, Generatoren, Glühbirnen bis zu Elektromotoren zu ermöglichen. In den Filialen der Firmen arbeiteten qualifizierte Ingenieure und nicht etwa nur Verkäufer. Sie berieten ihre Kunden und Kundinnen über die Installation und den sicheren Betrieb elektrischer Apparate und boten Reparaturdienste an. ${ }^{99}$ Beide Firmen unterhielten große Forschungslaboratorien, um neue Anwendungsgebiete für Elektrizität zu entwickeln. Der Konkurrenzkampf beider Unternehmen wurde mit harten Bandagen ausgetragen. Edison benutzte die weit verbreitete Überzeugung, Wechselstrom sei gefährlicher als Gleichstrom, um seinem Konkurrenten einzuheizen. Er ging sogar soweit, öffentlich einen Elefanten mit Wechselstrom zu exekutieren und diese Quälerei auch noch zu filmen, um für den angeblich sichereren Gleichstrom zu werben. ${ }^{100}$ Über Edisons Widerstand hinweg setzte sich das überlegene Wechselstromsystem

98 Skrabec, Quentin R. George Westinghouse: Gentle Genius. New York: Algora Pub, 2007, S. 93. 99 Frauen gehörten von Anfang an zu den Kunden der Elektrizitätsfirmen, da sie sich Gedanken über arbeitsersparende elektrische Apparaturen zum Beispiel auf dem Bauernhof machten. Holt, Marilyn Irvin. Linoleum, Better Babies, \& the Modern Farm Woman, 1890 -1930. Lincoln, London: University of Nebraska Press, 1995, S. 21-38.

100 Zur „Battle of the Currents“ siehe Moran, Richard. Executioner's Current: Thomas Edison, George Westinghouse, and the Invention of the Electric Chair. New York: A.A. Knopf, 2002, S.106139. 
trotzdem als Standard in den USA durch, allerdings auf der Basis von nur 110 Volt, was die Kundschaft beruhigen sollte, die Angst vor einem Stromschlag hatte. ${ }^{101}$

Bis zum Ende des Jahrhunderts hatte sich die Elektrizität durchgesetzt. Straßenbahnen, Untergrundbahnen und Maschinen wurden nun elektrisch angetrieben. Privathäuser, Fabriken und Bürogebäude wurden mit elektrischem Licht ausgestattet. Elektrizität wurde zum Synonym für Modernität und urbanes Leben. Die Großstadt mit ihren hellen Lichtern wurde dem Landleben mit seiner Dunkelheit gegenübergestellt. Noch in den dreißiger Jahren des 20. Jahrhunderts hatten nur zehn Prozent der Farmen elektrisches Licht.

Während sich die Bevölkerung der USA an der Beleuchtung der Großstädte erfreute, wichen die Erfinder den Managern und Investoren. 1892 schloss J. P. Morgan die Elektroindustrie zusammen, verkaufte Edisons General Electric an seinen Konkurrenten Thomson-Houston, setzte Edison damit de facto an die Luft und half so bei der Entstehung der General Electric Company, die viermal so groß war wie das alte Unternehmen von Westinghouse. Damit dominierte GE den Markt. ${ }^{102}$ Heute ist GE einer der größten Mischkonzerne der Welt mit einem Umsatz von 147 Milliarden Dollar im Jahr und über 300.000 Mitarbeitern in der ganzen Welt. ${ }^{103}$

\subsection{Die Entstehung des Massenmarktes}

Die Eisenbahn ermöglichte im Laufe der 1880er Jahre die Entstehung eines Massenmarktes für Verbrauchsgüter. ${ }^{104}$ Um diesen Markt zu etablieren mussten

101 Hargadon, Andrew B. und Douglas, Yellowlees. When Innovations Meet Institutions: Edison and the Design of the Electric Light. Administrative Science Quarterly. 2001 Sep; 46 (3):476-501. Finzsch, Norbert. Henry Adams, Nikola Tesla and the „Body Electric“: Intersections between Bodies and Electrical Machines. In: Hampf, M. Michaela und Snyder-Körber, MaryAnn (Hg.). Machine: Bodies, Genders, Technologies. Heidelberg: Winter, 2012, S. 253-278.

102 Reich, Leonard S. The Making of American Industrial Research Science and Business at GE and Bell, 1876-1926. Cambridge, New York: Cambridge University Press, 1985.

103 Zahlen für das Geschäftsjahr 2013. General Electric Company. GE Works: 2013 Annual Report. Fairfield, CT: General Electric Company, 2014, S. 42.

104 Die beste Einführung ist immer noch Strasser, Susan. Satisfaction Guaranteed: The Making of the American Mass Market. New York: Pantheon Books, 1989. Weiterführende Literatur: Blaszczyk, Regina Lee. American Consumer Society, 1865-2005: From Hearth to HDTV. Wheeling, IL: Harlan Davidson, Inc, 2009. Farrell, James J. One Nation under Goods: Malls and the Seductions of American Shopping. Washington, DC: Smithsonian Books, 2010. Glickman, Lawrence B. Buying Power: A History of Consumer Activism in America. Chicago, IL, London: University of Chicago Press, 2009. Goldstein, Carolyn M. Creating Consumers: Home Economists in Twentieth-Century America. Chapel Hill, NC: University of North Carolina Press, 2012. Hoganson, Kristin L. Consu- 
die Hersteller Methoden der Massenfabrikation mit Verfahren des Marketings für den Massenmarkt kombinieren. Wo dies gelang, entstanden Unternehmen, die auf lange Zeit eine marktbeherrschende Stellung einnehmen konnten. Die innerbetriebliche Reorganisation von Unternehmenszweigen wie dem Fleischhandel oder im Lebensmittelhandel sorgte für Extraprofite bei Produkten wie Hot Dogs oder Tomatenketchup.

Tabelle 6: Vergleich des Absatzes von lebendigem Vieh mit Kühlfleisch, New York $1882-1886^{105}$

\begin{tabular}{lrr}
\hline Jahr & Tonnen & Tonnen \\
\hline 1882 & 366,487 & 2,633 \\
1883 & 392,095 & 16,365 \\
1884 & 328,22 & 34,956 \\
1885 & 337,82 & 53,344 \\
1886 & 280,184 & 69,769 \\
\hline
\end{tabular}

Was Carnegie für das Stahlgeschäft tat, besorgte Gustavus Franklin Swift (18391903) für den Fleischhandel. Noch nach dem Bürgerkrieg wurde Schlachtvieh von Cowboys in die fleischverarbeitenden Zentren getrieben, wo es geschlachtet wurde. Swift kam 1875 nach Chicago, um Fleisch im Auftrag einer Firma aus Boston zu kaufen. Er verstand, dass es effektiver war, das Vieh bereits im Mittleren Westen zu schlachten und das Fleisch per Kühlwagen ohne Gewichtsverlust zu den Verbraucherinnen und Verbrauchern im Osten zu schaffen. ${ }^{106}$ Er schuf ein vertikal integriertes Fleischhandelsunternehmen, das den gesamten Vorgang vom Ankauf des Schlachtviehs bis zum Verkauf an die Haushalte kontrollierte. Swift entwickelte den Kühlwagen für Eisenbahnen und Kühlhäuser für die Geschäfte des Einzelhandels. Die Qualität seiner Waren war hoch, die Preise relativ niedrig und die Werbung für seine Produkte effektiv. ${ }^{107}$ Es gelang ihm, die Bedenken der Verbraucherinnen zu zerstreuen, die sich Sorgen machten, weil das angebotene Fleisch nicht vom lokalen Metzger geschlachtet worden war. Der Erfolg der Firma

mers' Imperium: The Global Production of American Domesticity, 1865-1920. Chapel Hill, NC: University of North Carolina Press, 2007. Ward, Douglas B. A New Brand of Business: Charles Coolidge Parlin, Curtis Publishing Company, and the Origins of Market Research. Philadelphia, PA: Temple University Press, 2010.

105 Railway Review, 29. Januar 1887, S. 62.

106 Walsh, Margaret. The Rise of the Midwestern Meat Packing Industry. Lexington, KY: University Press of Kentucky, 1982. Warren, Wilson J. Tied to the Great Packing Machine. The Midwest and Meatpacking. Iowa City, IO: University of Iowa, 2007, S. 1-7.

107 Strasser, Satisfaction Guaranteed, S. 52. 
Swift and Company überzeugte ältere Fleischlieferanten wie Philip Danforth Armour (1832-1901), ähnliche vertikal integrierte Unternehmen hochzuziehen und so in Konkurrenz mit Swift Würste und Hot Dogs an die Endverbraucherin abzusetzen.

So sehr wie Swift den Fleischmarkt veränderte, indem er Massenproduktion mit Massendistribution kombinierte, so sehr wandelte Henry John Heinz (18441919) den Lebensmittelhandel um. ${ }^{108} 1880$ war Heinz noch ein örtlicher Produzent von eingelegtem Gemüse, Soßen und Gewürzmischungen. Sein Geschäft am Stadtrand von Pittsburgh, PA, lief mehr schlecht als recht, da er sich noch von den Auswirkungen einer Insolvenz als Konsequenz der Wirtschaftskrise von 1873 erholen musste. In den 1880er Jahren übernahm er neue, effektivere Methoden zur Herstellung von Konserven und bei der Flaschenabfüllung und errichtete ein Netzwerk von Verkaufsstellen, die sein Angebot von 57 verschiedenen Gewürzmischungen in der ganzen Nation an die Verbraucherin brachten. Um einen nie abreißenden Fluss von Rohstoffen wie Gemüse und andere Ausgangsprodukte zu sichern, schuf er eine Einkaufsabteilung, die mit den örtlichen Farmern langfristige Lieferverträge abschloss. Angeschlossen war ein Warenlager, in dem die Ausgangsprodukte gelagert werden konnten. 1888 war Heinz einer der reichsten Bewohner Pittsburghs geworden und sein Ketchup fand sich in jeder amerikanischen Küche. Andere Lebensmittelhersteller nutzten ähnliche Methoden, darunter Quaker (Haferflocken), Campbell (Suppen) und Borden (Kondensmilch). Sie alle koordinierten Massenherstellung mit massenhaftem Vertrieb von fertig verpackten Lebensmitteln zu niedrigen Preisen. ${ }^{109}$ Andere Sparten wie Tabak, Getreide, Streichhölzer, Seife und Fotografie integrierten die Produktion in den Vertrieb und setzten sich so auf dem nationalen Markt durch. Unternehmen wie American Tobacco, Procter \& Gamble, Quaker Oats, Pillsbury Flour und Eastman Kodak sind auch heute noch Marktführer auf ihrem Gebiet. ${ }^{110}$

108 Skrabec, Quentin R. H.J. Heinz: A Biography. Jefferson, NC: McFarland \& Co, 2009.

109 DuPuis, Steven und Silva, John. Package Design Workbook: The Art and Science of Successful Packaging. Beverly, MA: Rockport Publishers, 2008, S. 13. Strasser, Satisfaction Guaranteed, S. 252-285.

110 Cox, Howard. The Global Cigarette: Origins and Evolution of British American Tobacco, 1880 - 1945. New York: Oxford University Press, 2000. Roberts, B. W. C. und Roberts, Snow L. Bull Durham: Business Bonanza, 1866-1940. Durham, NC: Genuine Durham Press, 2002. Dyer, Davis, Dalzell, Frederick und Olegario, Rowena. Rising Tide: Lessons from 165 Years of Brand Building at Procter \& Gamble. Boston, MA: Harvard Business School Press, 2004. Schisgall, Oscar. Eyes on Tomorrow: The Evolution of Procter \& Gamble. Chicago, IL, New York: J.G. Ferguson Pub. Co. Distributed by Doubleday, 1981. Musser, Joe. The Cereal Tycoon: Henry Parsons Crowell, Founder of the Quaker Oats Co. A Biography. Chicago, IL: Moody Press, 1997. Thornton, Harrison John. The 
Die Werbung spielte bei diesen Entwicklungen eine Schlüsselrolle, denn nur mithilfe der Werbung konnten regionale Produkte sich auf dem nationalen Markt durchsetzen. Die Medien, in denen Produkte vor der Erfindung des Radios und des Fernsehens beworben werden konnten, waren Billboards, Postkarten, Zeitungen und Zeitschriften. Während der Kinderzeit der Werbung war diese sehr weit entfernt von den teilweise witzigen und strategischen Werbekampagnen der Gegenwart. Der Werbefachmann am Ende des 19. Jahrhunderts entwarf weder ideenreichen Slogans, noch wählte er das graphische Material für die begleitenden Illustrationen aus. All das wurde vom Kunden besorgt. Der Agent kaufte und verkaufte lediglich Werbeplätze in den Zeitungen. 1876 erschienen rund achttausend Zeitschriften in den USA. Die Werbekunden konnten es sich einfach nicht leisten, jede einzelne Zeitschrift mit ihren Vertriebsdaten und Auflagenzahlen kennenzulernen und anzuschreiben, um ihre Produkte in ihr anzupreisen. Diese Aufgaben übernahm die Werbeagentur, die vom Kunden mit dem fertigen Werbematerial beliefert wurde. Die Werbeagentur wurde auch nicht vom Kunden bezahlt, sondern von der Zeitschrift, die der Agentur 15 bis 20 Prozent der Werbekosten als Kommission zahlten. Es war also aus Sicht der Agentur nicht ganz klar, ob sie im Auftrag des Werbekunden oder im Auftrag der Zeitschrift arbeitete. In der Praxis erhöhten die Werbeagenturen ihren Profit, indem sie vom Kunden sehr hohe Preise verlangten und bei den Zeitschriften sparten, wo sie konnten. Auf diese Weise konnten die Agenturen zusätzlich zu ihrer Kommission hohe Einnahmen verbuchen. ${ }^{111}$

Ein anderes Charakteristikum sorgte für ein schlechtes Image der Werbeindustrie in ihren Kindertagen. Beworben wurden zunächst allerlei Wundermittel, Elixiere und Hausmittel gegen Schuppen und Erkältungskrankheiten. Produkte, wie das Alkohol enthaltende Mittel gegen Menstruationsbeschwerden von Lydia E. Pinkham (,Vegetable Compound“) waren die Vorreiterprodukte im nationalen Werbemarkt und sorgten rasch dafür, dass Lydia Pinkham eine nationale

History of the Quaker Oats Company. Chicago, IL: The University of Chicago Press, 1933. Collins, Douglas. The Story of Kodak. New York: H.N. Abrams, 1990.

111 Applegate, Edd. The Rise of Advertising in the United States: A History of Innovation to 1960. Lanham, MD: Scarecrow Press, 2012. Cruikshank, Jeffrey L. und Schultz, Arthur W. The Man Who Sold America: The Amazing (but True!) Story of Albert D. Lasker and the Creation of the Advertising Century. Boston, MA: Harvard Business Review Press, 2010. McGovern, Charles. Sold American: Consumption and Citizenship, 1890-1945. Chapel Hill, NC: University of North Carolina Press, 2006. Sivulka, Juliann. Soap, Sex, and Cigarettes: A Cultural History of American Advertising. Boston, MA: Wadsworth, Cengage Learning, 2012. 
Berühmtheit wurde. ${ }^{112}$ Firmen, die auf ihren Ruf bedacht waren, waren zurückhaltend, wenn es um Werbeaufträge ging. Die rasch voranschreitende Professionalisierung der Medizin und die Berufs- und Standesorganisationen, wie die American Medical Association, die diese Professionalisierung vorantrieben, untersagten es ihren Mitgliedern zunächst, Werbekampagnen zu schalten. ${ }^{113}$ Gegen Ende des Jahrhunderts hingegen begann die Haltung zur Werbung sich zu wandeln. Der Druck, sich auf dem nationalen Markt zu behaupten, veranlasste viele Firmen, trotz des schlechten Rufs der Werbeindustrie Kampagnen zu schalten. Ivory Soap aus dem Hause Procter \& Gamble („99.44\% pure“, „It floats“), Quaker Oats („The easy food“) und Coca-Cola (,The ideal brain tonic“) waren die größten Profiteure nationaler Werbekampagnen. ${ }^{114}$ Die Agenturen wurden verantwortungsbewusster und verbesserten ihren Ruf. Sie schalteten nicht mehr nur die Anzeigen, sondern schrieben die Slogans selbst und entwarfen das Design der Werbung. Mit Beginn des 20. Jahrhunderts waren Werbung und Konsum nicht mehr voneinander zu trennen.

\subsection{Das Platzen der Spekulationsblase im Eisenbahngeschäft, 1893}

Auch wenn Industriegiganten vom Schlage eines Rockefeller oder Carnegie ihre Konzerne hochzogen, so zeichnete sich doch bald ein Ende der Ära ab, in der einzelne Unternehmer die Geschickte der Aktiengesellschaften im Alleingang lenken konnten. An ihre Stelle traten Manager, Vorstände und Aufsichtsräte. Die für die Investitionen nötige Kapitaldecke wuchs rasch an und Aktiengesellschaften alleine waren in der Lage, das notwendige Geld zu beschaffen und Fusionen und Übernahmen einzuleiten.

Schon gegen Ende des 19. Jahrhunderts hatte die Aktiengesellschaft die $\mathrm{GmbH}$ oder das Familienunternehmen als wichtigste Form der Geschäftsorganisation abgelöst. Aktiengesellschaften hatten den Vorteil der beschränkten Haftung wie die $\mathrm{GmbH}$ und schützten so die Investoren vor dem Verlust des Privatvermögens, sollte das Unternehmen Insolvenz anmelden müssen. Eine Aktiengesellschaft konnte die Person des Gründers überleben und wurde im

112 Stage, Sarah. Female Complaints: Lydia Pinkham and the Business of Women's Medicine. New York: Norton, 1979, S. 205-232. Washburn, Robert Collyer. The Life and Times of Lydia E. Pinkham. New York: Arno Press, 1976.

113 Baker, Robert. Before Bioethics: A History of American Medical Ethics from the Colonial Period to the Bioethics Revolution. Oxford, New York: Oxford University Press, 2013, S. 109.

114 Strasser, Satisfaction Guaranteed, S. 118f., 129-133. 
Todesfall des Präsidenten oder Aufsichtsratsvorsitzenden nicht in Familienstreitigkeiten verwickelt wie ein Familienunternehmen. Das für Familienunternehmen typische Auf und $\mathrm{Ab}$, das abhängig war vom Geschäftssinn der Erben, sorgte für wenig Stabilität. In der Aktiengesellschaft waren Eigentümer und Manager zwei verschiedene Körperschaften. Das Management kümmerte sich um die tagtäglichen Entscheidungen auf operativer Ebene, während die Gemeinschaft der Eigentümer den Aufsichtsrat und das Management bestimmte. Kapital konnte durch Ausgabe neuer Aktien jederzeit kurzfristig beschafft werden. Die meisten Investoren kauften Aktien, weil sie sich hohe Dividenden versprachen und überließen die Entscheidungen über den Kurs des Unternehmens sehr gerne professionellen Vorständen, die hohe Gehälter bezogen, sich aber durch einen Griff in die Kasse nicht bereichern konnten. Hinzu kam, dass das amerikanische Rechtssystem, das die Aktiengesellschaft als eine „Person“ behandelte, dem Gesetzgeber nach den Bestimmungen des 14. Verfassungszusatzes und dem Gebot des „due process of law“ weitgehende Freiheiten einräumte und sich einer stärkeren Regulierung des Aktiengeschäfts auch nach 1873 weitgehend widersetzte. ${ }^{115}$ Durch das Angebot von Aktien auf einem grundsätzlich offenen Markt konnten außerdem Aktiengesellschaften Konkurrenten aufkaufen oder durch eine Sperrminorität kontrollieren. Amerikanische Anwälte nutzten das liberale Körperschaftsrecht, um eine Aktiengesellschaft nach der anderen zu bilden. Im Jahre 1883 wurden in Deutschland 192 Aktiengesellschaften gegründet, in den Vereinigten Staaten waren es in neun Bundesstaaten alleine (ohne New York) 2.000 Aktiengesellschaften. 1910 lagen die Zahlen noch weiter auseinander: 261 (Deutschland) im Vergleich zu 22.000 in den USA. ${ }^{116}$ Dieser Umstand führte im 20. Jahrhundert zur Entstehung großer Konglomerate von Aktiengesellschaften, ja Oligopolen oder zu Mischkonzernen, die eine breite Palette von Produkten anboten.

Die Fusionsleidenschaft führte zwischen 1890 und 1930 u.a. zu Konzernen wie der Standard Oil oder der General Electric. Als die Trusts zunehmend politische Bedenken auslösten, bildeten sich Holding Companies oder Beteiligungsgesellschaften, um einer strafrechtlichen Verfolgung durch die Behörden zu entgehen. Während der Wirtschaftskrise von 1893 bis 1897 mussten viele Aktiengesellschaften Insolvenz anmelden, um umgehend durch vom Gericht ernannte

115 Grundlegend dazu Bowman, Scott R. The Modern Corporation and American Political Thought: Law, Power, and Ideology. University Park, PA: Pennsylvania State University Press, 1996, S. 55-59.

116 Carroll, Archie B, Lipartito, Kenneth, Post, James E., Werhane, Patricia Hogue und Goodpaster, Kenneth E. Corporate Responsibility: The American Experience. Cambridge, New York: Cambridge University Press, 2012, S. 65. 
Konkursverwalter restrukturiert, reorganisiert und konsolidiert $\mathrm{zu}$ werden. Die Aktiengesellschaften waren somit auch unter den Bedingungen einer Wirtschaftsdepression im Prinzip resilient: Sie entstiegen der Asche der Krise wie der Vogel Phoenix neu, wenn auch mit anderem Namen oder unter veränderten Besitzverhältnissen.

Banken und Investoren spielten eine wichtige Rolle in dieser Konsolidierungsphase nach 1890, so dass der individuelle Unternehmer dem anonymen Finanzkapital weichen musste, in dem Bankenkapital und Industriekapital zum Finanzkapital zusammengeschweißt wurde. ${ }^{117}$ Der Bankier J. P. Morgan war gegen Ende des 19. Jahrhunderts einer der wichtigsten Akteure in diesem Prozess der Umgestaltung. Er schmiedete mehrere Unternehmenszweige wie die Eisenbahnen und die Stahlindustrie in Großkonzernen zusammen. Ideologische Schützenhilfe erfuhren die fusionierenden Industriezweige durch die Philosophie des Sozialdarwinismus, der das Überleben des „Stärkeren“ mit pseudo-biologischen Theorien rechtfertigte und dem Staat das Recht bestritt, hier regulierend und begrenzend einzuschreiten. Der Supreme Court der USA war in dieser Epoche eine Bastion des Konservativismus und legte sich quer, wenn der Staat halbherzige Versuche unternahm, die Herausbildung von Oligopolen zu unterbinden oder bestehende Zusammenschlüsse wie in der Eisenbahn zu kontrollieren. ${ }^{118}$

117 Hilferding, Rudolf. Das Finanzkapital: Eine Studie zur jüngsten Entwicklung des Kapitalismus. Wien: Ignaz Brand \& Co., 1910. Sandleben, Guenther. Nationalökonomie und Staat: Zur Kritik der Theorie des Finanzkapitals. Hamburg: VSA, 2003.

118 Während durch die Entscheidung Munn v. Illinois (1879) den Staaten das Recht zugesprochen wurde, Eisenbahnen zu regulieren, wurde durch den Wabash-Fall (1886) diese Entscheidung grundlegend revidiert. In diesem Fall legte der Oberste Gerichtshof fest, bei Aktiengesellschaften handele es sich um „Personen“, die den gleichen Schutz wie Privatpersonen genössen. Damit entfiel das in der Verfassung garantierte Recht der Bundesstaaten, den zwischenstaatlichen Handel zu regulieren. Der Interstate Commerce Act von 1887 goß die weitgehenden Freiheiten der „Person“ Aktiengesellschaft in die Sprache eines Gesetzes. Siehe Wabash, St. Louis \& Pacific Railway Company v. Illinois (118 US 557), 1886. Die durch den Interstate Commerce Act gegründete Interstate Commerce Commission von 1887 erwies sich aber als Papiertiger. Ihre Beschlüsse mussten zum Beispiel durch einen eigenen Gerichtsbeschluss bzw. durch Anweisung des Justizministers umgesetzt werden. Interstate Commerce Act (1887) 24 Stat. 379. Erst mit dem Railroad Safety Appliance Act von 1893 erhielt die ICC genügend Durchschlagskraft. Weitere Modifikationen und Ausweitungen der Kompetenzen erfolgten 1903, 1906 und 1910. Stone, Richard D. The Interstate Commerce Commission and the Railroad Industry: A History of Regulatory Policy. New York: Praeger, 1991, S. 13f. Grundlegend auch Kleinsteuber, Hans J. Staatsintervention und Verkehrspolitik in den USA: Die Interstate Commerce Commission. Ein Beitrag zur politischen Ökonomie der Vereinigten Staaten von Amerika. Stuttgart: Metzler, 1977. 
Tabelle 7: Gründungen von Konzernen und Insolvenzrate $(1870-1900)^{119}$

\begin{tabular}{|c|c|c|}
\hline Jahr & Anzahl Konzerne in Tsd. & Insolvenzrate \\
\hline 1870 & 427 & 83 \\
\hline 1871 & 457 & 64 \\
\hline 1872 & 500 & 81 \\
\hline 1873 & 494 & 105 \\
\hline 1874 & 559 & 104 \\
\hline 1875 & 603 & 128 \\
\hline 1876 & 639 & 142 \\
\hline 1877 & 637 & 139 \\
\hline 1878 & 661 & 158 \\
\hline 1879 & 702 & 95 \\
\hline 1880 & 747 & 63 \\
\hline 1881 & 782 & 71 \\
\hline 1882 & 822 & 82 \\
\hline 1883 & 864 & 106 \\
\hline 1884 & 905 & 121 \\
\hline 1885 & 920 & 116 \\
\hline 1886 & 970 & 101 \\
\hline 1887 & 994 & 97 \\
\hline 1888 & 1047 & 103 \\
\hline 1889 & 1051 & 103 \\
\hline 1890 & 1111 & 99 \\
\hline 1891 & 1143 & 107 \\
\hline 1892 & 1173 & 89 \\
\hline 1893 & 1193 & 130 \\
\hline 1894 & 1114 & 123 \\
\hline 1895 & 1209 & 112 \\
\hline 1896 & 1152 & 133 \\
\hline 1897 & 1059 & 125 \\
\hline 1898 & 1106 & 111 \\
\hline 1899 & 1148 & 82 \\
\hline 1900 & 1174 & 92 \\
\hline
\end{tabular}

Die Wirtschaftsführer dieser Ära mochten keinen Wettbewerb und versuchten mit allen Mitteln, den freien Wettbewerb durch Zusammenschlüsse und Absprachen zu unterbinden. Unter diesen Unternehmerpersönlichkeiten ragte John Pierpont Morgan (1837-1913) hervor als der Bankier, der als Fusionspapst bekannt werden

119 Quelle: Historical Statistics of the United States, Band 2, Series V 20 - 30, S. 912f. Die jährliche Insolvenzrate bezieht sich auf 10.000 aufgeführte Unternehmen. Explizit nicht eingeschlossen in diese Statistik sind Banken und Einsenbahnen. 
sollte. ${ }^{120}$ Drei Jahrzehnte lang dominierte Morgan den amerikanischen Banksektor in derart eklatanter Weise, dass seine Gegner behaupteten, er kontrolliere einen riesigen „money trust.“121

Als Sohn eines prominenten Bankiers hatte J. P. Morgan neben seinem Vermögen auch die Geschäftsmoral der altmodischen Privatbankiers geerbt, Männer, die Charakter und Verlässlichkeit hoch schätzten. Morgan selbst hielt sich aber an die Ideale seiner Zeit: unternehmerische Initiative und Durchsetzungsvermögen. Er revolutionierte das Investment Banking, indem er aktiv in das Geschäft der Aktiengesellschaften eingriff und den Aktienmarkt reorganisierte.

Morgan benutzte seinen beträchtlichen Einfluss, um das Eisenbahngeschäft zu reorganisieren und Riesenunternehmen wie General Electric oder US Steel zu begründen. In den 1890er Jahren machten die Eisenbahnen eine Krise durch und Morgan ordnete das resultierende Chaos mit harter Hand und sehr viel Kapital. Er hatte in den 1880er Jahren schon Erfahrungen bei der Konsolidierung der Baltimore and Ohio Railroad, der Reading Railroad und der Chesapeake and Ohio Railroads sammeln können. Nach der Krise von 1893 fügte er seiner Sammlung die Santa Fe Railroad, die Erie Railroad, die Northern Pacific Railroad und die Southern Railroad hinzu. 1901 krönte er seine Anstrengungen durch die Gründung der Northern Securities Company, einem Eisenbahntrust, in dem Versuch, die Auseinandersetzungen zwischen der Great Northern Railroad und der Northern Pa-

120 Strouse, Jean. Morgan: American Financier. New York: Perennial, 2000. Allen, Frederick Lewis. The Great Pierpont Morgan: Pomp and Circumstance. Manley, Robert und Manley, Seon. The Age of the Manager: A Treasury of Our Times. New York: Macmillan, 1962; S. 3-23. S. 20. Zu J.P. Morgan und seinen Zeitgenossen weiterführend siehe Auchincloss, Louis. J.P. Morgan the Financier as Collector. New York: H.N. Abrams, 1990. Corey, Lewis. The House of Morgan: A Social Biography of the Masters of Money. New York: AMS Press, 1969. Jackson, Stanley. J.P. Morgan, a Biography. New York: Stein and Day, 1983. Markham, Jerry W. A Financial History of the United States. Armonk, N.Y: M.E. Sharpe, 2002. Morris, The Tycoons. Tett, Gillian. Fool's Gold the Inside Story of J.P. Morgan and How Wall Street Greed Corrupted Its Bold Dream and Created a Financial Catastrophe. New York: Free Press, 2010.

121 United States, Congress, House und Committee on Banking and Currency. Money Trust Investigation: Investigation of Financial and Monetary Conditions in the United States under House Resolutions Nos. 429 and 504, before a Subcommittee of the Committee on Banking and Currency. Interlocking Directorates. Washington, DC: Government Printing Office, 1913. United States; Congress; House und Committee on Banking and Currency. Money Trust Investigation: Investigation of Financial and Monetary Conditions in the United States under House Resolutions Nos. 429 and 504, before a Subcommittee of the Committee on Banking and Currency. Washington, DC: Government Printing Office, 1913, 3 Bände. 
cific Railroad friedlich zu beenden. ${ }^{122}$ Auch andere Investmentbanker versuchten ähnliche Fusionen herbeizuführen, doch keiner konnte Morgan das Wasser reichen. Die Northern Securities wäre - hätte sie Bestand gehabt - die größte Aktiengesellschaft der damaligen Welt gewesen.

Morgan schaffte die ruinöse Konkurrenz zwischen den Eisenbahngesellschaften $\mathrm{ab}$, indem er an die gemeinsamen Interessen der Kontrahenten appellierte. In den neu geschaffenen Konzernen wählte er die Manager selbst aus. Die Partner Morgans saßen mitunter in den Aufsichtsräten von Konkurrenzfirmen und bildeten so „interlocking directorates“ - eine Konstruktion, die im deutschen Aktienrecht untersagt ist. ${ }^{123}$ Bei Vollendung seines „Werks“ kontrollierten nur noch sieben Eisenbahnkonzerne zwei Drittel des amerikanischen Schienennetzes.

Kontrolle durch die Banken bedeutete das Ende des spekulativen Wildwuchses im Eisenbahnbau der 1860er und 1870er Jahre. Doch wurde die so hergestellte „Ordnung“ teuer erkauft. Morgan „verwässerte“ die Aktien der Eisenbahngesellschaften, indem er laufend neue Aktien ausgeben ließ und so die Profite nach oben trieb. Morgans Unternehmen profitierten in geradezu grotesker Weise von den Provisionen derartiger Aktienverkäufe. Die flagrante Überkapitalisierung der Gesellschaften schadete den Unternehmen langfristig, weil sie auf diese Weise Schulden akkumulierten. Die Rentabilität der betroffenen Unternehmen wurde zudem stark herabgesetzt, da der erzielte Gewinn ja in Relation zum investierten Kapital berechnet werden musste. Als ähnlich schädlich sollte sich der Führungsstil der Mitarbeiter Morgans herausstellen, die in seinem Auftrag den Eisenbahngesellschaften vorstanden. Sie waren keine Eisenbahnspezialisten und verstanden nichts vom operativen Geschäft. Für sie waren Eisenbahnen ein Bereich des Bankengeschäfts: Sie waren Männer, die lediglich die Zahlen in ihren Kontobüchern sahen. ${ }^{124}$ Aus diesem Grund unterblieben not-

122 Der Trust wurde 1904 auf Betreiben Präsident Theodore Roosevelts und unter Berufung auf den Sherman Antitrust Act als Monopol zerschlagen. Northern Securities Company v. United States, 193 US 197 (1904).

$123 \S 100$, Absatz 1 Aktiengesetz von 1965. 2014 ist eine Novelle des Aktienrechts vorgelegt worden, über deren Annahme bei Redaktionsschluß noch nicht entschieden worden ist. Der Begriff ist wegen seiner Sonderstellung im amerikanischen Wirtschaftsrecht unübersetzbar und wird auch in der deutschsprachigen Forschung so benutzt. Schneider, Volker, Janning, Frank, Leifeld, Phillip und Malang, Thomas. Politiknetzwerke: Modelle, Anwendungen und Visualisierungen. Wiesbaden: VS Verlag für Sozialwissenschaften, 2009, S. 181. Die amerikanische Entwicklung fasst zusammen Ebke, Werner F. Interlocking Directorates. Zeitschrift für Unternehmens- und Gesellschaftsrecht. 1990; 19 (1):50-109.

124 Jones, Arthur. Capitalism and Christians: Tough Gospel Challenges in a Troubled World Economy. New York: Paulist Press, 1992, S. 35. 
wendige technologische und organisatorische Reformen, die ein effizientes Wirtschaften hätten beflügeln können.

Nachdem Morgan die Eisenbahnen unter seine Kontrolle gebracht hatte, begann er 1898 im Stahlgeschäft zu investieren. ${ }^{125}$ Der Erwerb von Andrew Carnegies Stahlfabriken ist ein Kapitel aus dem Lehrbuch der kapitalistischen Akkumulation. Die Ära des individualistischen Erfindertyps, der erfolgreich ein Geschäft leitete, ging endgültig zu Ende. Die Aktiengesellschaft sollte auch im Stahlgeschäft die vorherrschende Gesellschaftsform werden. Carnegie repräsentierte die alte Ordnung, Morgan die neue Zeit. Morgan bereitete seinen Coup vor, indem er die Fusionen mehrerer kleiner Stahlfirmen überwachend begleitete, die sich bald vertikal $\mathrm{zu}$ integrieren begannen, d.h. sie entwickelten sich von der Herstellung von Stahlfertigwaren zur Produktion von Rohstahl. Carnegie, der seit Jahrzehnten die Produktion von Rohstahl kontrolliert hatte, konterte, indem er mit der Herstellung von Röhren, Nägeln, Draht und Stahlreifen begann. Carnegie ahnte aber, was Morgan vorhatte, denn er sandte seinem Partner Charles M. Schwab im Sommer 1900 ein Telegramm:

My recent letters predict present state of affairs; urge prompt action essential; crisis has arrived, only one policy open; start at once hoop, rod, wire, nail mills, no halfway about last two. Extend coal and coke roads, announce these; also tubes. ${ }^{126}$

Die Presse hatte große Freude an der bevorstehenden Auseinandersetzung zwischen dem kleinen Schotten und dem langen Wall Street-Bankier. Die „Schlacht der Riesen“ stellte sich am Ende als ein undurchsichtiges Manövrieren beider Kontrahenten heraus, bei dem es schwierig ist, zu entscheiden, wer sich letztlich durchgesetzt hat. Der 66 Jahre alte Carnegie akzeptierte es trotz seiner Kämpfernatur, sich letztlich auf Skibo Castle, sein Schloss in Schottland, zurückzuziehen. Es kann jedoch durchaus sein, dass er Morgan dazu gebracht hatte, ihm ein Übernahmeangebot zu machen, denn er wusste, dass Morgan wohl der einzige Bankier war, der über das nötige flüssige Kapital verfügte, um ihn aufzukaufen. Ein Gewährsmann Morgans stattete Carnegie einen Besuch auf dem Golfplatz ab und fragte ihn, wie hoch sein Preis sei. Carnegie kritzelte daraufhin eine Zahl auf seine Scorekarte. Der Gewährsmann eilte mit dieser Information zurück in Morgans Büro und überreichte ihm das „Dokument“ Morgan mochte nicht feilschen und bemerkte lakonisch: „I accept this price.“ Ohne mit der Wimper zu zucken

125 United States, Historical Statistics, Band 2, Series P 231-300, S. $693 \mathrm{f}$.

126 Nasaw, Andrew Carnegie, S. 581. Warren, Kenneth. Triumphant Capitalism: Henry Clay Frick and the Industrial Transformation of America. Pittsburgh, PA: University of Pittsburgh Press, 1996, S. 272. Krass, Peter. Carnegie. Hoboken, NJ: John Wiley \& Sons, 2002. 
hatte Morgan den Kaufpreis von 480 Millionen Dollar für Carnegies Stahlimperium akzeptiert. Carnegies persönlicher Anteil an dem Verkauf belief sich auf mehr als 250 Millionen Dollar. Unbestätigten Gerüchten zufolge, soll Carnegie Morgan später damit aufgezogen haben, er hätte 100 Millionen Dollar mehr verlangen sollen. Morgan hatte aber auch hier das letzte Wort: „You would have got it if you had."'127

Morgans nächsten Schritte richteten sich darauf, die Konkurrenten Carnegies in einem riesigen Stahlunternehmen zusammenzuschließen. United Steel, das Ergebnis dieses Konzentrationsprozesses, wurde im März 1901 aus der Taufe gehoben. Es war der erste Großkonzern, der die Grenze von einer Milliarde Dollar Aktienkapital sprengte. ${ }^{128}$ Das Aktienkapital erreichte die für Zeitgenossen unglaubliche Summe von 1,4 Milliarden Dollar und machte US Steel damit zur größten Aktiengesellschaft der Welt. Trotz ihrer Größe hatte die US Steel nicht das Monopol im Stahlsektor. Kleinere Wettbewerber wie die Bethlehem Steel blieben unabhängig. Anstelle eines Monopols entstand ein Oligopol, eine Marktkonstellation, bei der mehrere große Anbieter den Markt kontrollierten. ${ }^{129}$ Andere Industriesparten wie die Elektroindustrie und die Fleischkonzerne formierten sich ebenfalls als Oligopole. Durch die kleine Zahl von Wettbewerbern wurden Preisabsprachen und Kartellierungen leichter gemacht, so dass die Regeln des Wettbewerbs außer Kraft gesetzt wurden. Kleinere Firmen schlossen sich der Richtung der Oligopolisten an und erhielten dafür einen Anteil am Markt.

Als J. P. Morgan 1913 starb, hinterließ er ein Vermögen von 68 Millionen Dollar, worin die geschätzten 50 Millionen aus seiner Kunstsammlung noch nicht eingeschlossen sind. Andrew Carnegie, der vor seinem Tod im Jahre 1919 etwa 300 Millionen Dollar für wohltätige und kulturelle Zwecke spendete, soll über

127 Gartner, John D. The Hypomanic Edge: The Link between a Little Craziness and a Lot of Success in America. New York: Simon \& Schuster, 2005, S. 161.

$128 \mathrm{Zu}$ Carnegies Aufstieg siehe Bridge, James Howard. The History of the Carnegie Steel Company: An Inside Review of Its Humble Origin and Impressive Growth. New York: The Aldine Book Co, 1903. Walker, John Brisben und Bridge, James Howard. The History of the World's Largest Corporation. New York: The Aldine Book Company, 1903. Krass, Peter. Carnegie. Hoboken, NJ: John Wiley \& Sons, 2002. Lamont-Brown, Raymond. Carnegie the Richest Man in the World. Thrupp, Stroud, Gloucestershire: Sutton Pub, 2005. Livesay, Harold C. Andrew Carnegie and the Rise of Big Business. New York: Pearson Longman, 2007. Standiford, Les. Meet You in Hell: Andrew Carnegie, Henry Clay Frick, and the Bitter Partnership That Transformed America. New York: Crown Publishers, 2005.

129 Hall, Robert und Lieberman, Marc. Microeconomics: Principles and Applications. Mason, OH: Cengage Learning, 2009, S. 333. 
Morgan gesagt haben „[a]nd to think he was not a rich man!“130 Carnegie missverstand Morgans Ziele gründlich. Ihm war es nie um persönlichen Reichtum gegangen. Ihn interessierte nur die Macht, die aus der Formierung derartig riesiger Industriekonzerne entstand. Nicht die Millionen, die er verdiente, waren das Motiv für seine Handlungen, sondern die Millionen, die er kontrollierte. Morgan prägte so seine Epoche beinahe noch mehr als Rockefeller. ${ }^{131}$ Als 1895 im Zuge der Krise von 1893 der Staatsbankrott drohte, wandte sich der amerikanische Präsident an Morgan. Als Eisenbahnkönig, Gründer von US Steel und General Electric läutete Morgan das Zeitalter der Oligopole ein, das über den größeren Teil des 20. Jahrhunderts bestimmend für die US-amerikanische Wirtschaftsgeschichte werden sollte.

John D. Rockefeller Jr., der Sohn des Gründers der Standard Oil, predigte in seiner baptistischen Bibelstunde, dass die Standard Oil Company, wie eine Rosenrasse das Resultat sei von ,pruning the early buds that grew up around it. This is not an evil tendency in business. It is merely the working out of a law of nature and a law of God.“ ${ }^{132}$ Mit anderen Worten, die Auslese der Starken und das Beschneiden der Schwachen sei Gottes Werk - dachte jedenfalls der Sohn eines Multimillionärs. Der Vergleich des Kapitalismus mit der Natur bildete die Grundlage eines neuen Denkens innerhalb der sich formierenden Sozialwissenschaften: Man behauptete eine Homonomie oder mindestens eine Analogie zwischen dem Sozialen und dem Biologischen, die auf dem Gesetz der Evolution basierten, wie es vom britischen Biologen Charles Darwin formuliert worden war. In seinem monumentalen Werk „On the Origin of Species“ aus dem Jahre 1859 hatte Darwin die Theorie aufgestellt, dass in dem Kampf ums Überleben ein Prozess der Anpassung eines Organismus an seine Umwelt stattfinde, die zu einer

130 Homberger, Eric. Mrs. Astor's New York: Money and Social Power in a Gilded Age. New Haven, CT: Yale University Press, 2002, S. XIV. Morgan gehörte auch zu den Förderern der Universitätsbibliothek in Göttingen, die er großzügig unterstützte. Rohlfing, Helmut. John Pierpont Morgan als Förderer der Göttinger Universitätsbibliothek. In: Kelleter, Frank und Knöbl, Wolfgang. Amerika und Deutschland: Ambivalente Begegnungen. Göttingen: Wallstein, 2006, S. 242-248. 131 Das Quellenmaterial zu JP Morgan ist umfangreich und wurde in der Forschung bisher nicht ausreichend berücksichtigt. Eine Ausnahme stellt die ausgezeichnete Studie von Susie Pak dar, die zudem brandneu ist: Pak, Susie. Gentlemen Bankers: The World of J.P. Morgan. Cambridge, MA: Harvard University Press, 2013. So liegt u. a. in der Library of Congress die umgangreiche Korrespondenz des Erfinders Nikola Tesla mit JP Morgan aus dem Tesla Museum in Belgrad. Tesla, Nikola. Nikola Tesla Correspondence, MSS Library of Congress.

132 Bowler, Peter J. Darwin Deleted: Imagining a World without Darwin. Chicago IL: University of Chicago Press, 2013, S. 246. 
Auswahl und $\mathrm{zu}$ einem Entwicklungsgang führe. ${ }^{133}$ Im späten 19. Jahrhundert übertrugen der Brite Herbert Spencer und der Amerikaner William Graham Sumner (1840 - 1910) diese Theorie auf die Sozialwissenschaften. Der Sozialdarwinismus behauptete einen Zusammenhang zwischen sozialer und ökonomischer Konkurrenz der Individuen und dem, was man Fortschritt nannte. ${ }^{134}$ Dass die sozial Schwachen in dieser Konkurrenz Schaden nahmen oder „ausgemerzt“ wurden, nahm man nicht nur in Kauf, sondern billigte es ausdrücklich.

Die Theorie vom „Überleben des Stärksten“ („survival of the fittest“) hatte große Bedeutung für die gesellschaftliche Entwicklung der USA. Schließlich gründete sich auf der Idee der Überlegenheit des Stärksten auch der koloniale Anspruch der USA nach 1898. Wer stärker war als der Nächste erwarb damit quasi automatisch auch das Recht der Herrschaft über den Nachbarn. William Graham Sumner, ein Professor für Politische Ökonomie an der renommierten Yale-Universität, veröffentlichte 1883 ein Buch mit dem bezeichnenden Titel „What Social Classes Owe to Each Other“. ,The drunkard in the gutter is just where he ought to be, according to the fitness and tendency of things“, behauptete Sumner. ${ }^{135}$ Jeder Versuch der sozialen Reform oder die Einsetzung von Sozialprogrammen stelle einen Eingriff in die Naturgesetze dar und verlangsame damit die Evolution und den Fortschritt. Im Resultat bedeutete dies, dass dringend notwendige Sozialreformen unterbunden und Reichtum als äußerer Ausdruck von Stärke („Fitness“) glorifiziert wurden. Der Wirtschaftswissenschaftler Thorstein Veblen (1857-1929) schrieb 1899 zu diesem Thema:

For this class also the incentive to diligence and thrift is not absent; but its action is so greatly
qualified by the secondary demands of pecuniary emulation, that any inclination in this
direction is practically overborne and any incentive to diligence tends to be of no effect. The
most imperative of these secondary demands of emulation, as well as the one of widest
scope, is the requirement of abstention from productive work [...] [L]abour is felt to be de-
basing, and this tradition has never died out [...] In order to gain and to hold the esteem of

133 Darwin, Charles. On the Origin of Species by Means of Natural Selection. London: J. Murray, 1859.

134 In der Forschung ist es umstritten, ob Herbert Spencer zu den Sozialdarwinisten gerechnet werden kann. Ich halte an dieser Lesart fest und stütze mich dabei auf Hawkins, Mike. Social Darwinism in European and American Thought, 1860-1945: Nature as Model and Nature as Threat. Cambridge, New York: Cambridge University Press, 1997, S. 82f.

135 Sumner, William Graham. What Social Classes Owe to Each Other. New Haven: Yale University Press, 1925, S. 114. Die Erstausgabe erschien 1883. Ders. What Social Classes Owe to Each Other. New York: Harper \& Brothers, 1883. 
men it is not sufficient merely to possess wealth or power. The wealth or power must be put in evidence, for esteem is awarded only on evidence $[. . .]^{136}$

Deswegen sei es auch angebracht, Reichtum auffällig zur Schau zu stellen. ${ }^{137}$ Dieser Veblen-Effekt führte zur protzigen und offensichtlichen Dokumentation persönlichen Reichtums in Form von Villen, Kunstsammlungen und Stiftung von öffentlichen Gebäuden. ${ }^{138}$ In einer Epoche, in der Männer wie Rockefeller, Carnegie, Morgan und Vanderbilt riesige Vermögen anhäuften, während ein durchschnittlicher männlicher Arbeiter 500 Dollar im Jahr verdiente, lief der Sozialdarwinismus auf eine Apologie des ungerechten Status quo hinaus. ${ }^{139}$

Andrew Carnegie hat die Theorien Spencers und Sumners wahrscheinlich nie verstanden, aber wie die meisten Unternehmer seiner Zeit begrüßte er ein System, das nicht auf einer moralischen Ökonomie basierte, sondern die Notwendigkeit des Profits „wissenschaftlich“ begründete. 1889 veröffentlichte er „The Gospel of Wealth“, ein Buch, das die amerikanische Adaption der Theorien des Sozialdarwinismus in verständlicher Form darbot. ${ }^{140}$ Carnegie verstieg sich darin zu abenteuerlichen Behauptungen. Der Millionär handele als ein „[...] mere trustee and agent for his poorer brethren, bringing to their service his superior wisdom, experience, and ability to administer, doing for them better than they could or would do for themselves. “141 Carnegie übernahm nicht alle Prämissen des Sozialdarwinismus à la Sumner. Unter anderem betrachtete er soziales Engagement nicht als schädlich für die Evolution. Stattdessen betonte Carnegie die Pflicht der

136 Veblen, Thorstein. The Theory of the Leisure Class: An Economic Study in the Evolution of Institutions. New York, London: The Macmillan Company, 1899, S. 36.

137 Parvenus, Angehörige des Geldadels oder Erben wie Leonard Jerome (1817-1891), Samuel Ward McAllister (1827-1895), Caroline Webster Schermerhorn (1830 -1908), die nur als „Mrs. William Astor“ bezeichnet wurde, oder William H. Vanderbilt stellten ihren Reichtum gerne zur Schau. Siehe Rugoff, Milton. America’s Gilded Age: Intimate Portraits from an Era of Extravagance and Change, 1850-1890. New York: Holt, 1989, S. 68-95.

138 Als Veblen-Effekt bezeichnet man in der Volkswirtschaftslehre das Phänomen, dass die Nachfrage nach bestimmten Produkten trotz einer Preiserhöhung derselben zunimmt, weil Konsumenten durch den Konsum teurer Güter ihren Status gegenüber anderen Individuen herauszustellen versuchen. Der Begriff ist nach Thorstein Veblen benannt.

1391890 betrug der Durchschnttsverdienst für eine Lehrerin 256 Dollar, für einen Landarbeiter 233 Dollar und für einen Industriearbeiter 486 Dollar. Der Stundenlohn für einen Stahlarbeiter mit einer Zehnstundenschicht lag bei 17 Cents. Ein Kumpel in einer Braunkohlegrube verdiente 18 Cents/h. Die durchschnittliche Arbeitszeit lag bei 60 Stunden/Woche. United States, Historical Statistics of the United States, Band 1, D 765-793, S. 168.

140 Carnegie, Andrew. The Gospel of Wealth. London: F. C. Hagen \& Co, 1889.

141 Carnegie, Andrew. The Autobiography of Andrew Carnegie and His Essay: The Gospel of Wealth. Mineola, NY: 2014, S. 285. 
Reichen, ein bescheidenes Leben zu führen und den Überschuss für das Wohl der Menschen $\mathrm{zu}$ verwenden. ${ }^{142}$ Carnegies Ego war fast genauso groß wie sein Bankkonto: Ein Element von Eitelkeit begleitete alle seine Stiftungen und Zuwendungen. Die Bibliotheken, die er mit Riesensummen ausstattete, enthielten allesamt ein Porträt des edlen Spenders. „Gospel of Wealth“ erhielt lobende Rezensionen, überzeugte aber nur wenige seiner Adressaten. J. P. Morgan zog es vor, seine Privatschätze in seiner Bibliothek aufzubewahren und weigerte sich, sein Privatvermögen wie Carnegie zu verteilen.

Der Sozialdarwinismus und das „Evangelium des Reichtums“ („Gospel of Wealth“) fügten sich nahtlos in eine Zeit ein, in der die rasante Entwicklung der Industrialisierung scheinbar rationale Erklärungen erforderlich machte. Der Erfolg der Großindustrie und der an ihr beteiligten Unternehmen wurde als Ausweis ihrer Überlegenheit und damit als unvermeidlich bewertet. Da ein Eingriff in die Gesetze der Natur nach Überzeugung der Sozialdarwinisten den evolutionären Prozess behindere, konnte das individuelle schlechte Gewissen angesichts der eigenen Bereicherung beruhigt werden. Immerhin verhielt man sich in Übereinstimmung mit wissenschaftlich hergeleiteten Naturgesetzen. Die sozial Schwachen wurden auf dem Altar der sozialdarwinistischen Überzeugungen geopfert. Wenn die sozial Schwachen kurz zuvor aus dem Ausland eingewandert waren oder wenn es sich um African Americans handelte, bekam der Sozialdarwinismus eine rassistische Note: Der evolutionäre Prozess wurde mit dem „Rassenfortschritt“ der angeblich überlegenen angelsächsischen „Rasse“ gleichgesetzt. ${ }^{143}$

Sumner blieb bei seiner Auffassung, dass es notwendig sei, dass auch die Regierung sich jedes Eingriffs in die Wirtschaft enthalte, damit der Gang der

142 Hogarty, Richard A. Leon Abbett's New Jersey: The Emergence of the Modern Governor. Philadelphia, PA: American Philosophical Society, 2001, S. 40.

143 Webb, George E. The Evolution Controversy in America. Lexington, KY: University Press of Kentucky, 2002, S. 31, 67. Als Quelle sehr hilfreich Ryan, Frank X. (Hg.). Darwin's Impact: Social Evolution in America, 1880 - 1920. Bristol: Thoemmes Press, 2001, 3 Bände. Zum Zusammenhang von Sozialdarwinismus mit Rassismus siehe Becker, Peter Emil. Sozialdarwinismus, Rassismus, Antisemitismus und Völkischer Gedanke. Wege ins Dritte Reich. Stuttgart, New York: G. Thieme, 1990. Bublitz, Hannelore, Hanke, Christine und Seier, Andrea. Der Gesellschaftskörper: Zur Neuordnung von Kultur und Geschlecht um 1900. Frankfurt am Main, New York: Campus, 2000. Crook, D. P. Darwin's Coat-Tails: Essays on Social Darwinism. New York: Peter Lang, 2007. Jackson, John P. und Weidman, Nadine M. Race, Racism, and Science: Social Impact and Interaction. Santa Barbara, CA: ABC-CLIO, 2004. Lindquist, Malinda A. Race, Social Science and the Crisis of Manhood, 1890 -1970: We Are the Supermen. New York: Routledge, 2012. Numbers, Ronald L. und Stenhouse, John. Disseminating Darwinism: The Role of Place, Race, Religion, and Gender. Cambridge, New York: Cambridge University Press, 1999. 
Evolution sich ungehindert entfalten könne. Diese Doktrin des Laissez-Faire bedeutet u.a., dass Sozialdarwinisten sich gegen Schutzzölle aussprachen, die amerikanische Industriestandorte bevorteilten. Für Sumner waren Schutzzölle aus diesem Grund unakzeptabel. Seine scharfen Attacken gegen die Interventionen der Regierung auf dem Markt riefen den Protest der Yaleabsolventen hervor, die sich an der Diskrepanz zwischen sozialdarwinistischer Theorie und der dem Eigennutz verschriebenen Praxis der Schutzzölle nicht stießen. Während in der Theorie des Laissez-Faire die Regierung keine aktive Rolle in der Wirtschaft spielen sollte, bemühten sich Unternehmer immer wieder darum, die Regierung für ihre Interessen einzusetzen, ob es nun um Zölle, Landschenkungen oder Subventionen ging. Ging es jedoch um Steuern oder Regulierung der Wirtschaftspraktiken, waren amerikanische Unternehmer nur allzu bereit, sich auf die Doktrin des Laissez-Faire zu berufen. ${ }^{144}$

Die Geschäftswelt erfuhr in ihrem Bestreben starke Rückendeckung durch den Obersten Gerichtshof der USA. In den 1880er und 1890er Jahren erfolgte eine Neuinterpretation der amerikanischen Verfassung, die auf einen Schutz der Unternehmen vor Steuergesetzgebung, vor dem Einfluss von Gewerkschaften und vor Gesetzen zur Bewahrung des Wettbewerbs hinauslief. Eine Serie von wirtschaftlichen Grundsatzentscheidungen basierte auf der Nutzung des 14. Verfassungszusatzes zum Zwecke der Schonung der Industrie vor Maßnahmen der Bundesregierung. Das 14. Amendment war ja erlassen worden, um die befreiten Versklavten vor Maßnahmen der Staatenregierungen zu schützen. In diesem Verfassungszusatz heißt es, kein Bundesstaat könne „[...] deprive any person of life, liberty, or property, without due process of law.“145 Da Aktiengesellschaften vom Supreme Court als „Personen“ definiert wurden, konnte dieser Text auch auf Konzerne angewandt werden und stellte somit Industriebetriebe unter den besonderen Schutz der Verfassung. Damit wurde es möglich, Gesetze der Bundesstaaten zu kassieren, die das Eisenbahnwesen regulieren sollten, Einkommensteuergesetze für ungültig zu erklären und Gewerkschaften als illegale Formen der Preisabsprache (,conspiracy in restraint of trade“) zu diskriminieren. Angesichts der massiven Verwerfungen des sozialen Feldes als Folge der Industrialisierung und des Industriekapitalismus war eine derartig einseitige Stellungnahme des Obersten Gerichtshofs bedenklich: Die Rechte der Aktiengesellschaften wurden über die Rechte der Bevölkerung gestellt. In den Worten des Verfassungsrichters

144 Faulkner, Harold Underwood. The Decline of Laissez Faire, 1897-1917. Armonk, NY: M.E. Sharpe, Inc; 1989. Fried, Barbara. The Progressive Assault on Laissez Faire: Robert Hale and the First Law and Economics Movement. Cambridge, MA: Harvard University Press, 1998.

145 James, Joseph B. The Ratification of the Fourteenth Amendment. Macon, GA: Mercer University Press, 1984, S. 305. 
Stephen Johnson Field (1816-1899) erlaube die Verfassung „[...] no impediments to the acquisition of property. " 146 Field war ein Sohn aus einer reichen Familie und war auf die besten Schulen des Landes gegangen. Seine Klassenposition kam in derartig unausgewogenen Stellungnahmen deutlich zum Ausdruck. Auf der Basis dieser Auffassung ließ der Gerichtshof Fusionen ohne Behinderung zu und unternahm nichts, um die Exzesse des formierten Kapitalismus zu unterbinden. ${ }^{147}$

\subsection{Laissez Faire, Sozialdarwinismus und Small Government}

Der Romancier Thomas Clayton Wolfe (1900 - 1938) schrieb unter Bezug auf die Präsidenten des späten 19. Jahrhunderts: „Garfield, Arthur, Harrison, and Hayes [...] for me they were the lost Americans: Their gravely vacant and bewhiskered faces mixed, melted, swam together in the sea-depths of a past intangible, immeasurable, and unknowable as the buried city of Persepolis. " ${ }^{4148}$ Während die Unternehmerpersönlichkeiten wie Rockefeller, Carnegie oder Morgan auch heute noch faszinieren, bleiben die Präsidenten nach Ulysses S. Grant farb- und konturlos. ${ }^{149}$ Wolfe hat von ihnen als den „lost Americans“ gesprochen. ${ }^{150}$ Die Ursache für dieses Phänomen liegt in der relativen Schwäche der Präsidentschaft im Allgemeinen und der Hilflosigkeit der Bundesregierung zwischen der Präsidentschaft Abraham Lincolns (1861-1865) und derjenigen Theodore Roosevelts (19011909) im Besonderen. Nach dem Bürgerkrieg verschob sich das Machtzentrum weg von Washington und hin in die Kontore der Wirtschaftsführer. In Friedenszeiten konnte die Bundesregierung nicht die gleiche Durchschlagskraft entwickeln, wie dies noch während des Kriegs der Fall gewesen war, während dem viele

146 Siegan, Bernard H. The Supreme Court's Constitution: An Inquiry into Judicial Review and Its Impact on Society. New Brunswick, NJ: Transaction Books, 1987, S. 96.

147 Kens, Paul. Justice Stephen Field: Shaping Liberty from the Gold Rush to the Gilded Age. Lawrence, KS: University Press of Kansas, 1997. Cachan, Manuel. Justice Stephen Field and „Free Soil, Free Labor Constitutionalism“: Reconsidering Revisionism. Law and History Review. 2002 Autumn; 20 (3):541-576. Benedict, Michael Les. Laissez-Faire and Liberty: A Re-Evaluation of the Meaning and Origins of Laissez-Faire Constitutionalism. Law and History Review. 1985 Autumn; 3 (2):293-331. Bernstein, David. The Supreme Court and „Civil Rights,“ 1886-1908. The Yale Law Journal. 1990 Dec; 100 (3):725-744.

148 Wolfe, Thomas. The Four Lost Men. In: Skipp, Francis E. (Hg.) The Complete Short Stories of Thomas Wolfe. New York: Scribner, 1987, S. 106-119, S. 110.

149 Ketchersid, William Lester. The Gilded Age Presidency Reconsidered. Bloomington. 1st Books Library, 2003. Skidmore, Max J. Maligned Presidents: The Late 19th Century. New York: Palgrave MacMillan, 2014, S. 50 - 121.

150 Wolfe, The Four Lost Men, S. 109. 
außergewöhnliche oder neuartige Maßnahmen mit den Erfordernissen des Kriegs begründet werden konnten. Die amerikanische Regierung war - gemessen an der Periode nach 1933 - klein. ${ }^{151}$ Der Verlust der Macht im Zentrum der amerikanischen Regierung ging dabei einher mit der zahlenmäßigen Erweiterung des Regierungsapparats. ${ }^{152}$ Auch ein „,big government“ kann eine „schwache“ Regierung hervorbringen. Unterbrochen wurde dieser Prozess der Machterosion des politischen Zentrums zugunsten der Peripherie der Ökonomie durch den Aktivismus des Progressivismus, einer Bewegung, die als „Reparaturbetrieb des Kapitalismus“ bezeichnet werden könnte. ${ }^{153}$ Ähnlich ist der New Deal der 1930er Jahre beschrieben worden, der eine Kompetenzerweiterung des Präsidialamts mit einer Ausweitung der Regierungsaktivitäten und einer Zunahme der Regierungsinstitutionen kombiniert hat. Doch geschah dies in Zeiten des nationalen Notstands auf der Höhe der Weltwirtschaftskrise. Für die Mehrzahl der Jahrzehnte nach 1865 gilt indessen, dass die Regierung relativ schwach war (und auch sein wollte) und die Großunternehmen das Heft in der Hand behielten.

Die Präsidenten zwischen Rutherford B. Hayes und Grover Cleveland (18851889, 1893-1897) konnten wirklich als „vergessene Präsidenten“ bezeichnet werden, auch, weil von ihnen wenig erwartet wurde. Bis in die 1890er Jahre war die Mehrzahl der Bevölkerung anscheinend davon überzeugt, der Präsident und die Bundesregierung hätten wenig Befugnisse, sich in die Probleme einzuschalten, die das Ergebnis der radikalen industriellen Transformation nach dem Bürgerkrieg waren. Die Propagandisten von Laissez Faire und Sozialdarwinismus zogen an einem Strang und warnten die Regierung immer wieder davor, zu intervenieren. Jedwedes Einmischen müsse den Gang der natürlichen Entwicklung hemmen. Damit wurde die Bundesregierung zum Zuschauen verurteilt, während die wirklich wichtigen politischen Entscheidungen in der Parteipolitik auf lokaler Ebene getroffen wurden.

151 Wilson, Mark. The Business of Civil War: Military Mobilization and the State, 1861-1865. Baltimore, MD: Johns Hopkins University Press, 2006, S. 34- 71. Walker, John F. und Vatter, Harold G. The Rise of Big Government in the United States. Armonk, NY: M. E. Sharpe, 1997, S. 5-7.

1521891 hatte die Bundesregierung 150.844 Posten zu besetzen, davon 95.449 im Postdienst und 34.834 in anderen Bereichen (Zolldienst). 1901 waren es 239.476 Regierungsbeamte, davon 136.192 im Postdienst. United States, Historical Statistics, Band 2, Series Y 308-317, S. 1102 f.

153 Bristow, Nancy K. American Pandemic: The Lost Worlds of the 1918 Influenza Epidemic. Oxford, New York: Oxford University Press, 2012, S. 9-34. Keller, Morton. Social and Economic Regulation in the Progressive Era. In: Milkis, Sidney M. and Mileur, Jerome M. (Hg.). Progressivism and the New Democracy. Amherst, MA: University of Massachusetts Press, 1999; S. 126-144. S. 142. Rodgers, Daniel T. Atlantic Crossings: Social Politics in a Progressive Age. Cambridge, MA: Belknap Press of Harvard University Press, 1998, S. 298. Ninkovich, Frank A. The Wilsonian Century: U.S. Foreign Policy since 1900. Chicago, IL: University of Chicago Press, 1999, S. 48. 
Diesen Trends zum Trotz wurde die Politik des Sektionalismus, die die geographischen Großräume und ihre Interessen gegeneinandergestellt hatte, durch eine gemeinsame Auffassung von Politik ersetzt. Unternehmer denken nicht sektional, der Markt ist nicht sektional: Im Zusammenhang mit der enormen Ausweitung des nationalen Marktes durch neue Verkehrs- und Kommunikationsmittel musste auch eine nationale Wirtschaftspolitik gefunden werden. Die Korruption und die Missbräuche, die mit der lokalen Parteipolitik beider großer Parteien und den Problemen des Bossism verbunden waren, führten zur Reform des Beamtentums. In den 1880er Jahren wurden der Schutzzoll, die Währungsfrage und die Regulierung von Eisenbahnen und Trusts durch die Bundesregierung auf die Agenda gesetzt. Die ,vergessenen Präsidenten“ waren durchaus kompetent, aber nicht charismatisch. Sie versuchten, die Nation nach dem verheerenden Bürgerkrieg und den Jahrzehnten der sektionalen Auseinandersetzungen wieder zusammenzubringen. Dass ihnen das gelang, hat auch damit zu tun, dass die African Americans und ihre Belange auf dem Altar der übersektionalen Einigung geopfert wurden - vor allem von den Republikanern.

Trotz der geringen Erwartungen an die Präsidentschaft gingen Männer (und in einigen wenigen Bundesstaaten im Westen später auch Frauen) in Rekordzahlen zu den Wahlen. Durchschnittlich 75 Prozent der Wahlberechtigten machten von ihrem aktiven Wahlrecht Gebrauch. 1996 gingen gerade mal 49 Prozent der Wahlberechtigten an die Urnen. Warum waren diese Menschen so beflissen, zur Wahl zu gehen? Die Antwort liegt in der Rolle, die die Politik in der Kultur des Gilded Age spielte. Politische Parteien benutzten Posten auf allen Ebenen, von der städtischen über die bundesstaatliche bis zur nationalen Ebene, um ihre Anhänger für ihre politische Unterstützung zu belohnen. Viele Wähler verdankten ihre berufliche Existenz den Parteibossen und der von ihnen kontrollierten „Maschine“. In einer sich rasch ändernden und fluiden Welt offerierte die Parteizugehörigkeit auch ein Gefühl des Dazugehörens. So entstanden Gruppenidentitäten, die über Familienzugehörigkeit und Ethnizität hinausgingen. Ebenso wichtig ist der nicht unbeträchtliche Unterhaltungsfaktor der Politik in einer Zeit, in der es weder Radio noch Fernsehen gab. Politische Parteien veranstalteten Umzüge, Paraden, Reden, Picknicks und Fackelzüge. Am 4. Juli wurden zahllose Feuerwerke veranstaltet. Millionen von Wählern und Nichtwählern und -wählerinnen wohnten diesen Ereignissen bei. Außerhalb der großen Städte konnte mit diesen Veranstaltungen nur die innere Mission der protestantischen Kirchen und Glaubensgemeinschaften mithalten. 
Tabelle 8: Wahlbeteiligung $1868-1900^{154}$

\begin{tabular}{lrrr}
\hline Jahr & Prozent & Jahr & Prozent \\
\hline 1868 & 78.1 & 1968 & 60.9 \\
1872 & 71.3 & 1972 & 55.2 \\
1876 & 81.8 & 1976 & 53.5 \\
1880 & 79.4 & 1980 & 54.0 \\
1884 & 77.5 & 1984 & 53.1 \\
1888 & 79.3 & 1988 & 50.2 \\
1892 & 74.7 & 1992 & 55.9 \\
1896 & 79.3 & 1996 & 49.0 \\
1900 & 73.2 & 2000 & 50.3 \\
\hline
\end{tabular}

Politik in Gestalt von Wahlen blieb einem rein weißen männlichen Publikum vorbehalten. Frauen konnten vor 1890 nirgendwo wählen. ${ }^{155}$ Ab 1890 verliehen vier Bundesstaaten im Westen Frauen das Wahlrecht: Wyoming (1890), Colorado (1893) und Utah sowie Idaho (1896). In allen anderen Staaten setzten Frauenorganisationen den Kampf um das Wahlrecht fort, indem sie Referenden der Bundesstaaten anstrebten. Afroamerikaner hatten zwar nach der Reconstruction das Wahlrecht erhalten, aber wir haben in den vorhergehenden Kapiteln sehen können, wie es ihnen Schritt für Schritt wieder entzogen wurde. Mit dem Abzug der Bundestruppen aus dem Süden nach dem schmachvollen Kompromiss von 1877 entfiel die letzte Barriere, die afroamerikanischen Männern die rechtliche Gleichheit hätte garantieren können.

Die Democratic Party, die sich auf die Tradition Thomas Jeffersons und Andrew Jacksons berief, und die Republican Party in der Tradition Abraham Lincolns blieben die beiden dominanten politischen Parteien des späten 19. Jahrhunderts. Das „dritte Parteiensystem“, das sich nach 1854 etabliert hatte, blieb bis in die 1890er Jahre stabil. ${ }^{156}$ Die Wähler identifizierten sich stark mit ihrer jeweiligen Partei. Auch in einem sich rasch industrialisierenden Umfeld blieb die Persistenz

154 Wooley, John und Peters, Gerhard. Voter Turnout in Presidential Elections:1828 - 2008. [Web Page]: http://www.presidency.ucsb.edu/data/turnout.php. Gesehen am 23.04.2014.

155 Frauen hatten in New Jersey bis 1807 das Wahlrecht inne, das ihnen aber im Zuge der Abschaffung der Sklaverei in diesem Staat 1808 entzogen wurde. Dooley, Patricia L. The Early Republic: Primary Documents on Events from 1799 to 1820. Westport, CT: Greenwood Press, 2004, S. 189.

156 Calhoun, Charles W. From Bloody Shirt to Full Dinner Pail: The Transformation of Politics and Governance in the Gilded Age. New York: Hill and Wang, 2010, S. 16. Hansen, Stephen L. The Making of the Third Party System: Voters and Parties in Illinois, 1850 - 1876. Ann Arbor, MI: UMI Research Press, 1980, S. XVII. 
der Wählergruppen hoch, was viel mit gewachsenen kulturellen Identitäten wie Region, Ethnie oder Religion zu tun hatte und nicht so sehr mit wirtschaftlichen Interessen.

Religion und ethnische Identität spielten in der Politik deshalb eine große Rolle. Im Norden orientierten sich Protestanten der traditionellen Denominationen wie Presbyterianer und Methodisten an der Republikanischen Partei. Die Republikaner unterstützten eine Reihe moralischer Reformen wie die Temperenzbewegung und die Prohibition. ${ }^{157}$ Die Demokraten konzentrierten sich auf Migranten sowie Katholiken und Juden. Sie wehrten sich gegen die Schließung von Gasthäusern und Bars am Sonntag und vertraten die Auffassung, dass es beim vorgeblichen Kampf gegen den Alkohol eigentlich um einen Angriff auf die Kultur der Migrantinnen und Migranten ginge. ${ }^{158}$

Hinzu kam die geographische Identifikation des Südens mit den Demokraten. Nach dem Ende der Reconstruction hätten die Republikaner im Süden eigentlich nicht mehr antreten müssen. Der Süden wählte mit großer Mehrheit 70 Jahre lang demokratisch. ${ }^{159}$ Die Republikaner wurden sehr effektiv mit dem Totschlagargument ausgeschaltet, sie hätten nach dem Bürgerkrieg im Süden eine Herrschaft der African Americans etablieren wollen. Die Republikaner taten es ihnen im Norden und Osten gleich, wenn sie forderten, die Wähler sollen „,vote the way you shot.“160 Der demokratisch kontrollierte „Solid South“ stand so dem bevölkerungsreichen republikanischen Nordosten gegenüber, was den Republikanern mit wenigen Ausnahmen erlaubte, ihren Kandidaten bei Präsidentschaftswahlen durchzubringen. Um die Wahl zu gewinnen, reichte es, Schlüsselstaaten wie Ohio, Indiana und New York zu sichern und eine mögliche Allianz zwischen dem Süden und dem ebenfalls agrarisch geprägten Westen zu verhin-

157 Welskopp, Thomas. Amerikas grosse Ernüchterung: Eine Kulturgeschichte der Prohibition. Paderborn: Ferdinand Schöningh, 2010, S. 412.

158 Sismondo, Christine. America Walks into a Bar: A Spirited History of Taverns and Saloons, Speakeasies, and Grog Shops. New York: Oxford University Press, 2011, S. 119-136.

159 Zwischen 1880 und 1924 gewannen die Republikaner bei der Päsidentschaftswahl keinen einizigen Rebellenstaat. 1928 konnten sie erstmals Florida auf ihre Seite ziehen. 1948 stimmte wiederum Florida für den Republikaner Dwight Eisenhower. 1952 gesellte sich Louisiana zu Florida.

160 Nesbit, Robert C. und Thompson, William Fletcher. Wisconsin: A History. Madison, WI: University of Wisconsin Press, 1989, S. 364. House, Albert V. Republicans and Democrats Search for New Identities, 1870 - 1890. The Review of Politics. 1969 Oct; 31 (4):466 - 476. Benedict, Michael Les. Southern Democrats in the Crisis of 1876-1877: A Reconsideration of Reunion and Reaction. The Journal of Southern History. 1980 Nov; 46 (4):489-524. Summers, Mark Wahlgren. Party Games: The Art of Stealing Elections in the Late-Nineteenth-Century United States. The Journal of American History. 2001 Sep; 88 (2):424- 435. 
dern. Republikanische Politiker verstärkten die sektionalen Differenzen, indem sie in emotionaler Weise an die Opfer des Bürgerkriegs erinnerten. Man nannte diese Taktik „waving the bloody shirt“. Staaten des Mittleren Westens, die im Bürgerkrieg die Vereinigten Staaten unterstützt hatten, konnten auf diese Weise im republikanischen Lager gehalten werden. „Iowa will go Democratic when Hell goes Methodist“, witzelte der republikanische US-Senator Jonathan Dolliver (1858-1910). ${ }^{161}$ Kriegsteilnehmer der Grand Army of the Republic, einer Organisation von Veteranen des Bürgerkriegs der US Army, bildeten eine wichtige Massenorganisation, die die Republikaner unterstützte. ${ }^{162}$ Im Gegenzug garantierte die Partei den Veteranen großzügige Pensionen. Bald wurde ein Viertel des Bundeshaushalts der USA für diese Kriegsrenten ausgegeben, wobei Kriegsteilnehmer auf der Seite der Rebellenstaaten keinen Penny sahen. 1885 lebten fast 1,5 Millionen Veteranen in den USA, die im Jahr 1886 alleine 143 Millionen Dollar an Pensionsmitteln ausgezahlt bekamen. ${ }^{163}$

Die Machtverteilung im Land blieb bis in die 1890er Jahre hinein weitgehend stabil. Dem republikanischen Präsidenten stand dabei ein mehrheitlich demokratischer Kongress gegenüber, wobei die Demokraten besonders im House of Representatives stark waren, wo sich lokale Belange leichter artikulieren ließen. Im Senat sah das etwas anders aus. Senatoren wurden vor der Wahlreform durch das 17. Amendment (1913) nicht direkt von den Wählern bestimmt, sondern wurden in den jeweiligen Parlamenten der Bundesstaaten gewählt. ${ }^{164}$ Da die State Legislatures notorisch bestechlich und empfänglich für Korruption waren, setzten sich hier oft Vertreter der Unternehmerinteressen durch. Dies galt im Süden genauso wie im Norden. Henry Demarest Lloyd, Autor eines einflussreichen Sachbuchs über die Standard Oil Company mit dem Titel „Wealth against Commonwealth“ (1894), bemerkte im Hinblick auf das Parlament des Staates Pennsylvania: „The Standard [Oil] has done everything with the Pennsylvania

161 Morain, Thomas J. Prairie Grass Roots: An Iowa Small Town in the Early Twentieth Century. Ames, IO: Iowa State University Press, 1988, S. 68.

162 McConnell, Stuart Charles. Glorious Contentment: The Grand Army of the Republic, 18651900. Chapel Hill, NC: University of North Carolina Press, 1992. Johnson, Russell L. „Great Injustice“: Social Status and the Distribution of Military Pensions after the Civil War. The Journal of the Gilded Age and Progressive Era. 2011 Apr 1; 10 (2):137-160. Glasson, William Henry und Kinley, David. Federal Military Pensions in the United States. New York: Oxford University Press, 1918. 163 United States, Historical Statistics, Bd. 2, Series Y 957-970, S. 1145 und Series Y 971-983, S. 1146.

164 Dautrich, Kenneth und Yalof, David Alistair. American Government: Historical, Popular \& Global Perspectives. Belmont, CA: Wadsworth Cengage Learning, 2009, S. C-25. 
legislature except refine it." ${ }^{165}$ Senatoren vertraten oft kaum verschleiert die Interessen einzelner Unternehmen oder Unternehmergruppen, wie im Falle Nelson Wilmarth Aldrichs (1841-1915), eines mächtigen Republikaners aus Rhode Island.

Die Korruption und das Parteiengezänk, die für die Regierung von Präsident Ulysses S. Grant so typisch gewesen waren, setzten sich in den 1880er Jahren fort. Das Spoils System, die Belohnung politischer Unterstützer mit lukrativen Regierungsfunktionen, blieb die Antriebsfeder für die Politik der Parteien. Ein ethisches Verhalten, bei dem sich Individuen geweigert hätten, durch derartige politische Patronage reich $\mathrm{zu}$ werden, wurde lediglich von einer kleinen Minderheit von Reformern gefordert. Die meisten respektablen Bürger und Bürgerinnen waren von der Politik ohnehin abgestoßen. Korruption und Wahlbetrug wurden einfach als gegeben akzeptiert. ${ }^{166}$ Die Republikaner waren allerdings untereinander zerstritten und ihre Flügel wurden von starken Parteifunktionären geführt, die sich rühmten, den Präsidenten nach ihrer Pfeife tanzen lassen zu können. ${ }^{167}$

Bei der Präsidentschaftswahl von 1880 weigerten sich die Republikaner, Ullyses S. Grant ein drittes Mal zu nominieren. Auch der innerhalb der Partei pro-

165 Brock, James W. und Elzinga, Kenneth G. Antitrust, the Market, and the State: The Contributions of Walter Adams. Armonk, NY: M. E. Sharpe, 1991, S. 81. Lurie, Jonathan. H. D. Lloyd: A Note. Agricultural History. 1973 Jan; 47 (1):76-79, S. 77.

166 Zur Präsidentschaft Rutherford B. Hayes siehe Marschall, Richard. Bully! The Life and Times of Theodore Roosevelt. Washington, DC, New York: Regnery Pub., 2011, S. 26. Trefousse, Hans L. Rutherford B. Hayes. New York: Times Books, 2002. Als Quelle unverzichtbar Williams, Diary and Letters of Rutherford Birchard Hayes.

167 Zu den Lagern innerhalb der Republikanischen Partei und ihren jeweiligen Anführern sowei den Reformbestrebungen der Partei siehe Magness, Phillip W. und Weissburg, Paul. Rules of the Game: How Government Works and Why It Sometimes Doesn't. Prince Frederick, MD: Recorded Books; 2011. (7 CDs), Lecture 3: Half-Breeds, Stalwarts, Mugwumps, and Assassins. DiSalvo, Daniel. Engines of Change: Party Factions in American Politics, 1868-2010. New York: Oxford University Press, 2012, S. 161f. Peskin, Allan. Who Were the Stalwarts? Who Were Their Rivals? Republican Factions in the Gilded Age. Political Science Quarterly. 1984; 99 (4):703-716. McFarland, Gerald W. Mugwumps, Morals, \& Politics, 1884-1920. Amherst, MA: University of Massachusetts Press, 1975, S. 55. Tucker, David M. Mugwumps: Public Moralists of the Gilded Age. Columbia, MO: University of Missouri Press, 1998, Seite X. Summers, Mark W. Rum, Romanism \& Rebellion: The Making of a President, 1884. Chapel Hill, NC: University of North Carolina Press, 2000. Nevins, Grover Cleveland, S. 178. Muzzey, David Saville. James G. Blaine: A Political Idol of Other Days. Port Washington, NY: Kennikat Press, 1963, S. 160. Butler, Leslie. Critical Americans: Victorian Intellectuals and Transatlantic Liberal Reform. Chapel Hill, NC: University of North Carolina Press, 2007, S. 203. Zook, Ellsworth Erving. James G. Blaine and the Mulligan Letters. Madison, WI: University of Wisconsin, 1918. Summers, Rum, Romanism, and Rebellion, S. 135142. Clouatre, Doug. Presidential Upsets: Dark Horses, Underdogs, and Corrupt Bargains. Santa Barbara, CA: ABC-CLIO, 2013, S. $192 \mathrm{f}$. 
minente Blaine wurde übergangen. Stattdessen wurde ein relativ unbekannter Kandidat gekürt, James A. Garfield aus Ohio. ${ }^{168}$ Garfield konnte die Wahl relativ deutlich mit $214 \mathrm{zu} 155$ Wahlmännerstimmen für sich entscheiden.

In den Jahren nach dem Ende des Bürgerkriegs wuchsen der bürokratische Aufwand und die Befugnisse der Bundesregierung deutlich an. Es gab nahezu 150.000 Stellen, die aus dem Bundesbudget bezahlt wurden. Das alte Spoils System mit seiner Vergabe von Posten nach Parteizugehörigkeit schien nicht mehr zeitgemäß zu sein, denn es bekamen nicht die Qualifiziertesten die Regierungsjobs, sondern die treuesten Parteisoldaten. Politiker mit Einfluss sahen sich einem nie abreißenden Strom von Bittstellern ausgesetzt, die eine Anstellung für sich oder Familienmitglieder erheischten. Eine Reform sollte fortan Eingangsqualifikationen für alle Positionen definieren und eine Prozedur entwickeln, mithilfe derer man die geeigneten von den schlechten Aspiranten für Regierungsposten unterscheiden könnte. Der Ruf nach qualifizierten Staatsbeamten stellte sowohl ein Bestreben dar, nur die Besten für derartige Aufgaben zu gewinnen, war darüber hinaus aber auch ein verschleierter Versuch, die ethnische Diversifizierung in den Vereinigten Staaten zumindest auf dem Gebiet der Regierungsposten zu verhindern. Die Auseinandersetzungen um die Reform des Öffentlichen Dienstes sollten in der Ermordung des Präsidenten James Garfield münden.

Am 2. Juli 1881 wurde Präsident Garfield von einem offensichtlich geisteskranken und enttäuschten Parteigänger der Republikaner in den Rücken geschossen, während er auf einen Zug im Bahnhof von Washington, DC wartete. Die Presse schob den Stalwarts den Tod des Präsidenten in die Schuhe, nicht so sehr, weil sie den Täter angestiftet, sondern weil sie das politische Klima für den Mord bereitet hatten. Ironischerweise führte der Tod Garfields zum Niedergang eben jener Fraktion der Republikaner, die zunächst von ihm zu profitieren schien. Das Spoils System geriet immer mehr unter Druck. Die Menschen verlangten nach einer Reform des Öffentlichen Dienstes. Auch wenn Garfields Ermordung sich als Segen für die Befürworter einer solchen Reform herausstellte, so war der Weg hierhin lang und steinig. Etliche Gegner der Reform sahen ganz genau, dass der Öffentliche Dienst Angehörige der Arbeiterklasse und Einwanderer und Einwandererinnen diskriminieren würde. Just $\mathrm{zu}$ dem Zeitpunkt, als irische Einwanderer begannen, sich in der lokalen und regionalen Politik einen Platz zu erkämpfen, drohten die Reformer damit, die Regierungsposten wieder in die Hände der gebildeten weißen angelsächsischen Elite zu legen.

168 Morgan, H. Wayne. From Hayes to McKinley: National Party Politics, 1877-1896. Syracuse, NY: Syracuse University Press, 1969, S. 100. 
Die Reform kam trotz aller Kritik. 1883 wurde der Pendleton Act nach einer erhitzten Debatte und vielen Kompromissen im Kongress verabschiedet. ${ }^{169}$ Der Gesetzesentwurf wurde im Kongress vom langjährigen demokratischen Senator, Kandidat für das Amt des Vizepräsidenten und Reformer George Hunt Pendleton (1825 - 1889) aus Ohio gesponsert. ${ }^{170}$ Der Pendleton Act verfügte, dass Posten der Bundesregierung nach dem Leistungsprinzip vergeben werden sollten und dass die Bewerber - von Frauen war noch keine Rede - eine Aufnahmeprüfung zu absolvieren hatten. Das Gesetz verbot ebenso die Entlassung von Beamten aus politischen Gründen. Es machte es auch unmöglich, dass Parteien von Regierungsangestellten Zahlungen einfordern konnten. Eine Kommission, die dreiköpfige Civil Service Commission, wurde eingerichtet, um das Gesetz durchzusetzen. ${ }^{171}$ Ihre Mitglieder wurden vom Präsidenten eingesetzt. Von den rund 150.000 Regierungsposten wurden allerdings nur knapp zehn Prozent durch das Gesetz abgedeckt. ${ }^{172}$ Die Hälfte aller Posten bei der Bundespost und die meisten Stellen beim Zoll fielen unter das Gesetz. Durch den Wegfall der Zahlungen von Amtsinhabern an die Parteien (Kickbacks) hoffte man die finanzielle Basis der Bosse austrocknen zu können. Anstelle der Kickbacks finanzierten nun zunehmend große Unternehmen die Parteien, so dass die nicht intendierte Folge der Reform des Öffentlichen Dienstes eine größere Einflussnahme der Großunternehmen auf die Politik war.

Die Populisten entstanden aus einer Revolte der Farmer im Süden und Westen der USA gegen die Finanzpolitik der Vereinigten Staaten. Die Kontraktion des Währungsvolumens nach dem Ende des Bürgerkriegs führte zu einer deflationären Politik des teuren Geldes, durch die Zinsen nach oben gingen und Kredite knapp wurden. Ein Farmer, der sich 1868 1.000 Dollar geliehen hatte, um seine Farm aufzubauen, musste 1888 die doppelte Menge an Weizen produzieren, um in der Lage zu sein, seine monatlichen Kreditraten zurückzuzahlen. Hinzu kam, dass er seine Kredite in harten Golddollar zurückzahlen musste, während sein Kredit wahrscheinlich in Greenbacks ausgezahlt worden war. ${ }^{173}$ Hinzu kamen die

169 Rosenbloom, David H. und Emmert, Mark A. Centenary Issues of the Pendleton Act of 1883: The Problematic Legacy of Civil Service Reform. New York: M. Dekker, 1982.

170 Mach, Thomas S. „Gentleman George“ Hunt Pendleton: Party Politics and Ideological Identity in Nineteenth-Century America. Kent, OH: Kent State University Press, 2007.

171 Smith, Darrell Hevenor. The United States Civil Service Commission: Its History, Activities, and Organization. New York: AMS Press, 1974.

1721891 hatte die Bundesregierung 150.844 Posten zu besetzen, davon 95.449 im Postdienst und 34.834 in anderen Bereichen (Zolldienst). United States, Historical Statistics, Band 2, Series Y 308-317, S. 1103.

173 Goodwyn, Democratic Promise, S. 13. 
Schutzzölle, die Importwaren verteuerten und dafür sorgten, dass amerikanische Farmer Schwierigkeiten hatten, ihre Produkte auf dem Weltmarkt abzusetzen.

Schutzzölle waren keine ganz neue Erscheinung der amerikanischen Wirtschaftspolitik. Die Preise der importierten Produkte sollten auf diese Weise erhöht werden und die amerikanische Industrie sollte angekurbelt werden. Schon Alexander Hamilton hatte diese Politik vorgeschlagen. Der Kongress hatte den ersten Schutzzoll nach dem Krieg von 1812 im Jahre 1816 verabschiedet. Er belegte Importwaren mit einem Einfuhrzoll zwischen 7,5 und 40 Prozent und wurde damals in einer vollständig anderen Situation mit den Stimmen des Südens verabschiedet. ${ }^{174} 1828$ folgte der protektionistische Tariff of Abominations, der beinahe zu einer sektionalen Krise geführt hätte. ${ }^{175}$ Die Republikaner benutzten die Zollpolitik zu politischen Zwecken: Sie belohnten 1861 damit ihre Unterstützer aus dem Lager der Wirtschaft und benutzten ihn gleichzeitig, um den Bundeshaushalt in Zeiten eines sehr kostspieligen Bürgerkriegs aufzustocken. Nach dem Ende des Kriegs passten die Republikaner die Zollpolitik immer weiter den Bedürfnissen der Unternehmer im Nordosten der Republik an. Um 1880 drohte der Schutzzoll zu einem echten Problem zu werden, denn er bremste die Prosperität der sich immer mehr auf den Export verlegenden Industrie und er generierte mit anderen Einnahmen des Bundes sehr viel Einkommen. Die Regierung wusste kaum noch, wohin mit dem vom Zoll generierten Reichtum. Anstatt im Geldkreislauf der Nation zu zirkulieren, lagen enorme Kapitalien in den Tresoren des Schatzamtes und wurden nicht investiert. Grafik 5 zeigt die erwirtschafteten Überschüsse in Tausend Dollar. Zwischen 1866 und 1900 wurde im Staatshaushalt so ein Überschuss von 1,61 Milliarden Dollar erwirtschaftet. Erstaunlicher ist, dass von den eingenommenen 13 Milliarden Dollar knapp die Hälfte aus den Einfuhrzöllen des Customs Service stammten.

Für viele amerikanische Farmer, vor allem im Süden und im Westen, die versuchten, ihre Produkte auf dem Weltmarkt zu platzieren, war dies ein Ärgernis, weil sie mit hohen Zöllen belegte Produkte einkaufen mussten. Diese Gruppe war an einer deutlichen Senkung der Zölle interessiert. Vertreter der Idee des Freihandels und gemäßigte Politiker aller Lager verlangten nach einer Zollreform. Schon die Wahlprogramme der Demokraten in den Jahren 1876 und 1880 hatten eine Zollpolitik verlangt, die Abstand vom Schutzzoll nehmen und nur zur Fi-

174 Finzsch, Konsolidierung und Dissens, S. 191.

175 Finzsch, Konsolidierung und Dissens, S. 270 f. Northrup, Cynthia Clark und Turney, Elaine C. Prange. Encyclopedia of Tariffs and Trade in U.S. History. Westport, CT: Greenwood Press, 2003, 3 Bände, Band 1, S. 363. 
nanzierung des Bundeshaushalts eingesetzt werden sollte. ${ }^{176} 1892$ wurde diese Forderung erneuert und die republikanische Zollpolitik wurde in Bausch und Bogen als verfassungswidrig und einseitig attackiert. Diejenigen aber, die vom Schutzzoll profitierten wie Andrew Carnegie, der auf dem Schutz der ,jungen“ Industrie gegen europäische Konkurrenz bestand, und die Produzenten von Wolle, Häuten und die Holzindustrie, bestanden auf der Weiterführung der republikanischen Zollpolitik. Viele Arbeiter glaubten, die Schutzzölle garantierten ihnen ihre Stelle und ihre relativ hohen Löhne, da sie der amerikanischen Industrie einen Vorteil gegenüber ausländischen Unternehmen gewähre.

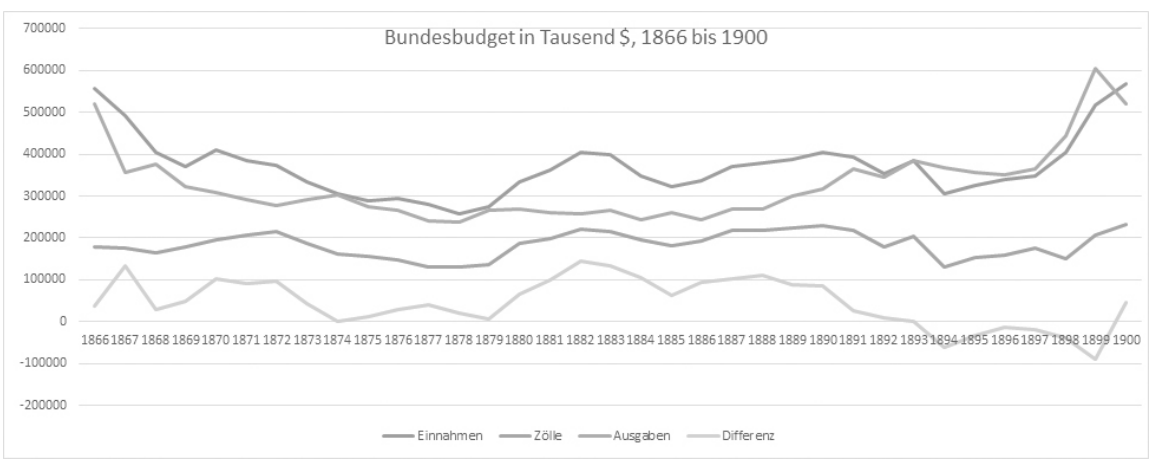

Grafik 5: Bundesbudget in Tausend US-Dollar, 1866-1900 ${ }^{177}$

Die Republikaner witterten eine Gelegenheit, die Zollpolitik zu ihren Gunsten politisch nutzbar zu machen. James G. Blaine erkannte als erster die Möglichkeit, von der Bürgerkriegsrhetorik wegzukommen. ${ }^{178}$ Er befürwortete eine Allianz von Unternehmern, den Gewerkschaften und den Produzenten von Rohmaterialien im Westen und hoffte, auf diese Weise den Osten und den Westen gegen den konsistent demokratisch wählenden Süden zu vereinen. Diese Taktik versagte zwar in der Wahl von 1884, war jedoch erstmalig 1888 erfolgreich. Cleveland hatte seine Lektion gelernt: 1884 noch hatte er die Zollfrage eher vernachlässigt, 1887 engagierte er sich im Kampf gegen die hohen Zölle.

Die Republikaner entgegneten, das „Herumfummeln“ („Tinkering“) am Zoll sei dazu angetan, den Wohlstand des Landes zu gefährden, indem die Industrie

176 Goldstein, Judith. Ideas, Interests, and American Trade Policy. Ithaca, NY: Cornell University Press, 1993, S. 108.

177 United States, Historical Statistics, Band 2, Series Y 335-338 und Y352-357, S. 1104-1106. 178 Campbell, Ballard C. The Human Tradition in the Gilded Age and Progressive Era. Wilmington, DE: SR Books, 2000, S. 25. 
geschädigt und die Löhne gesenkt würden. Außerdem würden die Farmer ihre Absätze auf dem nationalen Markt in Frage stellen. Mit dieser Taktik gewann Benjamin Harrison das Weiße Haus bei der Wahl von 1888. Cleveland holte zwar ein Prozent mehr Wählerstimmen als sein Gegner, da Harrison aber alle Staaten im Westen und Norden mit Ausnahme von Connecticut und New Jersey gewinnen konnte, lag er bei den Wahlmännerstimmen mit 233 zu 168 vorn.

Mit der Rückgewinnung der Macht fuhren die Republikaner einen noch wirtschaftsfreundlicheren Kurs. Die Abkehr von der Bürgerkriegsrhetorik erlaubte ihnen auch, die Situation der ehemals Versklavten neu zu überdenken. Die Force Bill aus der Feder des republikanischen Senators Henry Cabot Lodge, die das Ziel gehabt hatte, das den African Americans im Süden de jure zugesagte Wahlrecht de facto durchzusetzen, starb 1890 im mehrheitlich aus Republikanern bestehenden Kongress einen unrühmlichen Tod, im Wesentlichen, weil der republikanische Vizepräsident Levi P. Morton (1824-1920) während des demokratischen Filibuster im Senat untätig herumsaß und Republikaner aus dem Westen, die ein Interesse an der Prägung von Silber als Münzgeld hatten, die Force Bill in einem politischen Kuhhandel mit den Demokraten im Austausch für die Zustimmung zum Sherman Silver Purchase Act aufgaben. ${ }^{179}$ Derselbe Kongress verabschiedete den höchsten Zollsatz in der Geschichte der Vereinigten Staaten. Dieser neue Zolltarif, der vom Kongressabgeordneten William McKinley aus Ohio eingebracht worden war, löste im Süden große Bestürzung aus. Präsident Harrison war unter anderem gewählt worden, um den Schutz der Industrie aufrechtzuerhalten, nicht um einen noch höheren Zollsatz durchzusetzen. Der McKinley-Zoll hätte das Problem zu hoher Überschüsse auf die Weise gelöst, dass überhaupt keine ausländischen Waren mehr in den Vereinigten Staaten hätten abgesetzt werden können. Die Demokraten verdammten deshalb den McKinley-Zoll und bezeichneten den recht spendablen Kongress unter der Kontrolle der Republikaner als „Milliardenkon-

179 Mit Filibuster ist die Verschleppung und letztlich Verhinderung einer Abstimmung im Kongress gemeint, die durch künstliche Ausdehnung der Redezeit erreicht wird. Der Sherman Silver Purchase Act von 1890 erhöhte die Menge des von der Bundesregierung aufgekauften Silbers. Der Staat erwarb nach 1890 monatlich 4,5 Millionen Ounces (127,5 Tonnen) Silber. Bezahlt wurde der Kauf durch besondere Banknoten (coin notes), die entweder in Gold oder in Silber eingetauscht werden konnten. Der Zweck des Gesetzes lag in der Erhöhung der Inflation. Das Gesetz wurde im Doppelpack mit dem McKinley Zolltarif verabschiedet. Der Zweck des Gesetzes wurde nicht erreicht, da die meisten Käufer der Banknoten diese umgehend in Gold umtauschten und auf diese Weise der Goldvorrat der Bundesregierung abschmolz. 1893 wurde das Gesetz auf Initiative von Präsident Grover Cleveland deshalb kassiert. Cleveland, Grover. Message on the Repeal of the Sherman Silver Purchase Act. In: Hofstadter, Richard und Hofstadter, Beatrice K. (Hg.). Great Issues in American History from Reconstruction to the Present Day, 1864-1981. New York: Vintage Books, 1982, S. 145-148. 
gress“. ${ }^{180}$ Der 51. Kongress (1889-1891), der in beiden Häusern eine republikanische Mehrheit aufwies, erwarb sich diesen Namen zu Recht, denn er verwendete den Überschuss des Bundeshaushalts für die Finanzierung bestimmter Maßnahmen, die einer kleinen Minderheit von republikanischen Wählern und Unterstützern zugutekamen. So wurden mit Bundesmitteln öffentliche Baumaßnahmen und weitere großzügige Kriegsrenten für (republikanische) Veteranen des Bürgerkriegs bewilligt - sehr zum Ärger der Demokraten. ${ }^{181}$ Der Versuch John Bynum (D-IN), die Erhöhung der Ausgaben für Kriegspensionen an die Steigerung der Steuerausgaben zu binden, schlug fehl. ${ }^{182}$ Die Konsequenzen für die Republikaner waren drastisch. In den Midtermwahlen von 1890 wurden die Republikaner hart abgestraft. McKinley verlor sein Mandat. 1892 siegte Cleveland über Harrison und versprach, den McKinley-Zoll wieder rückgängig zu machen.

Die Wähler waren sich in der Frage der Zoll- und Fiskalpolitik keineswegs einig, doch bildete sich ein Konsens heraus, in dem es um die Regulierung der Eisenbahnlinien durch den Bund ging. Auch die Trusts erregten allgemeinen Unwillen und sollten stärker kontrolliert werden. Schon 1870 hatte sich Widerstand gegen die Preispolitik der Eisenbahnlinien geregt. Die Patrons of Husbandry, auch Grange genannt, hatte sich 1867 gegründet. Zunächst handelte es sich bei dieser Organisation um einen Zusammenschluss der Farmer zum Zwecke von Schulungen. Rasch politisierten sich die Mitglieder der Grange und überführten ihre Organisation in eine politisierte Plattform des Widerstands gegen die Eisenbahnen und die Preispolitik des Bundes. Grangers wurden auf lokaler Ebene in politische Ämter gewählt und ermöglichten es einigen Staaten des Mittleren Westens, Gesetze zur Kontrolle der Eisenbahnen durchzusetzen. Diese Gesetze galten zunächst als verfassungskonform. Noch 1877 im Fall Munn v. Illinois (94 U.S. 113) hatte der Oberste Gerichtshof das Recht auf Regulierung der Eisenbahnen durch Bundesstaaten mit dem Hinweis auf das öffentliche Interesse unterstützt. ${ }^{183}$ Munn v. Illinois sollte jedoch eine Ausnahme bleiben. Schon 1886

180 Cashman, Sean Dennis. America in the Gilded Age: From the Death of Lincoln to the Rise of Theodore Roosevelt. New York: New York University Press, 1993, S. 270.

181 Chisholm, Donald. Waiting for Dead Men's Shoes: Origins and Development of the U.S. Navy’s Officer Personnel System, 1793-1941. Stanford, CA: Stanford University Press, 2001, S. 399. 182 Stewart, Charles Haines. Budget Reform Politics: The Design of the Appropriations Process in the House of Representatives, 1865-1921. Cambridge, New York: Cambridge University Press, 1989, S. 174.

183 Munn v. Illinois, 94 US 113 (1877), war eine Entscheidung des Supreme Court, die es Bundesstaaten gestattete, bestimmte Geschäftssparten innerhalb ihrer Grenzen zu regulieren. Der 14. Verfassungszusatz begrenzte nicht das Recht des Saates Illinois, in die Preisgestaltung der großen Getreidezwischenhändler einzugreifen. Privatfirmen könnten im öffentlichen Interesse durch den Bundesstaat mit Restriktionen belegt werden. Lepsius, Oliver. Verwaltungsrecht unter 
nahm der Supreme Court eine radikal andere Position ein. In Wabash, St. Louis, and Pacific Railway Co. v. Illinois entschied der Oberste Gerichtshof, dass Eisenbahngesellschaften im grenzüberschreitenden Verkehr zwischen Bundesstaaten nicht unter die Jurisdiktion der Bundesstaaten, sondern unter die Zuständigkeit des Bundes fielen. ${ }^{184} \mathrm{Da}$ mehr als Dreiviertel aller Eisenbahnlinien zwischen einzelnen Bundesstaaten operierten, hatte der Supreme Court die Gesetze der Bundesstaaten zur Regulierung der Eisenbahnen weitgehend unwirksam gemacht.

Die öffentliche Empörung über die Entscheidung des Obersten Gerichtshofs führte zur Einrichtung einer Senatskommission und zur rasch folgenden Verabschiedung des ersten Bundesgesetzes zur Regulierung der Eisenbahnen, dem Interstate Commerce Act, der 1887 während der ersten Regierungszeit Clevelands beide Häuser passierte. ${ }^{185}$ Das Gesetz etablierte die erste Regulierungsbehörde des Bundes, die Interstate Commerce Commission (ICC). Zur Anwendung kam dabei das Verfassungsgebot, das dem Bund die Hoheit in Angelegenheiten des zwischenstaatlichen Verkehrswesens zusprach (interstate commerce clause). Die ICC war anfangs noch eine schwache Institution, die aber über die Jahre an Einfluss gewann.

Wenig später erließ der Kongress den Sherman Antitrust Act (1890). ${ }^{186}$ Dieses Gesetz ließ die Konzentration von Unternehmen durchaus zu, verbot aber Trusts. Theoretisch wurde es Unternehmen untersagt, Absprachen zu tätigen, die den

dem Common Law: Amerikanische Entwicklungen bis zum New Deal. Tübingen: Mohr Siebeck, 1997, S. 76.

184 Wabash, St. Louis \& Pacific Railroad Company v. Illinois, 118 US 557 (1886). Lepsius, Verwaltungsrecht, S. 77.

185 United States, Congress, Senate und Select Committee on Interstate Commerce. Report of the Senate Select Committee on Interstate Commerce (With Appendix). Forty-Ninth Congress, First Session.-Submitted to the Senate January 18, 1886. Washington, DC: Government Printing Office, 1886, 2 Bände. Prager, Robin A. Using Stock Price Data to Measure the Effects of Regulation: The Interstate Commerce Act and the Railroad Industry. The RAND Journal of Economics. 1989 Summer; 20 (2):280 - 290. Gilligan, Thomas W., Marshall, William J. und Weingast, Barry R. Regulation and the Theory of Legislative Choice: The Interstate Commerce Act of 1887. Journal of Law and Economics. 1989 Apr; 32 (1):35-61. Childs, William R. State Regulators and Pragmatic Federalism in the United States, 1889-1945. The Business History Review. 2001 Winter; 75 (4):701738. Hovenkamp, Herbert. Regulatory Conflict in the Gilded Age: Federalism and the Railroad Problem. The Yale Law Journal. 1988 May; 97 (6):1017-1072.

186 Cefrey, Holly. The Sherman Antitrust Act. Getting Big Business under Control. New York: Rosen Pub. Group, 2004. Letwin, William. Law and Economic Policy in America: The Evolution of the ShermanAntitrust Act. Chicago, IL: University of Chicago Press, 1981. Worth, Richard. Sherman Antitrust Act. New York: Marshall Cavendish Benchmark, 2012. 
freien Wettbewerb behinderten. ${ }^{187}$ Das Gesetz untersagte die Bildung von Pools und Trusts, doch es unternahm nichts gegen Holding Companies wie die Standard Oil, da die Holding Company ja eine einzige Firma (und nicht ein Konglomerat) darstellte, also auch keine unfairen Preisabsprachen oder Behinderungen des freien Wettbewerbs umsetzen konnte. ${ }^{188}$

Diese Schwäche sorgte für weitgehende Ineffizienz des Sherman Act. In dem Jahrzehnt nach der Verabschiedung des Gesetzes erreichte die Bundesregierung in nur sechs Fällen eine Auflösung von Trusts. Dagegen schritt die Regierung in vier Fällen gegen Gewerkschaften ein, die sie einer „conspiracy in restraint of trade“ bezichtigte. Zu allem Überfluss kassierte der Supreme Court 1895 das Gesetz im Fall United States v. E. C. Knight Co. ${ }^{189}$ Das Gericht befand, das Monopol der American Sugar Refining Company, die 98 Prozent der Zuckerproduktion in den USA kontrollierte, könne nicht gebrochen werden, da die lokale Herstellung von Zucker (manufacture) nicht dasselbe sei wie der Handel (trade) zwischen den Staaten. ${ }^{190}$

Sowohl die Interstate Commerce Commission als auch der Sherman Antitrust Act belegen die Besorgnis eines großen Teils der Öffentlichkeit über die Rolle der Großkonzerne. Die Bereitschaft der Bundesregierung, sich im Interesse des Ge-

187 Grandy, Christopher. Original Intent and the Sherman Antitrust Act: A Re-examination of the Consumer-Welfare Hypothesis. The Journal of Economic History. 1993 Jun; 53 (2):359-376.

188 Letwin, William. Law and Economic Policy in America: The Evolution of the Sherman Antitrust Act. Chicago, IL: University of Chicago Press, 1981. Sehr knapp: Cefrey, Holly. The Sherman Antitrust Act. Getting Big Business under Control. New York: Rosen Pub. Group, 2004. McNeese, Tim. The Robber Barons and the Sherman Anti-Trust: Reshaping American Business. New York: Chelsea House Publishers, 2009, S. 88.

189 United States v. E. C. Knight Co., 156 US 1 (1895). 1891 kaufte Henry O. Havemeyer (1847-1907), der CEO der American Sugar Refinery die Hälfte der Aktien des Zuckerimperiums von Claus Spreckels (1828-1908) und gewann damit Zugang zur Zuckerproduktion in Hawai'i. 1892 übernahm die American Sugar Refinery Company (ASRC) die Kontrolle über die E.C. Knight Company und andere Hersteller von Zucker. Damit hatte sie ein nahezu vollständiges Monopol. Präsident Cleveland wies die Bundesregierung an, gegen die ASRC nach den Bestimmungen des Antitrust Law vorzugehen, um den Kauf des kleineren Konkurrenten zu verhindern. Der Supreme Court widersprach der Regierung und ließ verlauten, ,[...] that the result of the transaction was the creation of a monopoly in the manufacture of a necessary of life“, doch könne dies durch das vorliegende Gesetz nicht verhindert werden. Barnikel, Hans Heinrich. Probleme der wirtschaftlichen Konzentration. Darmstadt: Wissenschaftliche Buchgesellschaft, 1975, S. 180. Zu Havemeyer siehe Catlin, Daniel. Good Work Well Done: The Sugar Business Career of Horace Havemeyer, 1903-1956. New York: D. Catlin, 1988. Havemeyer, Harry W. Henry Osborne Havemeyer: The Most Independent Mind. New York: H.W. Havemeyer, 2010.

190 Das Gesetz machte „[...] every contract, combination in the form of trust or otherwise, or conspiracy, in restraint of trade [meine Hervorhebung, M.H.] or commerce among the several States, or with foreign nation [...] illegal.“ 
meinwohls einzuschalten, wuchs. Es sollte aber noch bis ins 20. Jahrhundert dauern, bevor Präsidenten bereit waren, die gesetzlichen Möglichkeiten zu Verhinderung von Wettbewerbsverzerrungen durch die Konzerne auch einzusetzen.

Mit den Konzentrationsbewegungen des Kapitals in Form von Trusts und Kartellen stand das zweite große wirtschaftspolitische Problem des Gilded Age nur indirekt in Beziehung: Die Frage, auf welcher Edelmetallgrundlage die amerikanische Währung basieren sollte. Der Bund hatte während des Bürgerkriegs Papiergeld ausgegeben, die Greenbacks, so genannt, weil die Geldscheine auf einer Seite mit grüner Farbe bedruckt waren. Mit diesem Geld hatte der Norden den Bürgerkrieg gewonnen, gleichzeitig hatte die Ausgabe von rund 450 Millionen Dollar als Greenbacks die Inflation beschleunigt. Kreditnehmer, die ihre Schulden in inflationären Greenbacks abtragen konnten, schätzten das Papiergeld, Gläubiger, die für ihre Kredite im Wert abgesenktes Fiatgeld erhielten, lehnten die Greenbacks ab. Weil vor allem Farmer im Westen und Süden Kredite aufgenommen hatten und weil die meisten Banken sich im Nordosten der USA konzentrierten, konnte die Währungsfrage auch zu einem Problem zwischen den Sektionen der Nation werden. Der Westen und Süden unterstützten eine inflationäre Währung und forderte zusätzlich zur Ausprägung von Goldmünzen die Zirkulation von ,überbewertetem“ Silber, während der Nordosten eine Beschränkung auf die Ausprägung von deflationär wirkenden Goldmünzen verlangte.

Mit der Entscheidung für den Goldstandard 1873 waren die Währungsprobleme aber nicht gelöst, im Gegenteil. Durch die Umstellung auf die Goldwährung wurde es noch schwerer, Kredite zu bekommen. Bald wurden Rufe nach einer höheren Inflationsrate laut, um die Kreditsituation zu entspannen. Statt der Greenbacks sollten jetzt allerdings Silbermünzen in Umlauf gebracht werden. Die Silberfrage erregte die Gemüter wie kein anderes politisches Problem dieser Jahre. Auf der einen Seite standen diejenigen, die glaubten, nur eine auf Gold basierende Währung sei „ehrlich“, darunter viele Gläubiger aus dem Osten, die kein Interesse an einer inflationären Entwicklung hatten. Auf der gegenüberliegenden Seite fanden sich neben den Schuldnern und Farmern aber auch die Magnaten der Silberindustrie, die mit den riesigen Silberfunden im Westen einen Absatzmarkt für ihr Silber suchten. Die Silberfunde der 1860er und 1870er Jahre hatten den Markt mit billigem Silber überflutet. Staaten wie Nevada und Colorado, in denen sich viele Silberbergwerke befanden, verlangten vom Bund den Ankauf von Silber, um den Preis für das Edelmetall zu stützen. Farmer und Schuldner sahen in der Ausprägung inflationärer Silbermünzen den Ausweg aus der Hochzinspolitik für private Anleihen. Verschuldung und Deflation hatten viele Farmer brotlos gemacht, weil ihre Farmen unter den Hammer gekommen waren. „The farmer pays his debts with his labor. His crops cost him as much labor now as in 1870, but he receives only from one-fourth to one-half as much for them“, bemerkte 1891 ein 
Zeitungsverleger aus Kansas. ${ }^{191}$ Farmer erhofften sich einen stetigen Zustrom von Silberdollars und eine Verbesserung ihrer Situation. ${ }^{192}$

Die Vertreter des Silbers wurden nicht müde, darauf hinzuweisen, dass die Vereinigten Staaten bis 1873 ein Bimetall-System unterhalten hatten, bei dem sowohl Gold- wie auch Silbermünzen zirkulierten. In diesem annus horribilis hatte der Kongress Silber aus dem Währungssystem ausgeschlossen, indem er den Ankauf und die Prägung von Silber unterbunden hatte. Dieses „Crime of '73“ wurde später mit Verschwörungstheorien unterlegt, in denen der Süden und der Westen vom Nordosten und dem Finanzkapital verraten und verkauft worden seien. 1878 verabschiedete der Kongress den Bland-Allison Act und überstimmten President Hayes` Veto der Maßnahme. Das Gesetz verlangte von der Regierung den Ankauf von Silber und kam so den Vertretern der Silberstaaten entgegen. Minenbesitzer freuten sich über steigende Silberpreise. $\mathrm{Zu}$ einer spürbaren Inflation kam es dennoch nicht. ${ }^{193}$

Der öffentliche Druck zur Erleichterung der Inflation nahm nicht ab. Die virtuelle Koalition von Minenbesitzern und Anhängern des Farmer-Arbeiterblocks erreichte zunächst jedoch nichts. Dies änderte sich erst wieder 1890, als Staaten im Westen den McKinley-Zolltarif unterstützten und der Kongress dafür den Sherman Silver Purchase Act verabschiedete, der die Menge des anzukaufenden Silbers auf 4,5 Millionen Unzen (knapp 128 Tonnen) im Monat herauf setzte. Wieder resultierte dies nicht in merkbarer Reduktion des Geldwerts, weshalb ungeduldige Verfechter der Silberwährung eilends die Parole „free and unlimited coinage of silver“ ausgaben. Dies wäre eine Maßnahme gewesen, die die gesamten Silbervorräte der USA in Münzgeld umgewandelt hätte, wobei das Verhältnis des Werts von Silber in Relation zum Gold auf 16:1 festgeschrieben worden wäre. ${ }^{194}$

Die Silberfrage verlief quer zu Parteigrenzen. Die Demokraten hofften, Gemeinsamkeiten zwischen den Wählern des Südens und des Westens dazu nutzen zu können, den Sieg über die Republikaner erringen zu können. Der demokratische Präsident Grover Cleveland war jedoch in Finanzfragen ein Konservativer und verteidigte den Goldstandard entschlossen. Trotz der Wirtschaftskrise von

191 Peffer, William Alfred. The Farmer's Side: His Troubles and Their Remedy. New York: D. Appleton and Company, 1891, S. 29.

192 Ostler, Jeffrey. Why the Populist Party Was Strong in Kansas and Nebraska but Weak in Iowa. The Western Historical Quarterly, Band 23, No. 4 (Nov., 1992), S. 451- 474.

193 McCulley, Richard T. Banks and Politics during the Progressive Era: The Origins of the Federal Reserve System, 1897-1913. New York: Garland Pub, 1992, S. 23f. Thiemeyer, Guido. Internationalismus und Diplomatie: Währungspolitische Kooperation im europäischen Staatensystem 1865-1900. München: Oldenbourg, 2009, S. 112f.

194 Walton, Gary M. History of the American Economy. Mason, OH: Cengage, 2013, S. 349. 
1893 berief er im August 1893 eine Sondersitzung des Kongresses ein und ließ beide Häuser den Sherman Silver Purchase Act widerrufen. Innerhalb von vier Tagen fiel der Silberpreis von 83 Cents/Unze auf 62 Cents. Die Wirtschaft im Westen der USA wurde von diesem Preissturz schwer getroffen. Die Arbeitslosigkeit in den Minenstädten erreichte Rekordmarken. ${ }^{195}$ Der Verfall des Silberpreises beflügelte den Umtausch von Papier- und Silbergeld in „harte“ Golddollars, so dass die Goldreserven des Bundes rasch abnahmen. ${ }^{196}$ Die Kassation des Gesetzes verhalf den USA nicht zu einer Besserung der wirtschaftlichen Lage, spaltete aber die Nation in zwei geographische Hälften, wobei der Mississippi eine Zeitlang eine ähnlich unüberwindliche Grenze darstellte, wie es die Mason-Dixon-Linie vor 1865 gewesen war. ${ }^{197}$ Wütende Farmer rieten Präsident Cleveland, sich nicht im Westen blicken zu lassen, wenn ihm sein Leben lieb sei. Ihre Situation verschärfte sich in der Depression nach 1893 und bald sprachen die von der Krise gebeutelten Menschen von einer Verschwörung der Goldbugs, womit sie die Vertreter der Hochfinanz im Osten meinten. ${ }^{198}$ Eine Zeitung aus Nebaska bediente sich der Rhetorik des Klassenkampfes, als sie meldete: „The conflict between the common people and the overbearing, despotic, insulting moneyed aristocracy, who have set themselves up as our dictators, is inevitable." 199

Im Winter 1894/95 belastete Cleveland das politische Klima mit seinem Abkommen mit J.P. Morgan, um die Goldreserven zu retten. Nun schien offensichtlich, dass die Regierung nicht nur enge Bindungen zur Hochfinanz unterhielt, sondern von ihr sogar abhängig war. Zahlreiche Menschen verloren die Illusion, auf friedlichem oder reformatorischem Wege noch etwas erreichen zu können. Der harte Winter, die hohe Arbeitslosigkeit, die Verzweiflung der Farmer und der Klassenkampf von Oben gegen die Arbeiterinnen und Arbeiter ließen so manchen von offenem Aufruhr reden.

Mit den Konzentrationsbewegungen der amerikanischen Wirtschaft, der Ideologie der individuellen Stärke, der Gleichsetzung von Individuen und Korporationen im Wirtschaftsrecht, der Vergabe riesiger Ländereien, die den Native Americans gehört hatten, und der Festlegung auf den Goldstandard in Zeiten der wirtschaftlichen Krisen war der Weg bereitet für eine Zuspitzung wirklicher

195 Iversen, Kristen. Molly Brown: Unraveling the Myth. Boulder, CO: Johnson Books, 1999, S. 102.

196 Poole, Keith T. und Rosenthal, Howard. Ideology \& Congress. New Brunswick, NJ: Transaction Publishers, 2007, S. 134.

197 Poole, Keith T. und Rosenthal, Howard. Ideology \& Congress, S. $134 \mathrm{f}$.

198 Milton Friedman. Bimetallism Revisited. The Journal of Economic Perspectives. $1990 \mathrm{Au}-$ tumn; 4 (4):85-104.

199 Pollack, Norman. The Populist Mind. Indianapolis, IN: Bobbs-Merrill, 1967, S. 42. 
und gefühlter Klassengegensätze. Die Lösung dieser Gegensätze hätte eine aktive Wirtschafts- und Reformpolitik der Regierung erfordert. Das Zinsniveau hätte gesenkt werden müssen. Den Arbeiterinnen und Arbeitern hätte ein Koalitionsrecht die Möglichkeit gegeben, höhere Löhne durchzusetzen, die den Konsum von in den USA produzierten Waren gefördert hätte. Eine zurückhaltende Landpolitik und die Einhegung der Rechte von Aktiengesellschaften hätten die Rechte der Native Americans und der unmittelbar produzierenden Bevölkerung geschützt. Da sich die republikanischen Administrationen solchen Lösungen verschlossen, kam es zu Gegenreaktionen, die sich in gewaltsamen Konflikten entluden. 